\title{
CANADA
}

DEPARTMENT OF MINES

Hon, Es. L. Patenaude, Minister; R. G. McConnell, Deputy Minister.

GEOLOGICAL SURVEY

William Mcinnes, Directing Geologist

$$
\text { MEMOIR } 100
$$

No. 83, Geological Series

\section{The Cretaceous Theropodous Dinosaur Gorgosaurus}

Lawrence M. Lambe

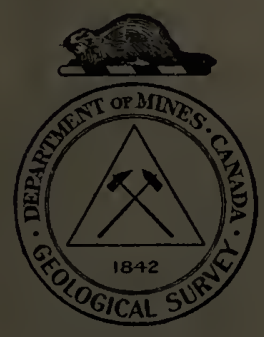

OTTAWA

Gonernment Printing Bureau 1917 
$\underset{\text { K2072 }}{\text { Med }}$

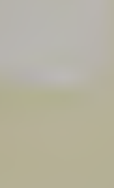

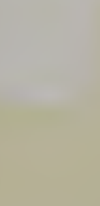

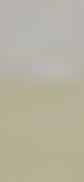

\author{
.
}

*

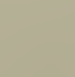

(2) 

CANADA

DEPARTMENT OF MINES

Hon. Es. L. Patenaude, Minister; R. G. McConnell, Deputy Minister.

GEOLOGICAL SURVEY

William McInnes, Directing Geologist

\title{
MEMOIR 100
}

No. 83, Geological Series

\section{The Cretaceous Theropodous Dinosaur Gorgosaurus}

BY

\author{
Lawrence M. Lambe
}

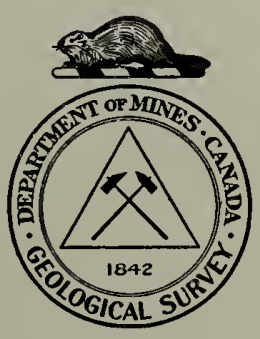

OTTAWA

Government Printing Bureau 
510706

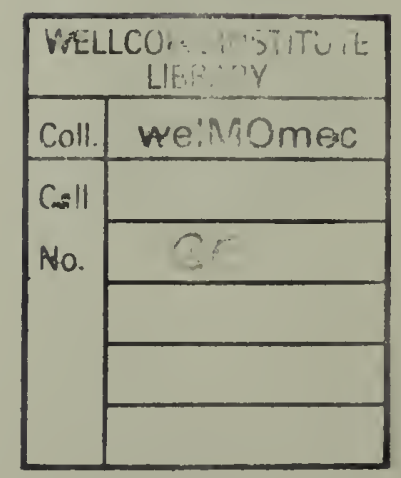




\section{CONTENTS.}

PAGE

Introduction $\ldots \ldots \ldots \ldots \ldots \ldots \ldots \ldots \ldots \ldots \ldots \ldots \ldots \ldots \ldots \ldots \ldots \ldots \ldots$

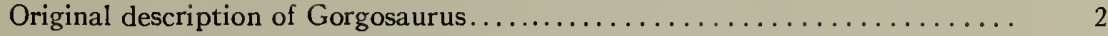

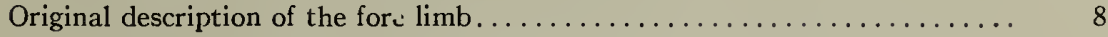

Genus Deinodon................................. 9

Position of the skeleton of Gorgosaurus as found . . . . . . . . . . . . 10

Description of the of Gorgosaurus....................... 11

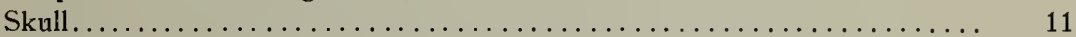

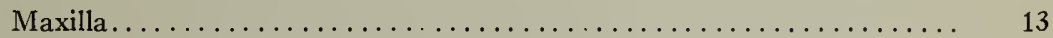

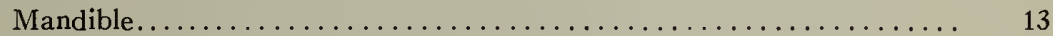

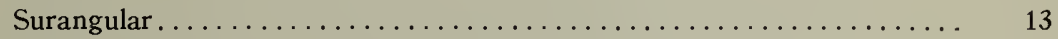

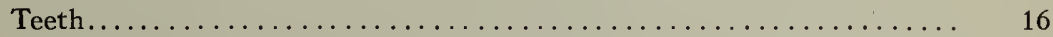

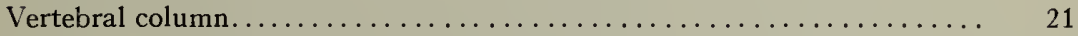

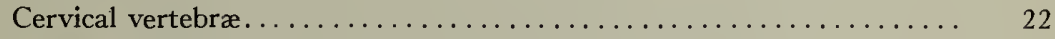

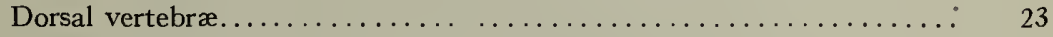

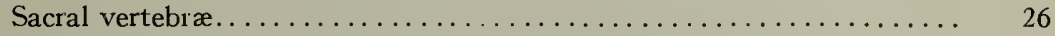

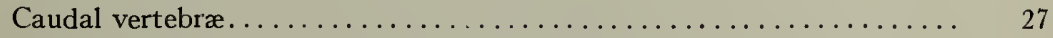

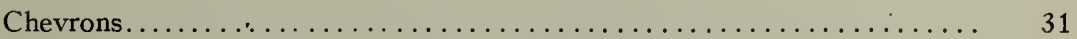

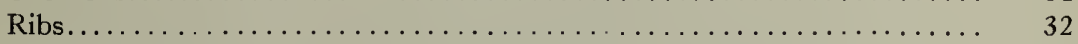

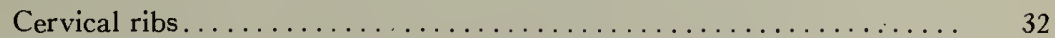

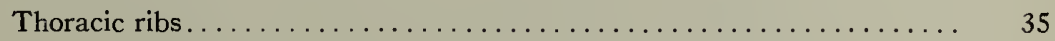

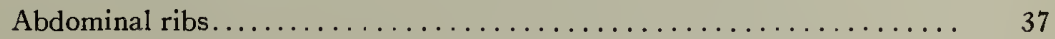

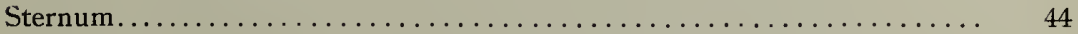

Pectoral girdle................................ 46

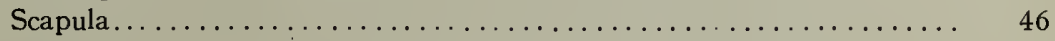

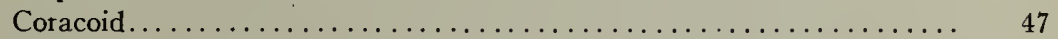

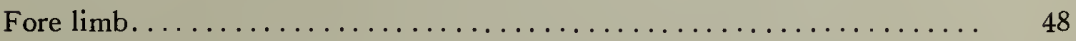

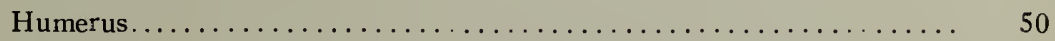

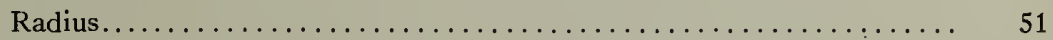

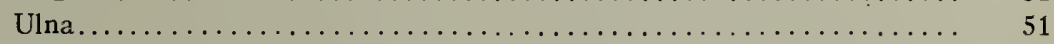

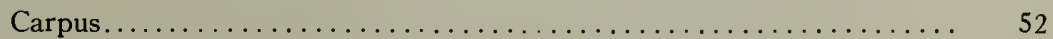

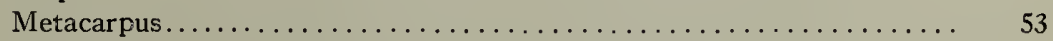

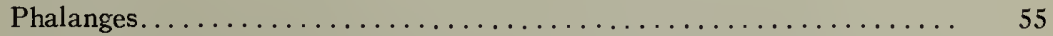

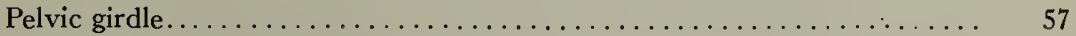

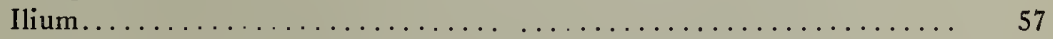

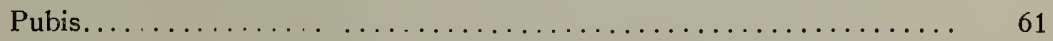

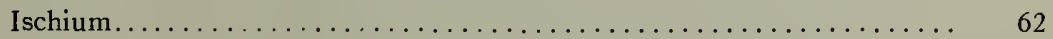

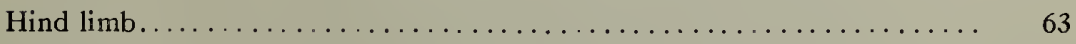

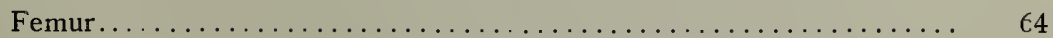

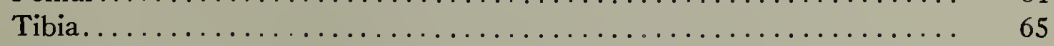

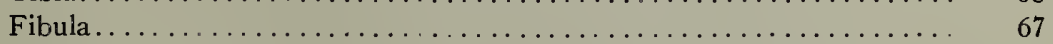

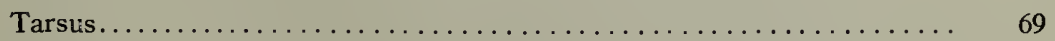

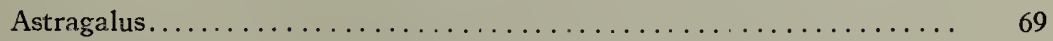

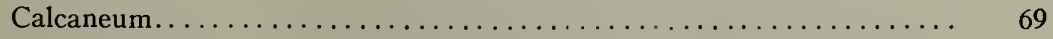

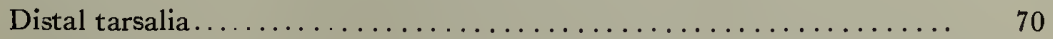

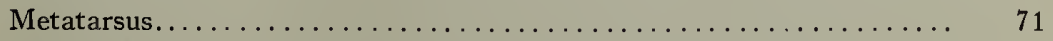

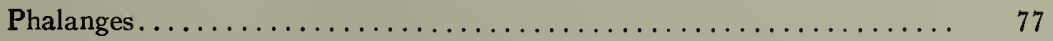

Remarks on the supposed appearance, habits, etc............. 80 
Figure 1. Discovery of the type of Gorgosaurus.................. 3

2. Removal of the skeleton of Gorgosaurus................ 4

3. Appearance of excavation after the removal of the skeleton........ 5

4. General view of Belly River beds near Gorgosaurus "quarry"....... 6

5. Plan of the skeleton as found in the rock................. 10

6. Left lateral aspect of the type of Gorgosaurus libratus exclusive of the

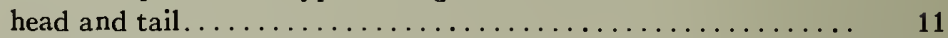

7. Right lateral aspect of the same...................... 11

8. Skull of the type of Gorgosaurus; right lateral aspect............ 12

9. Separate left surangular, provisionally associated with Gorgosaurus; external, internal, and superior views............... 14

10. Right premaxillary and maxillary teeth of the type of Gorgosaurus;

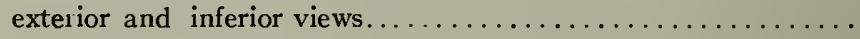

11. Right mandibular teeth of the type of Gorgosaurus; exterior and sup-

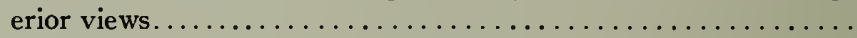

12. Premaxillary teeth of the type of Gorgosaurus; anterior view .......

13. Diagram illustrating tooth replacement in Gorgosaurus............

14. Cervical and caudal vertebræ of the type of Gorgosaurus; right lateral

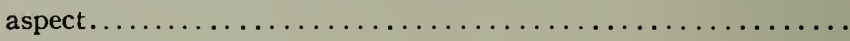

15. Distal end of neural spine of dorsal vertebia of Gorgosaurus; left late1al and anterior views, and outline of transverse section......

16. Pelvic arch of the type of Gorgosaurus; right lateral aspect.........

17. Caudal vertebra of Ornithomimus; right lateral and superior views...

18. Twenty-eighth caudal vertebra of the type of Gorgosaurus; right lateral, superior, inferior, and posterior views..................

19. Second, seventh, fifteenth, and twentieth chevrons of the type of Gorgosaurus; right lateral, posterior, and superior views........

20. Anterior right cervical rib of the type of Gorgosaurus; external and

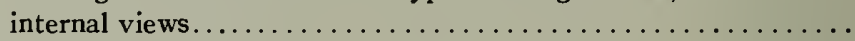

21. Right rib of eighth cervical vertebra of the type of Gorgosaurus;

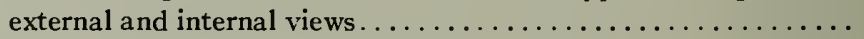

22. Proximal end of right rib of third dorsal vertebia of the type of Gorgosaurus; anterior and superior views...............

23. Fourth (or fifth) left thoracic rib of the type of Gorgosaurus, with outlines of three transverse sections of the same.............

24. Transverse section of trunk of Gorgosaurus toward the front........

25. Right abdominal ribs of the type of Gorgosaurus; ventral aspeci.....

26. Heads of abdominal ribs in the type of Gorgosaurus, to show meihod of overlap; ventral and dorsal views...................

27. Restoration of abdominal ribs of Gorgosaurus; ventral aspect........

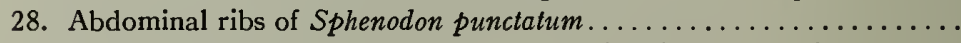

29. Sternal bone of type of Gorgosaurus; superior view and outline of trans-

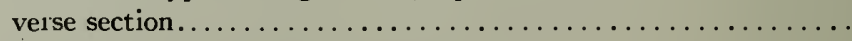

30. Plan of sternum of Gorgosaurus $\ldots \ldots \ldots \ldots \ldots \ldots \ldots \ldots \ldots \ldots \ldots$

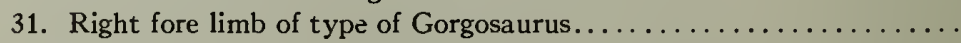

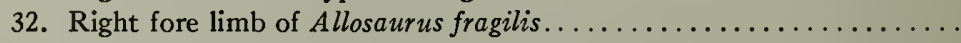

33. Carpal bones of the type of Gorgosaurus; superior and anterior views

34. End views of phalanx and metacarpal of lef $t$ manus of type of Gor-

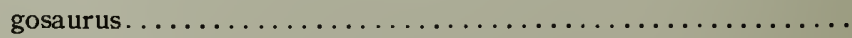

35. Right manus of the type of Gorgosaurus; internal, external, and super-

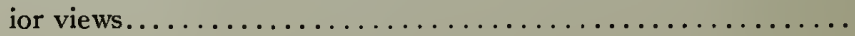


PAGE

36. Digits of right manus of the type of Gorgosaurus; inner aspect...... 55

37. Digits of right manus of Allosaurus fragilis; inner aspect......... 56

38. Pelvic arch of the type of Gorgosaurus; right lateral aspect........ 58

39. Separate left ilium, provisionally associated with Gorgosaurus; inner

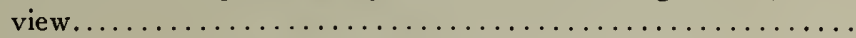

40. Femur of left limb (Cat. No. 350) provisionally associated with Gorgosaurus; anterior and interior views..................

41. Superior view of proximal end, and outline of transverse section of shaft of femur shown in Figure $40 \ldots \ldots \ldots \ldots \ldots \ldots \ldots \ldots \ldots$

42. Tibia, fibula, astragalus, and calcaneum of left limb (Cat. No. 350);

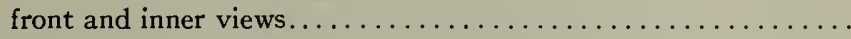

43. View from above, and outline of transverse section of tibia and fibula

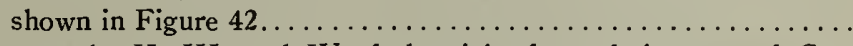

44. Metatarsals, II, III, and IV of the right foot of the type of Corgosaurus; anterior, inferior, and superior views.............

45. Outline of transverse sections of metatarsals shown in Figure $44 \ldots \ldots$.

46. Metatarsal I of right foot of type of Gorgosaurus; anterior, interior, posterior, exterior, and inferior views, and outline of transverse

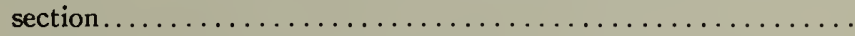

47. Metatarsal V of the left foot of the type of Gorgosaurus; inner and

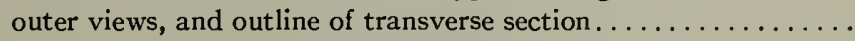

48. Restoration drawings of Gorgosaurus libratus; (a) standing, (b) sitting,

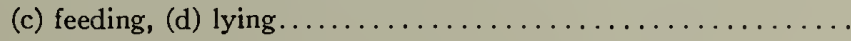

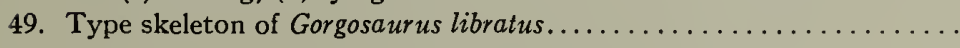





\section{The Cretaceous Carnivorous Dinosaur Gorgosaurus.}

\section{INTRODUCTION.}

The remains of carnivorous dinosaurs are not nearly as abundantly preserved as are those of the herbivorous dinosaurs. This is found to be so throughout the whole of the dinosaur-bearing beds of the Mesozoic group, proving conclusively that the flesh eating dinosaurs were not present in such numbers as the plant eaters.

Although the field parties of the Geological Survey, in exploring the Cretaceous badland areas in the valley of Red Deer river, Alberta, have been rewarded by finding a number of nearly complete skeletons of herbivorous dinosaurs, only parts of skeletons and separate bones of carnivores had been obtained prior to 1913. In the summer of that year, in the Belly River formation, the discovery was made of the unusually perfect skeleton which forms the subject of the present memoir. This unique specimen from the Belly River formation of Alberta is more complete, so far as the writer is aware, than any carnivorous dinosaur skeleton yet discovered in Mesozoic rocks in any country. This is not surprising when the excellent state of preservation and the abundance of the remains of dinosaurs occurring in the Edmonton and Belly River formations in the valley of Red Deer river are considered.

This specimen constitutes the type of Gorgosaurus libratus first described by the writer in April 1914, in the Ottawa Naturalist. ${ }^{1}$ In January of the same year the writer published a paper, also in the Ottawa Naturalist, on the fore limb of the type. ${ }^{2}$

The specimen was collected in the summer of 1913, by the Geological Survey vertebrate palæontological field party under Charles H. Sternberg, chief preparator and collector, in the Belly River formation (Cretaceous), Red Deer river, Alberta, $3 \frac{1}{2}$ miles below the mouth of Berry creek, on the south side of the river, near the prairie level. The discovery of the skeleton in the field was made by C. M. Sternberg, of this party, who after the specimen had been successfully quarried, devoted much time to the removal of matrix and since the arrival of the specimen at Ottawa has skilfully prepared it for study and exhibition.

The majority of the drawings reproduced in this report have been made by Rudolph Weber and Arthur Miles under the writer's direction.

\footnotetext{
1 On a new genus and species of carnivorous dinosaur from the Belly River formation of Alberta, etc. The Ottawa Naturalist, vol. XXVIII, April 1914.

${ }^{2}$ On the fore limb of a carnivorous dinosaur from the Belly River formation of Alberta, etc. The Ottawa Naturalist, vol. XXVII, Jan. 1914. With ore plate.
} 
Figures 32 and 37 are included in the illustrations through the courtesy of Dr. Charles W. Gilmore of the United States National Museum, Washington, D C. Figures 1 to 4 are from photographs taken by C. M. Sternberg in the field.

\section{ORIGINAL DESCRIPTION OF GORGOSAURUS.}

The type specimen of Gorgosaurus libratus was described in April, 1914 , in the following words:

"The osteological characters of one of the carnivorous dinosaurs of the Cretaceous are revealed in a wonderful manner by a nearly complete skeleton obtained last summer. . . . . . . The specimen includes the head, the greater part of the vertebral column, the pectoral and pelvic arches, one at least of the fore limbs complete, both hind limbs also complete, the ribs, and apparently the entire series of abdominal ribs. The cervical vertebræ appear to be missing, but as all of the sandstone matrix has not yet been removed, they, or some of them, as well as the other fore limb, may yet be uncovered. The extreme end of the tail, back of the twenty-second caudal vertebra, was not found.

"The mandible is present and all of the teeth, both upper and lower, are in place, giving the complete dentition. The writer has already published a short description of the fore limb which has not hitherto been known in any of the Cretaceous carnivorous dinosaurs. Nor has a complete series of ventral ribs in any of these reptiles previously been discovered.

"For the undescribed genus of Theropodous dinosaur, brought to light by this magnificent specimen, the name Gorgosaurus is proposed. The species may be called libratus in reference to the animal's probable well-balanced and easy gait.

"Gorgosaurus libratus, gen. et sp. nov."

"Carnivorous dinosaur of large size, reaching a length of about 29 feet; head narrow and moderately elongate; trunk compact; forelimbs minute; hind limbs long and robust; tail nearly half the total length of the animal, tapering, and with only a slight lateral compression. In the skull there is a large antorbital vacuity, preceded by a very small opening in the centre of a depressed area. No triangular alveolar plates on the inner sides of the jaws. A foramen present in the surangular, far back and near its upper border. No presplenial. Teeth trenchant, powerful, 4 premaxillary, 13 maxillary, and 14 dentary. First tooth of the maxilla similar in shape and size to those of the premaxilla. Vertebræ slightly amphicœlus, concave on the sides and beneath; 2 cervico-dorsals, 11 dorsals, 5 sacrals, and about 34 caudals. Neural spines short throughout the vertebral column. Chevron bones 


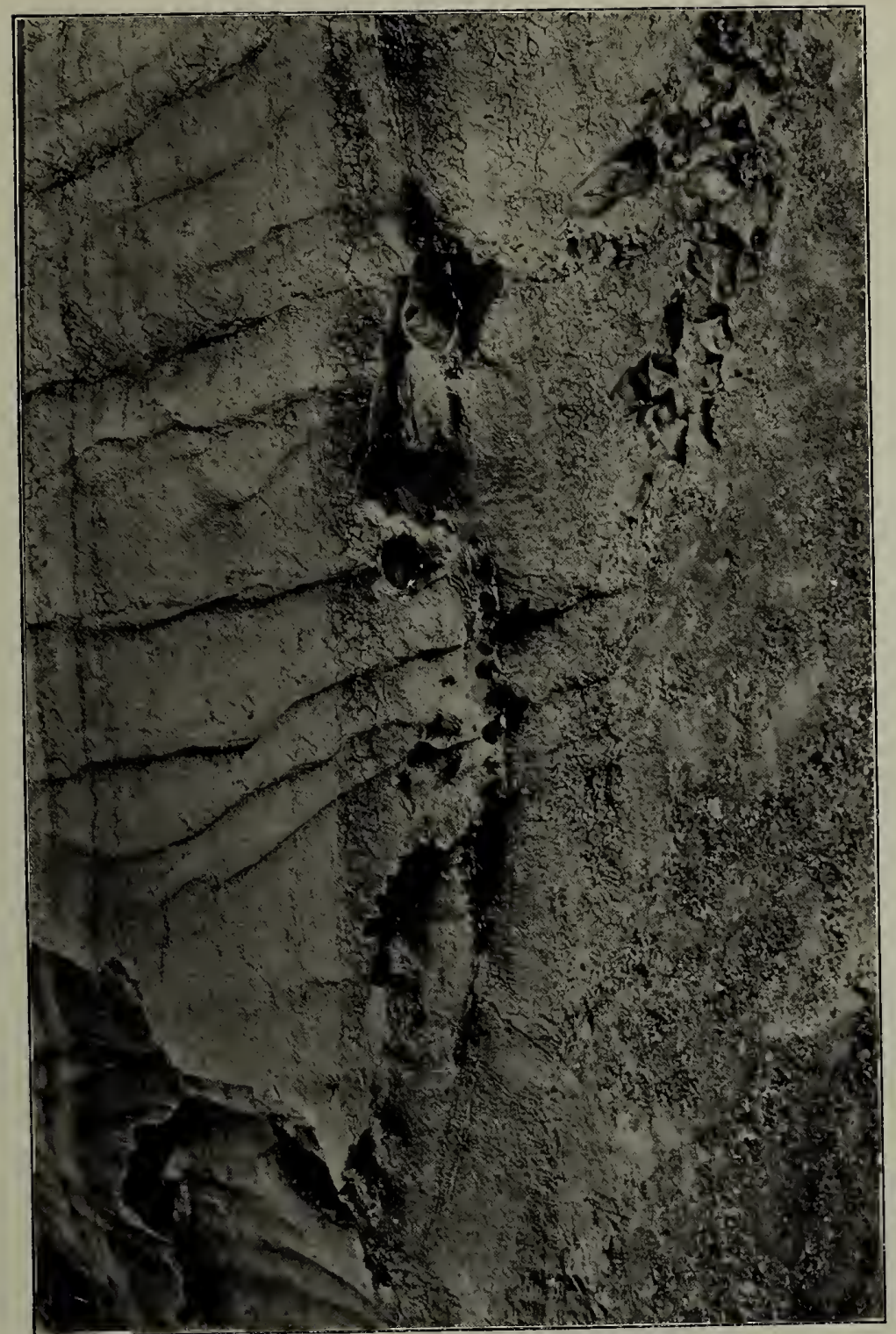

苛.

बं

닌

은. 이

เป

壳

के

ด.

可点

4

오응

동

꼴

I $\Xi$

은

폴

워

눈

串里

8

유

峁。

必

2.

承

응

금

त्र

당

:

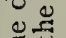

E

$-i$ 온

范范 


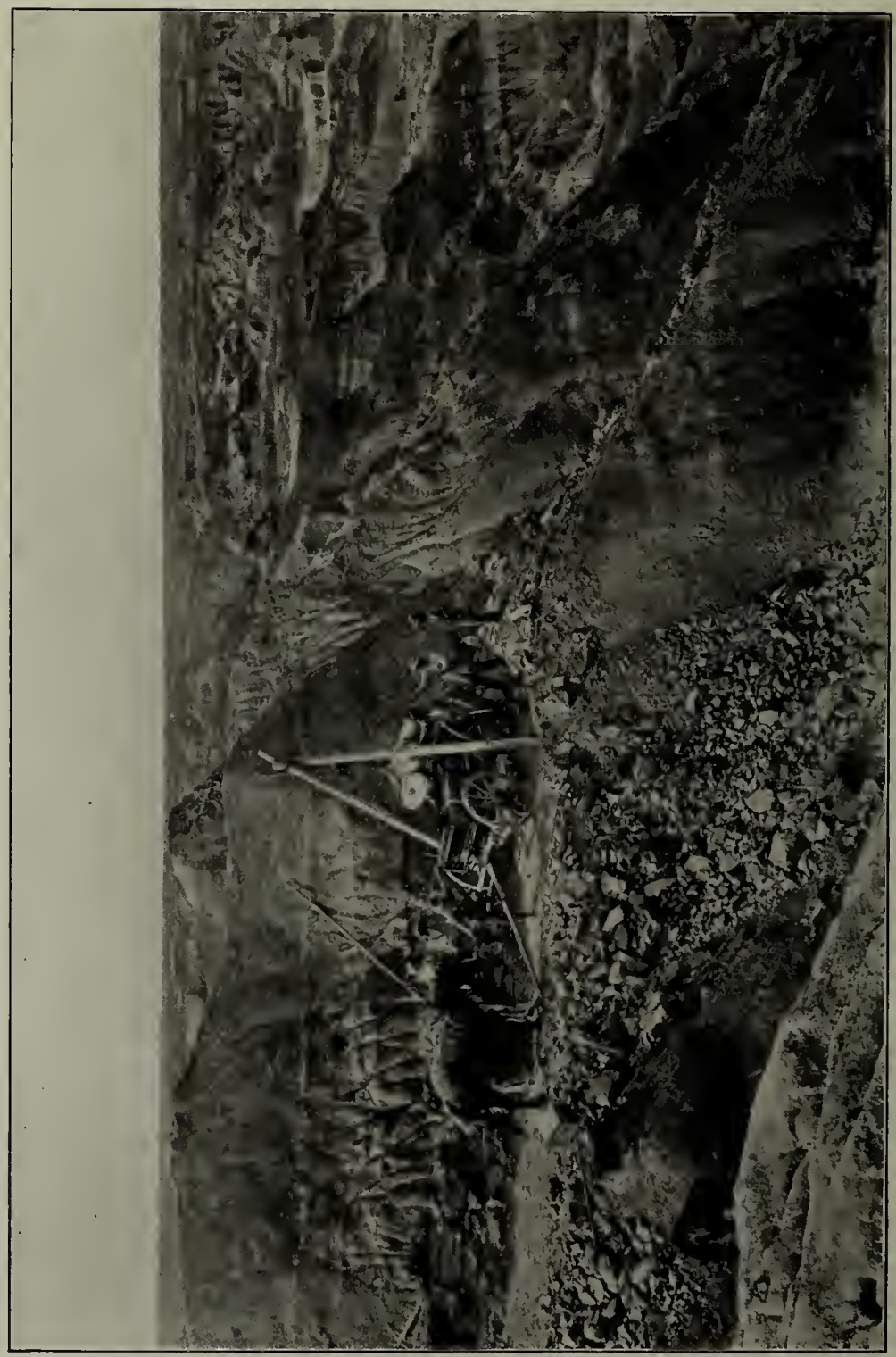

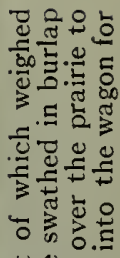
获苛 สำ 氙它施 क्ष कै 응 旸它? 可 E. $\exists \geq 000$

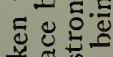
需的. ใ $\Xi \div$ 30 ऽ过 5 क \% 800 is 8.5 눈옹 两 bo

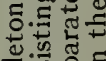

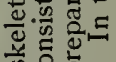
के ठ․

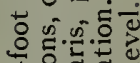
过过要。 क्षे

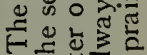
$i^{2}$ 究

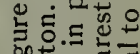
蛇它 仓. 


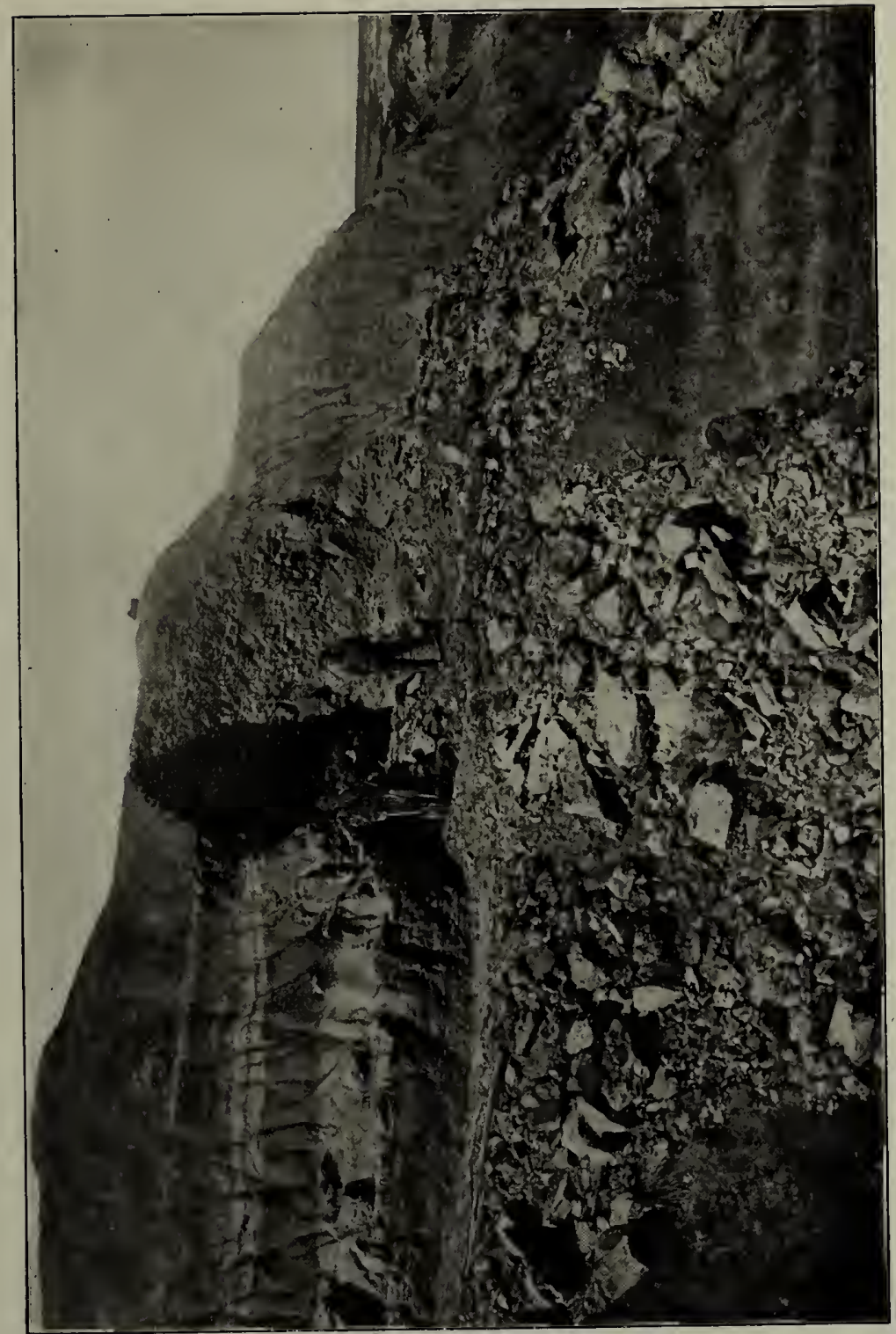



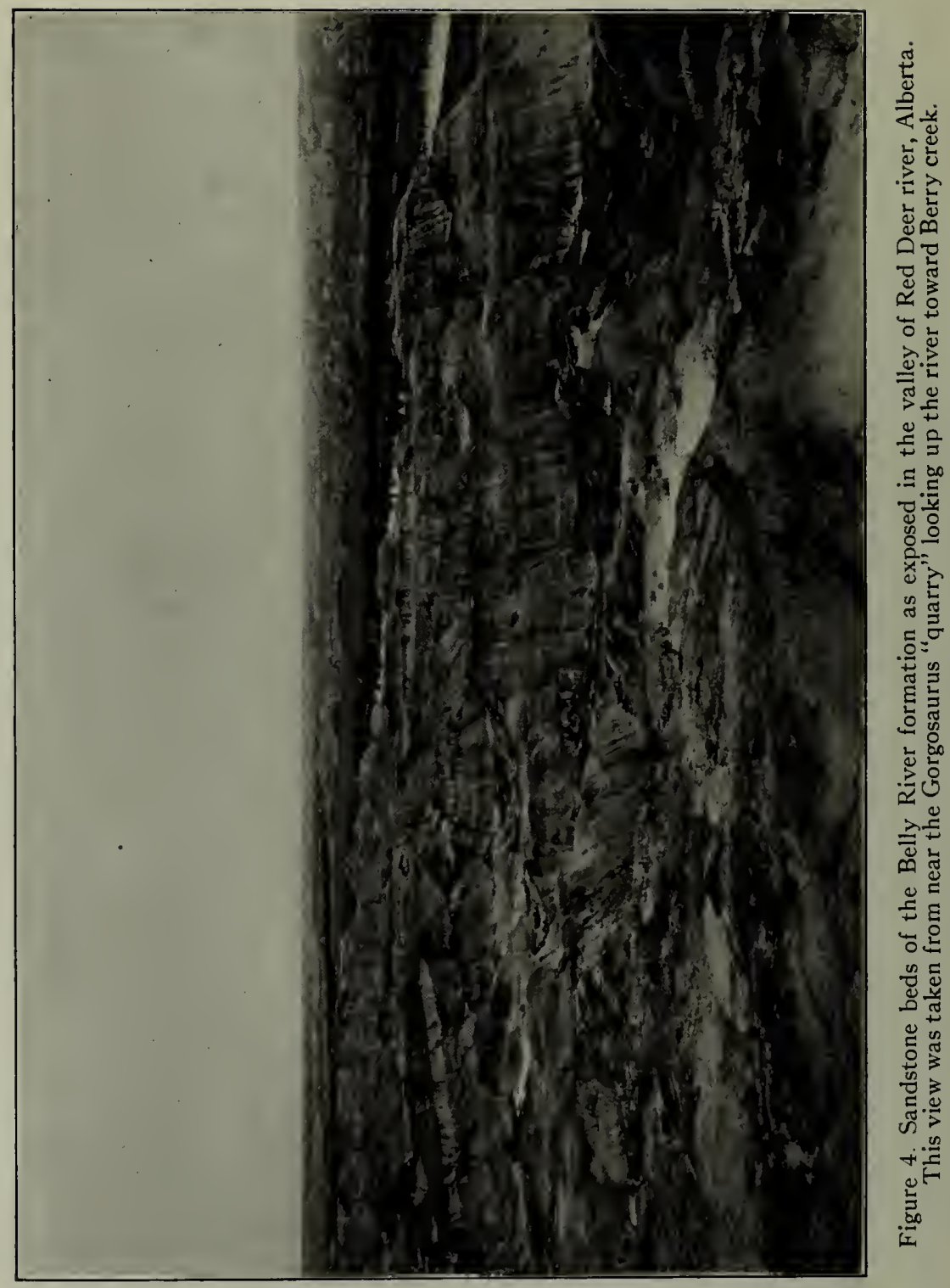
short, beginning with the first caudal. Transverse processes of the caudal vertebræ decreasing in size to and ending with the 14 th vertebra. Anterior zygapophyses of the posterior caudals greatly lengthened. Scapula longer than the fore limb. Humerus twice the length of the ulna. Two digits, Nos. II and III, to the manus, of which the phalangeal formula is 2 II, 3 III, the terminal phalanges being claw-bones. Metacarpal IV represented by a proximal vestigial bone. Ilium elongate, plate-like, with a flat upper outline and rounded ends. Preacetabular part shorter than the hinder portion, of which both are strengthened on the outer surface by a prominent, overhanging flange running horizontally at midheight. Ischium terminating narrowly below. Pubis ending in a horizontally expanded foot, of which the posterior extension is the greater. Femur about the same length as the tibia. Metatarsals II, III, and IV elongate, of which III, the longest, is nearly two-thirds the length of the femur. Metatarsal I represented distally by a short vestigial bone, and metatarsal $\mathrm{V}$ represented in a similar manner proximally. Four clawed digits to the pes, viz. Nos. I, II, III, and IV, of which the phalangeal formula is 2 I, 3 II, 4 III, and 5 IV. Ventral ribs composite, sixteen in number, overlapping at the longitudinal $\mathrm{m}$ d-line of the body, and bearing distally slender, closely applied supplementaries.

"Gorgosaurus libratus, apart from its dentition, is remarkable for the extreme shortness of the fore-legs and the great length of the hind ones. The long, narrow ilium rises slightly above the short sacral spines, and, in addition to the horizontal flanges, already mentioned, there are two small strengthening buttresses running upward from the centre of the acetabular border. The length of the metatarsals is surprising. The close application of the vestigial distal end of metatarsal I to metatarsal II is indicated by a slightly concave surface on the latter bone, which gives digit I a forwardly rather than a backwardly directed position in the foot. The vestigial proximal end of metatarsal $\mathrm{V}$ is in place in each leg, recalling to mind a similarly reduced bone in Ornithomimus altus Lambe, also from the Belly River formation of Alberta.

"Each abdominal rib consists of two well ossified, flattened lengths, which overlap at their inner ends. Outwardly, each lateral half is slightly grooved on its front margin for the reception of a slender rodlike bone (supplementary), which lies closely against the rib and projects but slightly beyond its outer end.

"The four premaxillary teeth are remarkably long and slender, with a keel on each side of a slightly convex inner or lingual surface. They are latterly compressed to a slight extent, evenly rounded in front, with their fore and aft diameter a little greater than their breadth. The first or anterior tooth of the maxilla is similar to the premaxillary teeth, in which respect Gorgosaurus differs from other known genera of Cret- 
aceous carnivorous dinosaurs. The other maxillary teeth are long and powerful of the Megalosauroid type, with two serrated keels, one along the front edge, the other behind. In the second maxillary tooth the anterior keel in descending passes slightly toward the inner side of the crown, and this is seen in a lessening degree in the next two or three succeeding teeth. A similar slight variation is seen also in the more anterior teeth of the dentary.

"The chevron bones are intervertebral, but with a greater surface of attachment to the front vertebra of the two. The more anterior ones are bent slightly backward from their midlength. This angulation in succeeding ones becomes more pronounced until the lower edge of the distal half is parallel to the longitudinal axis of the tail. By a gradually increased development and prolongation forward of the anterior angulation at the mid-length of the bone, a 'meat-chopper' shape is attained and adhered to with a gradual diminution in size, more apparent in the depth of the bone than in the length of its 'foot.'

"The long and slender anterior teeth (premaxillary and first maxillary) of Gorgosaurus are very different in shape from the robust supposed anterior teeth of Deinodon horridus of Leidy. In all the large Cretaceous carnivorous dinosaurs, the majority of the teeth, apart from the more anterior ones, are remarkably similar in the different genera and do not afford data for generic distinctions.

"Another large form of carnivorous dinosaur, having supporting alveolar plates on the inner sides of the jaws, occurs in the Belly River formation of Alberta and is represented in the collection of 1913."

\section{ORIGINAL DESCRIPTION OF THE FORE LIMB.}

The description of the fore limb, which appeared prior to the above, was as follows:

"The first impression received of the fore limb is its extremely small size.

"The arm has been pressed upward so that the humerus lies beside the back border of the blade of the scapula with its front face directed forward and its inner surface outward, its head remaining within the glenoid cavity.

"The fore-arm is flexed downward and the manus is closed with the claw-bones uppermost. The ulna and radius lie together, and the digits, of which there are two, are in place. From the regular succession of the phalanges of the digits to each other it is presumed that none of them is missing. The digits are regarded as Nos. II and III, and there is a vestigial metacarpal IV, consisting of a short, slender bone, slightly curved and tapering to its distal end. 
"Metacarpal II is very short, being only about one-half the length of metacarpal III. There are only two phalanges to digit II, an elongated one and a comparatively large, laterally compressed, curved, and sharply pointed ungual. In digit III the first phalanx is short, the second long, and the distal one claw-shaped but smaller than that of digit II. In the ungual phalanx of digit II there is a decided claw-groove. The first phalanx of digit II and the first and second of digit III have a deep pit on each side of the distal end. In the corresponding part of the metacarpals there is only a slight irregular depression.

"Four carpal bones are preserved between the ulna and radius and the metacarpals, but they are slightly displaced. One is roughly discoidal and larger than the others which are compressed ovoid in shape. The largest one occurs at the proximal end of metacarpal III, the other three lie together at the distal end of the radius. The ulna and radius are solid except for a small axial area of cancellous bone.

"As already mentioned, the elements of the manus follow each other in regular succession and are apparently all in place with none of the phalanges missing. The phalangeal formula revealed is, therefore, probably the correct one.

"The figure accompanying this description shows the relative size of the fore limb and the scapula with the coracoid. The limb is here shown in lateral aspect, in a natural position below its articulation with the scapula, and with the digits only slightly curved.

"Attention is drawn to the extreme shortness of metacarpal II and the elongation of the penultimate phalanx in each digit. A similar lengthening of the corresponding phalanges is seen in the manus of the small Jurassic Ornitholestes hermanni Osborn, in which also there are two digits, a vestigial metacarpal IV, and an enlarged ungual phalanx in digit II."

There are reasons for believing that two forms at least of large carnivorous dinosaurs occur at the Belly River horizon of the Cretaceous of Alberta, leaving out of consideration the extremely slender Ornithomimus. Of these larger flesh-eaters Gorgosaurus is the only one of which comprehensive information has been obtained.

\section{GENUS DEINODON.}

Reference may here be made to the genus Deinodon of Leidy 1856. This genus was primarily based on teeth of carnivorous dinosaurs from the Judith River Cretaceous on Missouri river, Montana (then included in Nebraska), U.S.A., a horizon synchronous, or nearly so, with the Belly River formation of Alberta. The teeth on which Dr. Leidy based his

I Proc. Acad. Nat. Sc. Phila., vol. VIII, p. 72. 
genus were figured and more fully described by him in a paper published in $1860^{1}$. From these figures and descriptions it is most probable, in the light of our present knowledge of the dentition of Cretaceous carnivorous dinosaurs, that at least two carnivorous forms, one large and the other small, are included under this generic term. In all probability the small tooth with a U-shaped transverse section, Figures 41-45, does not belong with the large sized teeth, Figures 21-40. Referring to all of these teeth Dr. Leidy wrote (p. 73 of his 1856 paper) "having been discovered together, and possessing the same structural appearances, I suspect them to have belonged to one and the same species." In this opinion Dr. Leidy was probably correct, if we exclude the smallest tooth mentioned by him (Figures 41-45), which to all appearances did not belong to Deinodon.

Later, in $1868^{2}$, Leidy separated the U-shaped, posteriorly truncate teeth from the others, proposing the genus Aublysodon for their reception. That this course was erroneous is probable from the evidence of the discoveries of recent years. We know that the Jurassic Allosaurus, and Gorgosaurus and Tyrannosaurus of the Cretaceous have the upper anterior teeth truncate posteriorly. In the case of Gorgosaurus the first maxillary tooth in addition to those of the premaxillary is of this shape, the remainder of the maxillary teeth and those of the dentary having the well known trenchant, laterally compressed form with a lenticular cross section near the tip.

If the majority of the teeth described by Leidy belonged to a single individual, and the name Deinodon is retained, a form clearly distinct from Gorgosaurus is represented differing from the latter in having larger and more robust upper anterior teeth in comparison with which those of Gorgosaurus are remarkable for their slenderness.

If on the other hand these teeth belonged to two separate individuals, the trenchant teeth to one and the truncate to another, then in neither case are sufficient diagnostic characters available for generic or specific differentiation.

\section{POSITION OF THE SKELETON OF GORGOSAURUS AS FOUND.}

The skeleton of Gorgosaurus was discovered in a thick bed of tough clayey sandstone. The phalanges of the left hind foot were first noticed lying as they had fallen, after having weathered from the rock, at the base of a low bluff. What proved to be abdominal ribs, and the metatarsals of the left foot were observed protruding slightly from the steep

1 Trans. Am. Phil. Soc., "Extinct vertebrata from the Judith River and Great Lignite formations of Nebraska," p. 143, pl. 9, figs, 21-48.

2 Proc. Acad. Nat. Sc. Phila., vol. XX, p. 198. 


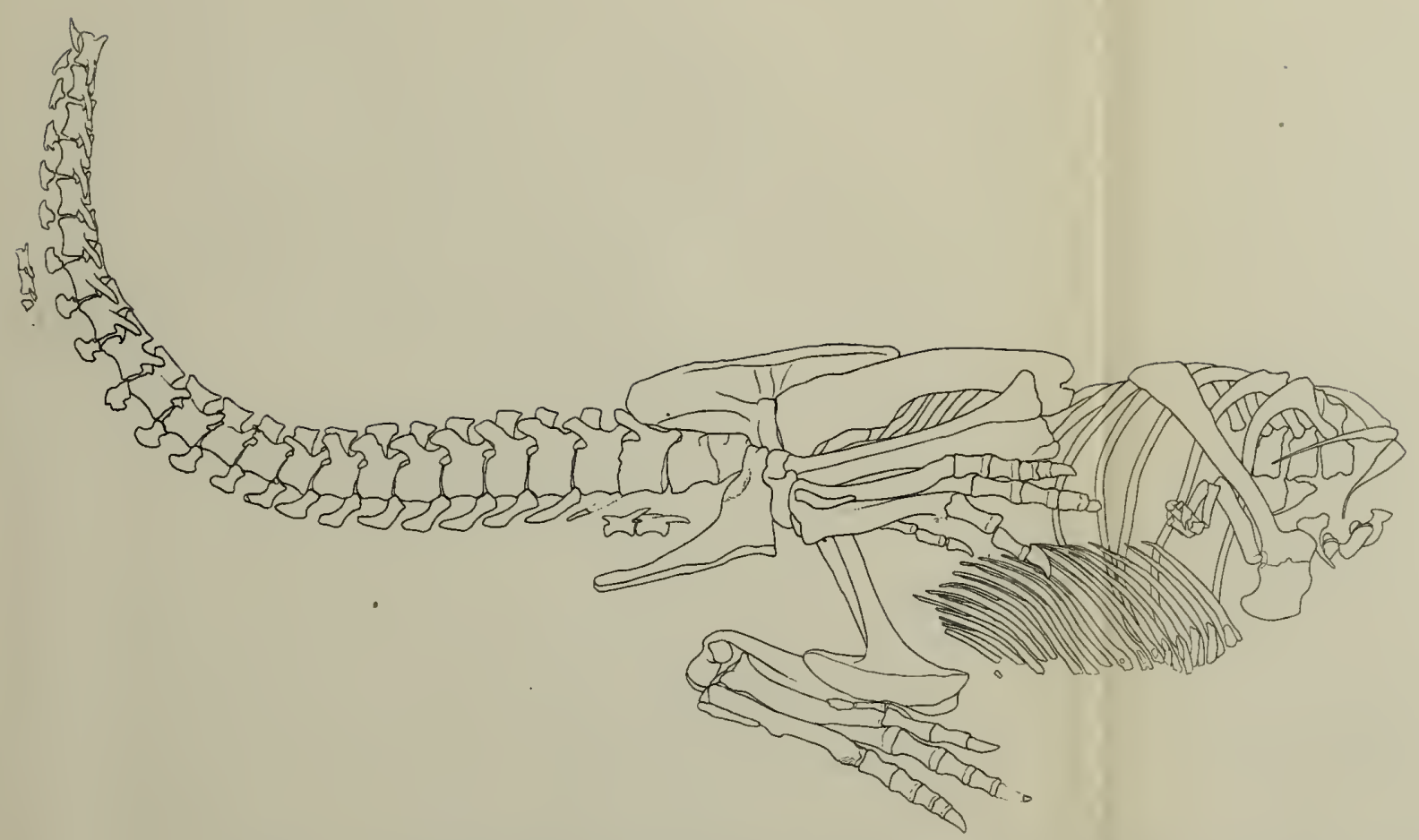

Figure 5. Plan of the right (or under) side of the type of Gorgosaurus libratus to show the relative position of the bones of the skeleton to each other as found; $\frac{1}{30}$ natural size. Cat. No. 2120. 



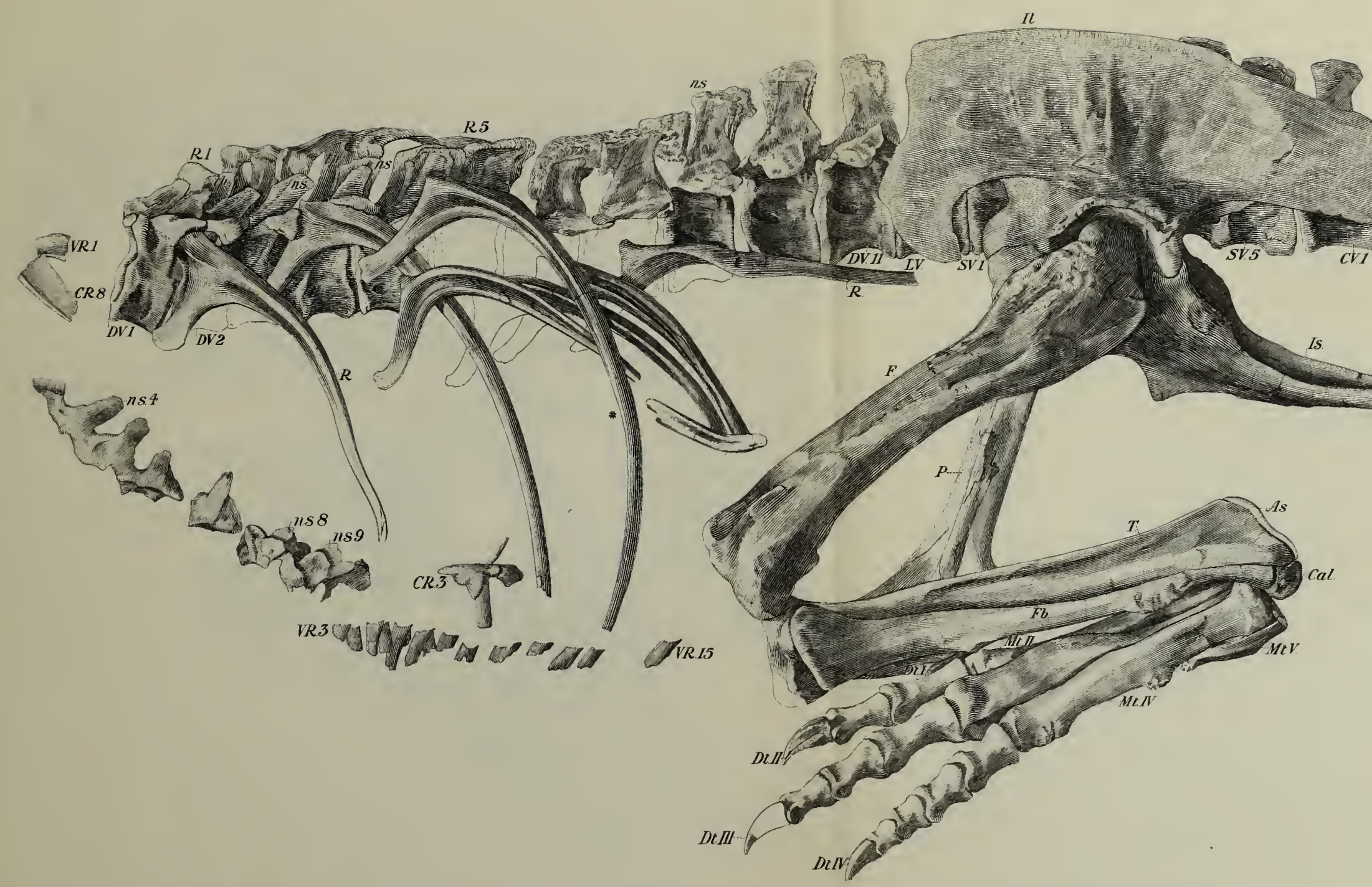

Figure 6. Left lateral aspect of the section of the type specimen shown in Figure 7 ; 1 is natural size. Cat. No. 2120. 


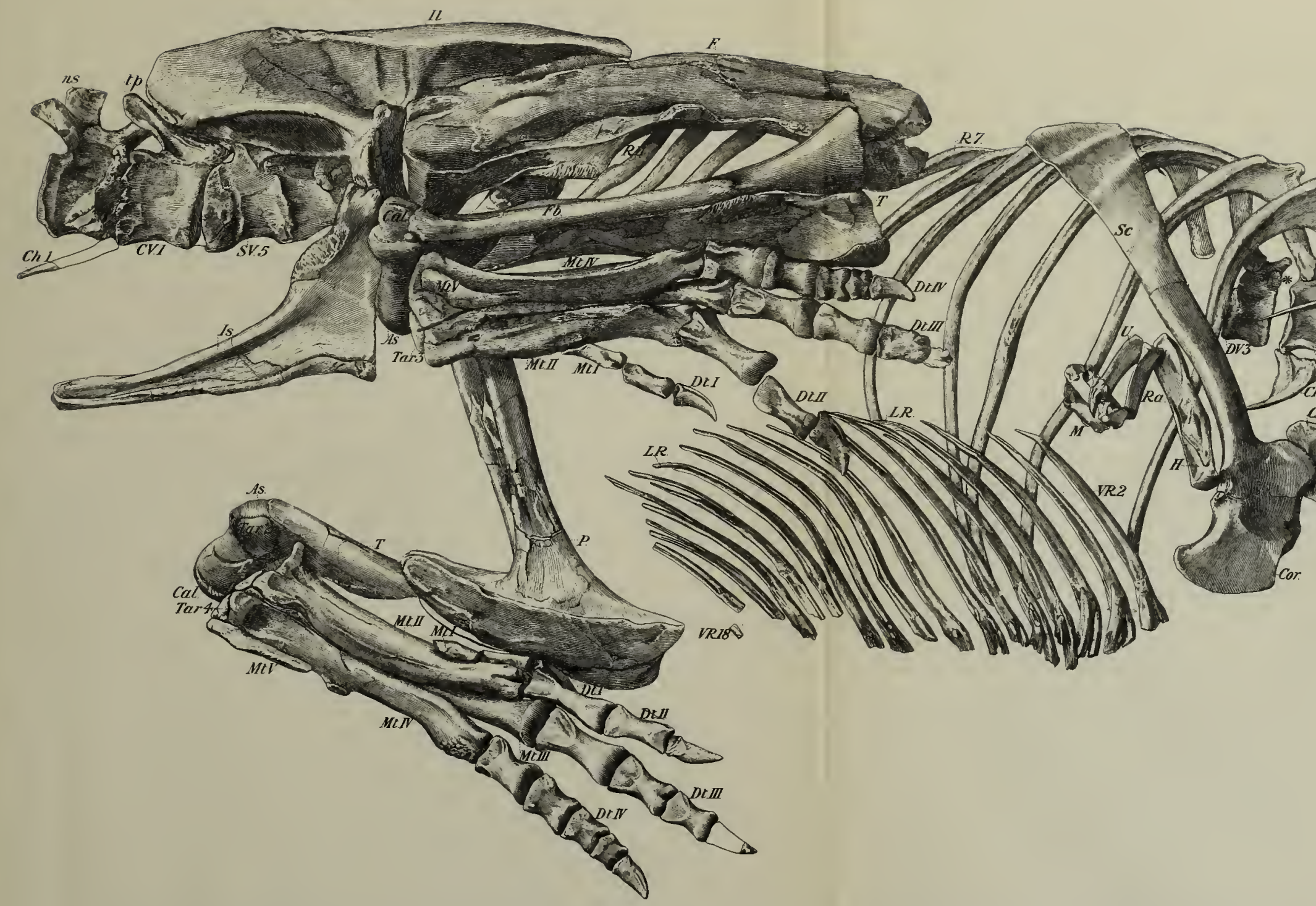

Figure 7. Right lateral aspect of the type of Gorgosaurus libratus from the first dorsal to the second caudal vertebra, including the right fore limb, hind limb, the left foot, vertebral and abdominal ribs, etc.; 1 natural size. Cat. No. 2120. 

rocky slope at a level above the loose phalanges as shown in the reproduction of the photograph, Figure 1, taken at the time of the discovery. The removal of a thickness of from 3 to 12 feet of sandstone revealed the skeleton lying on its right side.

The left hind limb was intact and drawn up in a natural position. The skull was found apart from the neck vertebræ, and had been crushed and otherwise damaged in its upper hinder part. The left shoulder blade and the whole of the left fore limb, with the exception of two phalanges and some fragments of the fore arm, were missing, as well as the greater part of the left half of the series of abdominal ribs. The neck had been displaced and had suffered considerable injury, but behind it the whole of the vertebral column was in place with the exception of a few vertebræ at the end of the tail.

13 Later it was found that on the right, or under side of the specimen as found, both limbs were present, as well as the scapula, coracoid, thoracic ribs, and abdominal ribs. The fore limb, bent at the elbow and wrist had been thrust upward, and the hind limb, drawn tightly up on itself, lay in line with the vertebral column (Figures 5, 6, and 7).

\section{Explanatory Lettering of Figures 6 and 7.}
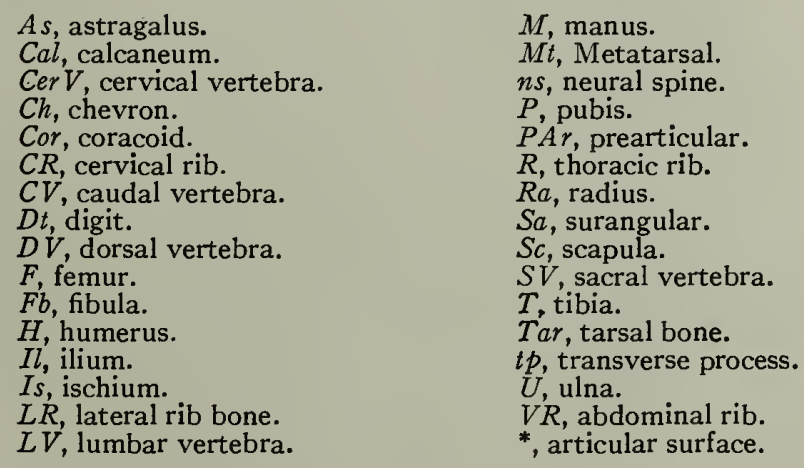

Since the original summary of the principal characters of Gorgosaurus was published further study of the type makes it desirable to state that the supposed absence of alveolar plates on the inner side of the jaws in the type may be due to non-preservation, and the same may be said of the presplenial. It will be noticed also in the following pages that the vertebral formula has been slightly modified, that the two digits of the manus are now regarded as being Nos. I and II, that there are thought to be nineteen instead of sixteen composite ventral ribs, and that another bone of the carpus has been brought to light. Also a slight change has been made in describing the angulation of digit I of the pes.

\section{DESCRIPTION OF THE TYPE OF GORGOSAURUS.}

\section{SKULL.}

The pressure to which the type of Gorgosaurus has been subjected has injured the back half of the head more than any other part of the skeleton. The head as a whole has been compressed but in the neigh- 
bourhood of and behind the orbits the cranium has been also crushed downward and fractured and many of the bone fragments lost. The anterior half of the skull is better preserved, more particularly on the

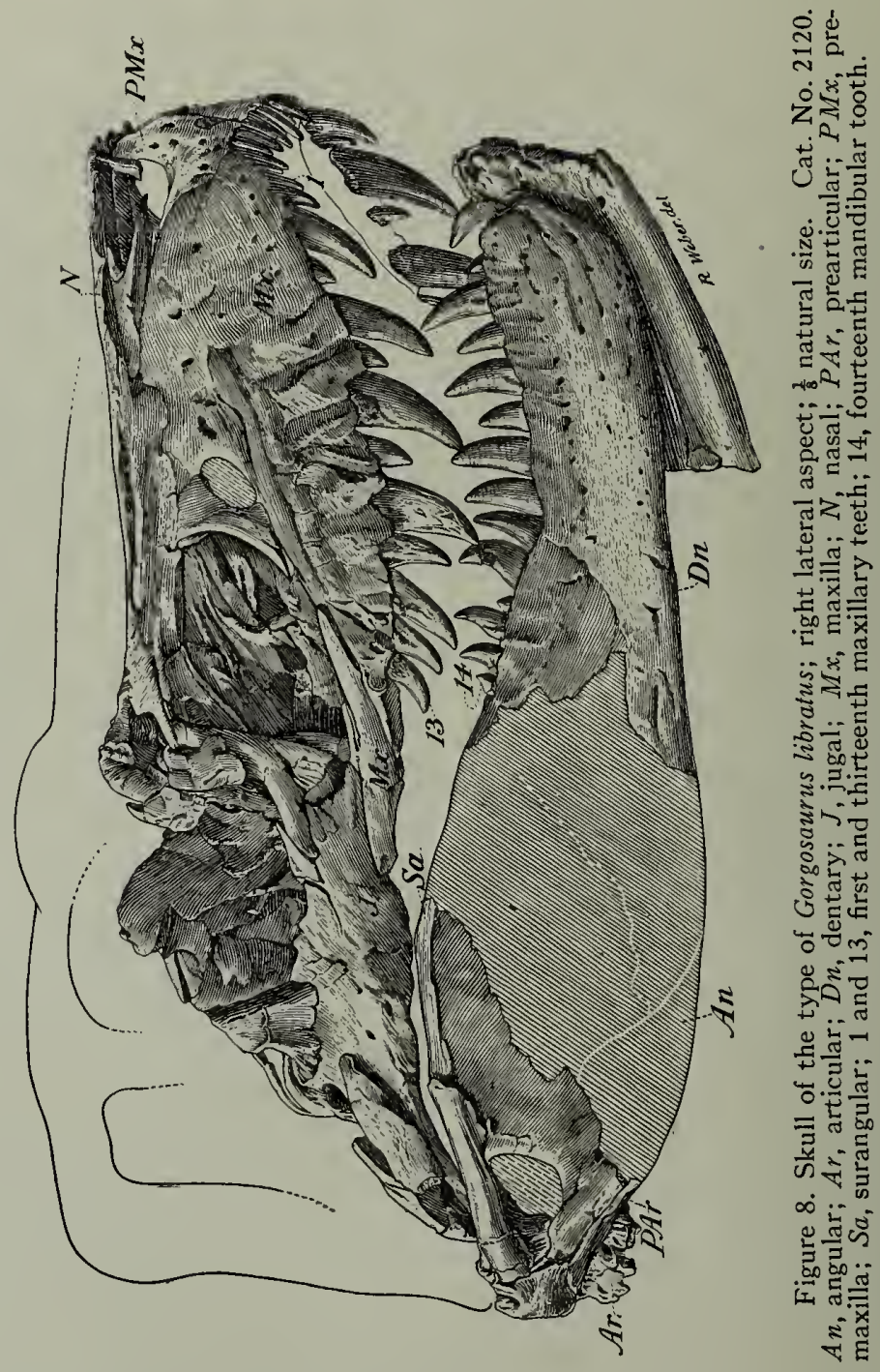

right side where the outer surface of the maxilla, premaxilla, and dentary are seen to advantage. The anterior end of the nasal bones and the left premaxilla are in equally good condition. All the teeth of the"right maxilla, of both premaxillæ and of the right dentary as well as the more anterior ones of the left maxilla and dentary are in place, and in each 
case display the shape of the crown to the tip with all details of structure and change of form (Figure 8).

Maxilla. The maxilla is large, obtusely pointed in front in lateral aspect, and highest behind where it is deeply emarginated by a large preorbital vacuity. The alveolar border is irregularly undulating. The outer surface is rugose, and displays many foramina in the front part generally and above the hinder alveolar border.

The preorbital vacuity is subtriangular in shape, highest behind with a rather straight posterior margin and a rounded anterior one which latter is directly above the ninth maxillary tooth; its 'ength exceeds its height. In advance of and close to this large opening is a small, oval one, the anterior preorbital vacuity, fully within the maxilla.

Height of preorbital vacuity at its midlength...................

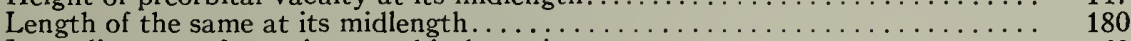

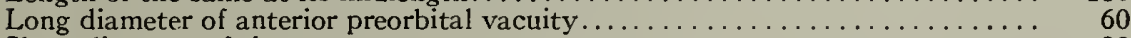

Short diameter of the same $\ldots \ldots \ldots \ldots \ldots \ldots, \ldots, \ldots, \ldots, \ldots, \ldots, \ldots,{ }_{2}$

The maxilla does not enter into the formation of the narial opening but is excluded therefrom by a downward process from the nasal and a posterior extension upward of the premaxilla which meet and bound the opening posteriorly.

Mandible. When the skull was found there was a gap in the right ramus of the mandible behind the dentary. Nearly two-thirds of the surangular in front had broken away and been lost, with some fragments of the posterior border of the dentary. The angular was missing except possibly a small portion of it posteriorly, and the prearticular was not found. The dentary and the hinder part of the surangular had remained in their proper position relative to each other, giving $950 \mathrm{~mm}$. as the exact length of the mandible. The outer surface of the dentary was in an excellent state of preservation.

Of the left ramus the surangular and prearticular, complete though crushed, were found displaced (Figure $7, S a$ and $P A r$ ), and the dentary was represented by its anterior half which had shifted forward and downward as figured. The prearticular is a long, narrow, thin, hook-shaped bone which curves anteriorly upward to the inner, superior border of the surangular.

Surangular. A particularly well preserved and nearly perfect right surangular, found separately, but apparently referable to Gorgosaurus, is shown in Figure 9. It is free from any distortion and all details of surface markings are sharply defined. In size it is slightly larger than the surangular of the type. On account of its excellent state of preservation it is described and figured here in preference to that of the type.

The separate right surangular, Figure 9, has the form of a somewhat lenticular plate about three times as long as high, narrowing to 
either end, and highest at midlength. It is thickest near the posterior end, continues modera ely strong along the superior border and thins downward to an irregularly undulating lower edge.

There is a large posterior opening, nearly circular in outline, at a distance of one-fifth of the bone's length from the posterior end, and placed
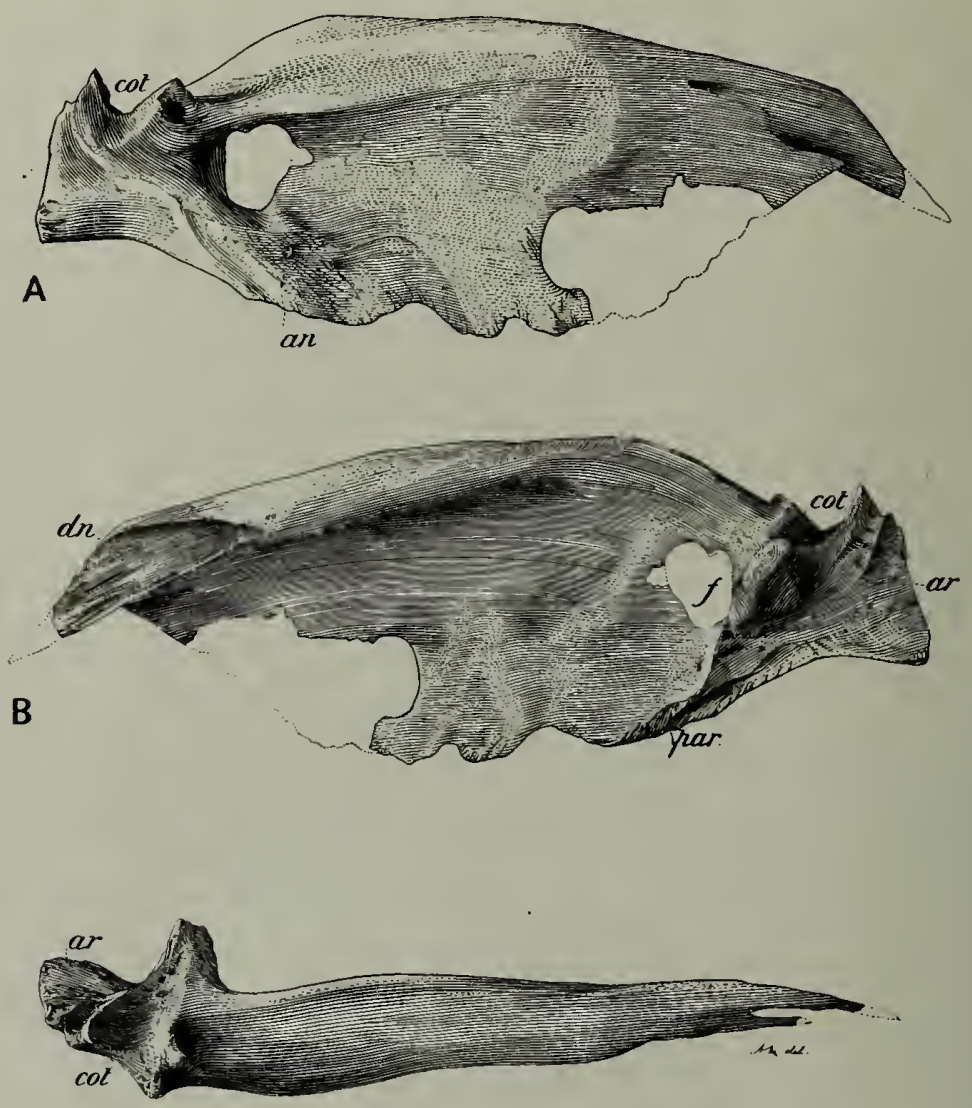

C

Figure 9. Separate surangular of Gorgosaurus; $\frac{1}{8}$ natural size. Cat. No. 2193. A, exterior view; B, interior view; C, superior view. an, surface for angular; ar, surface for articular; cot, mandibular cotylus; $d n$, surface for dentary; $f$, posterior opening; par, surface for prearticular.

at about midheight. It is relatively larger th $\mathrm{n}$ the mandibular opening in Dryptosaurus (Albertosaurus), being about one-half as high again.

The upper part of the bone is bent strongly inward from near the posterior end for the greater part of its length forward, the amount of 
inturn diminishing toward the front. Behind the posterior opening the bone is greatly thickened and a short, stout, inwardly directed process is developed whose anterior surface is in continuation with the posterior margin of the opening. At the anterior margin of the opening the bone is thin and continues so with little variation to the front.

Exteriorly the posterior thickening of the bone is excavated in front for the opening which occupies nearly the whole of the excavation. Superiorly it extends forward horizontally above the opening and for a short distance beyond it as a strong narrow ridge, adding to the breadth of the superior surface and greatly strengthening the bone at this part. . Beneath the opening the thickening diminishes rapidly forward. The opening is thus seen to be sunken in the general level of the outer posterior surface. The remainder of the exterior surface has minor undulations in a general flattened convexity. The superior surface is broad posteriorly and flat with a slightly outward and downward slope. Passing forward it becomes rounded with a diminishing breadth. Viewed from within the surangular presents a general concave surface in advance of the inwardly directed process, deeply excavated beneath the superior border and slightly concave elsewhere.

In the lower front portion of this separate surangular a considerable part of the border is missing in advance of a smooth incurved edge, rather more than a semi-circle in extent, which may represent the even curve of a deep emargination, or possibly a nearly circular opening through the thin bone with the front margin broken away. In the left surangular of the type such an opening is not present nor does a deep emargination occur antero-inferiorly. Although the undulatory nature of the lower front border of the surangular in Gorgosaurus might allow of an unusually deep incurve of the edge as an individual variation yet the regularity of the curve and its extent in this particular specimen is suggestive of an opening within the bone. A large, oval, anterior opening is described and figured by Marsh as occurring in the surangular of Ceratosaurus nasicornis of the Jurassic.

The surangular's contribution to the transversely placed mandibular cotylus is behind the broad flat posterior portion of the superior border and separated from it exteriorly by a pointed elevation curving upward, forward, and slightly inward. This part of the cotylus is well excavated and is above and exterior to the greater portion of the large, roughened, nearly vertical surface for the articulation of the articular. It extends on to the inwardly directed process which at this point gives the surangular its maximum breadth. The suture tetween the surangular and the articular strikes obliquely back across the cotylus from within outward, the floor of the cotylus rising to the suture and indicating its bifossate nature as described and figured by the writer in his 
report on Dryptosaurus (Albertosaurus) from the higher horizon of the Edmonton ${ }^{1}$.

Internally the surface for the articulation of the prearticular is seen for a considerable distance along the lower border in advance of the surface for the articular. It is rugose and narrow as figured.

On the inner side of the prolonged, front termination of the superior border is a depressed surface, much longer than high, and horizontally striated in the direction of its length ( $d n$, Figure 9B), for the articulation of the dentary. A short, forwardly directed, laterally compressed process developed on the outer side below the narrow upper termination of the bone overlaps a small portion of the posterior border of the dentary providing an interlocking of the two elements and further strengthening a sutural union which was already a strong one.

Externally a very clearly defined rugose area passing forward and downward from beneath the posterior opening marks the extent of the overlap of the angular behind (an, Figure 9A). Anteriorly this element by a sharp inward and then upward bend enters into the formation of the lower border and inner surface of the mandible.

A foramen leads forward through the bone to the outer surface from the anterior end of the inner concavity under the overhanging superior border. Other foramina of smaller size lead into the interior of the bone. These occur in the cotylus, in the surface for the articulation of the articular, and near the hinder margin of the posterior opening in the curve of the excavation encircling it behind.

Measurements of Separate Surangular, Cat. No. 2193.

Maximum length $(525 \mathrm{~mm}$. + estimated length of fragment missing from

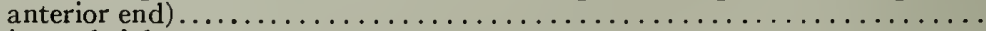

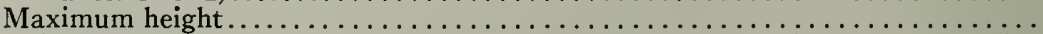

Thickness 18 and $45 \mathrm{~mm}$. in advance of the anterior margin of the posterior

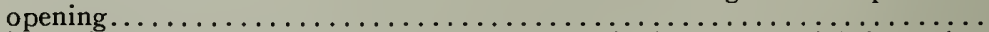

Vertical thickness of inturned superior border near its inner edge slightly behind

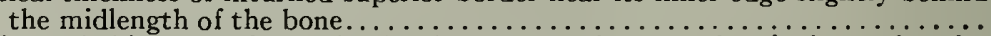

Horizontal thickness of superior border at posterior end of articular surface for

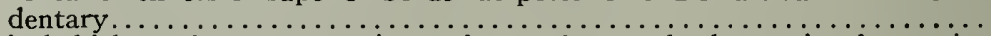

Vertical thickness between superior surface and upper back margin of posterior

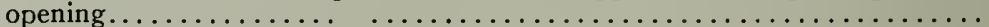

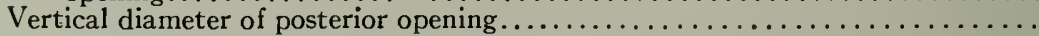

$\mathrm{Mm}$.

Teeth. In Gorgosaurus there are four teeth in the premaxilla, thirteen in the maxilla, and fourteen in the dentary, a number exceeding by one (or two) that of Tyrannosaurus, of a higher horizon in the Cretaceous, which has four premaxillary, twelve maxillary, and from thirteen to fourteen dentary teeth.

One of the principal distinctive characters of the dentition of Gorgosaurus is the similarity of the first maxillary tooth in size and shape to those of the premaxilla. 
The side teeth in both jaws are large, laterally compressed with an anterior and a posterior serrated keel; they taper to a rather obtuse point and curve slightly backward, the curvature being most accentuated in the distal half of the crown (Figures 10 and 11). Those of the upper jaw reach a greater size than those below. In these teeth both the anterior and posterior faces are flattened in an increasing degree from a short distance from the tip to the base of the crown, the anterior keel
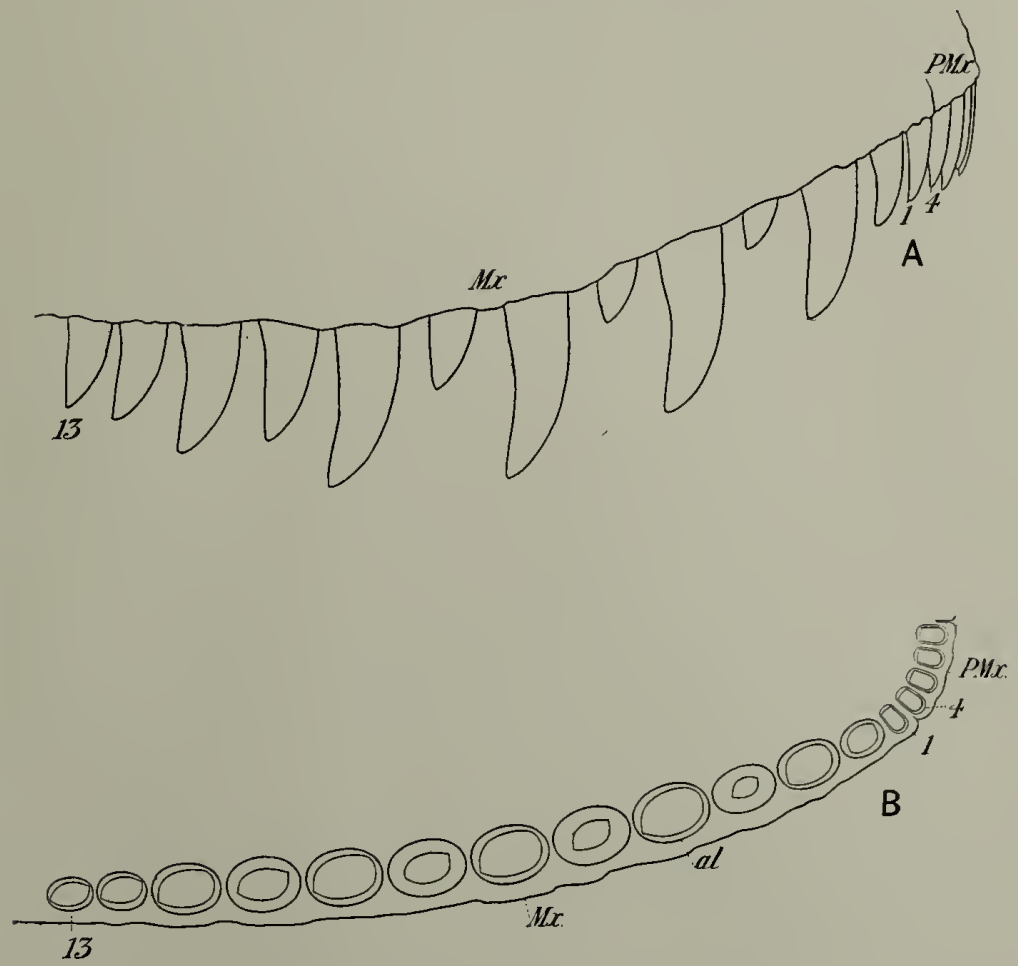

Figure 10. Right premaxillary and maxillary teeth of the type of Gorgosaurus; $\frac{1}{5}$ natural size. A, outer aspect. $\mathrm{B}$, transverse sections. $a l$, alveolus; $M x$, maxilla; $P M x$, premaxilla; 4 , fourth premaxillary tooth; 1 , first maxillary tooth, 13 , thirteenth and last maxillary tooth.

passing gradually inward and defining the inner boundary of the anterior face, the posterior keel marking the outer limit of the posterior face. The anterior keel ends at about one-third of the crown's length from the base, but the posterior one is continued to the base. The anterior flattening of the crown beyond the cessation of the front keel is conspicuously more broadly transverse than in the corresponding part of the tooth posteriorly where the flatness generally retains a slight obliquity 
on the inner side of the keel. The outer and inner faces likewise become increasingly flat as the base is approached. For a short distance from the tip the teeth are lenticular in cross section with a keel at each end of the lens. Beyond this the cross section, due to the flattening of the faces, becomes increasingly more subovate until at the base a subquadrangular outline is reached, the anterior transverse diameter being greater than the posterior one.

The keels are serrated throughout their full extent, there being eleven or twelve serrations in a space of $5 \mathrm{~mm}$. in the larger sized teeth and nine or ten in the smaller ones. The serrations are transversely
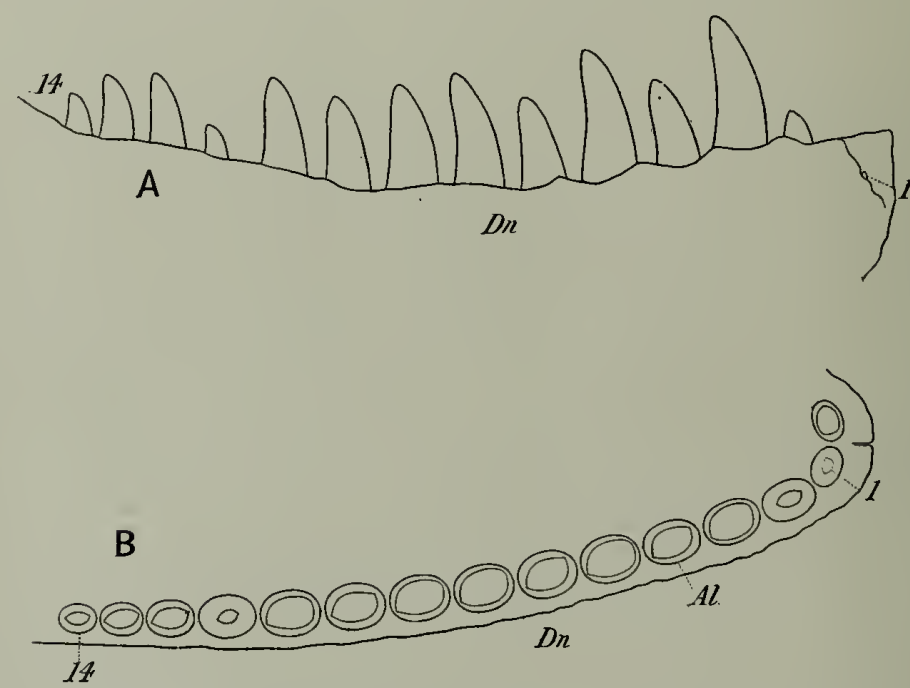

Figure 11. Right mandibular teeth of the type of Gorgosaurus; $\frac{1}{5}$ natural size. A, outer aspect; $\mathrm{B}$, transverse sections; $a l$, alveolus; Dn dentary; 1, first mandibular tooth; 14, fourteenth and last mandibular tooth.

compressed, and remarkably regular in alignment, with a scarcely perceptible decrease in size near the tip and toward the base of the tooth.

The majority of the maxillary teeth are identical in general form with those of the mandible.

In a number of separate teeth, from the Belly River formation on Red Deer river, indistinguishable from those of Gorgosaurus, the middle of one of the lateral faces is considerably worn for some distance from the tip on which the wear has only been sufficient to efface the minute serrations of the keel. As the upper teeth closed outside those of the mandible any wear, not on the point, would result from the contact of the inner surface of the upper teeth with the outer surface of the lower ones. This lateral wear of the crown is the only means by which an 
upper tooth can be distinguished from a lower one-unless one of the side faces of the crown is abraded, a left mandibular tooth is not distinguishable from a right maxillary one, nor a right tooth of the mandible from a left maxillary one.

A peculiar feature of the side teeth of the type specimen of Gorgosaurus is the almost total absence of signs of wear or abrasion. Not one of the side teeth shows any lateral wear, and even at the tip the surface has been so little affected through use that the minute serrations of the keel are not obliterated. The absence of lateral wear would indicate that the maxillary teeth passed clear of the mandibular ones in this particular individual. The small or not fully protruded teeth might be expected to show few signs of wear at the tip but not so in the longer ones which would bear the brunt of feeding. The lack of wear on the points of these teeth in the type specimen suggests that the individual was young and probably also that the food was soft without much abrasive effect. This in the case of a carnivorous dinosaur indicates most probably that the flesh of a carcass, possibly not always freshly killed, was torn from the bones and that the latter were le $t$ untouched.

The premaxillary teeth, four in number (Figure 12), a e remarkable for their slenderness in comparison with the robust side teeth of both jaws. They are laterally compressed with flat sides, the fore and aft diameter exceeding the transverse one, evenly convex transversely in front, and truncate on the posterior or lingual face. Two minutely serrated keels are present, one on either side of the narrow posterior face which is slightly convex between them. The anterior transverse diameter slightly exceeds the posterior one. These teeth are slender throughout. As viewed from the front they are rod-like in form and narrowly rounded below. In lateral aspect they are relatively broader, the back face is almost straight to the tip, to which the front face curves rapidly backward below.

The first maxillary tooth is similar in size and shape to those of the premaxilla.

These narrow upper front teeth were, in their downward direction, probably only very slightly inclined backward. In the type specimen all the teeth of the upper jaw, and some of the lower ones, have been pressed backward to some extent, the normal position of the teeth in both jaws being probably in a nearly vertical direction leaving out of consideration the slight backward curvature found in all the teeth near the pointed end.

The other twelve teeth of the maxilla are all of the trenchant shape already described and form a series of which the second, twelfth, and thirteenth are smaller than the others, the largest and longest, when fully protruded, being the fifth to the nin th inclusive. 
None of the fourteen mandibular teeth reaches as large a size as the middle ones of the maxilla; the teeth of the mandible form a more uniform series of smaller size. The third to the tenth would be of about equal size when fully protruded; beyond these at either end there is a diminution in size, the fourteenth being the smallest. The first, owing to its anterior position, has developed a broadly convex front face, the keels occurring one on either side of the flatly convex posterior face, suggesting an approach to, although the tooth remains more robust than the premaxillary teeth.

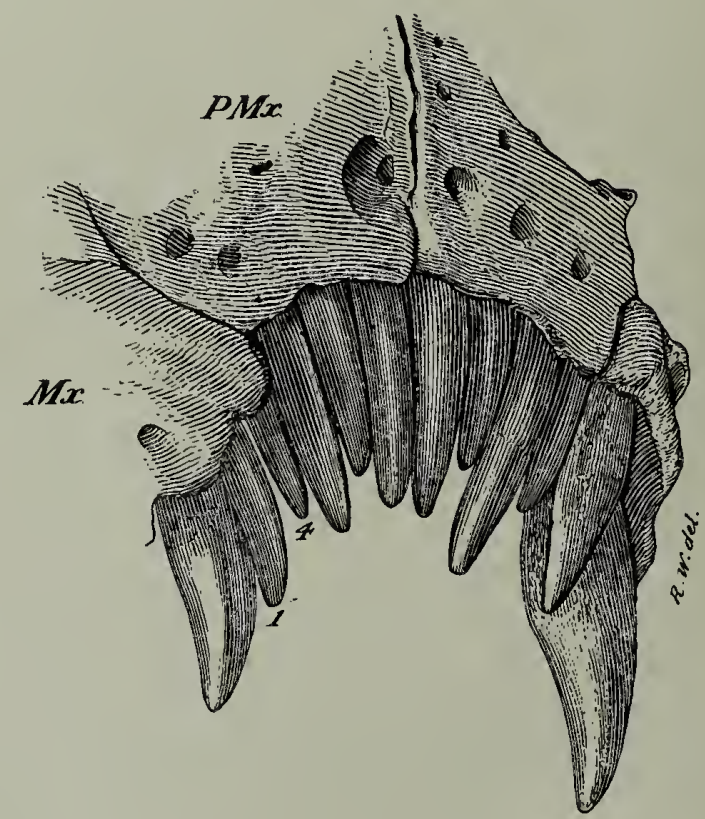

Figure 12. Premaxillary teeth of the type of Gorgosaurus libratus; anterior aspect $\frac{1}{2}$ natural size. $M x$, maxilla; $P M x$, premaxilla; 1 , first maxillary tooth; 4 , fourth premaxillary tooth.

The teeth replace each other from beneath, apparently as in the living Ghavial (Gavialis gangeticus) of India. In Gorgosaurus it is seen that a new tooth makes its appearance on the inner side of the base of the old tooth. The root of the latter is absorbed at this point allowing the new tooth to enter into its central cavity. With increased size the growing tooth, through pressure exerted directly from beneath, ejects the old tooth whose root has been weakened by further absorption. Even before a new tooth has grown sufficiently large to protrude beyond the margin of the alveolus a germ tooth may be formed, to be ready in 
its turn to become functional (Figure 13). We thus find in a carnivorous dinosaur provision for a rapid replacement of teeth functioning in a single row, the mode of succession being identical, so far as we can judge, with that of the existing Gavialis. The inner face of the roots of old teeth is usually slightly concave and it is here that the tips of new teeth are first observed pressing against the old ones which they are later to replace. With the partial absorption of the root of an old tooth, the new one by moving to the centre of the alveolus, directly beneath the old tooth, would gain a position more advantageous for pressure against the tooth, and at the same time make room for the formation of the succeeding germ.

The old teeth were lost alternately to some extent, a provision of nature by which large gaps in the series were avoided This is well shown in the type specimen where the side teeth in full use are seen to alternate rather regularly with new ones incompletely protruded.

Attention is drawn to the fact that the lateral teeth of Gorgosaurus are lenticular in cross section only near the tip, and that they are all similarly flattened on the front and back faces near the base, as well as on the sides (buccal and lingual) as already mentioned, the front keel passing inward so as to be hidden in an outer view of the jaw. In this, as in a number of other particulars, the teeth of Gorgosaurus differ from those of Tyrannosaurus ${ }^{1}$ in which there is a transition backward in the jaws from those having a sub-oval transverse section to posterior ones of a lenticular section with the serrated keels on the anterior and posterior border of the crown.

\section{Vertebral Column.}

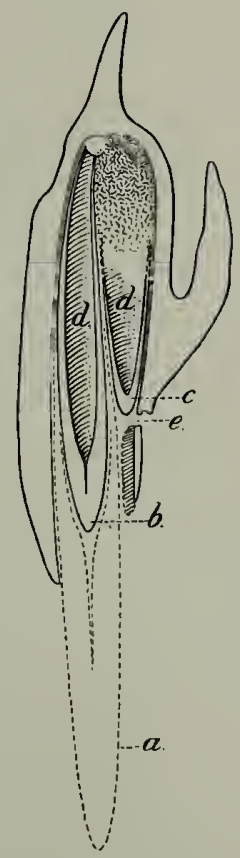

Figure 13. Transverse section of maxilla of Gorgosaurus through alveolus of sixth tooth to show

The vertebral formula of Gorgosaurus may be placement; $\frac{1}{2}$ natural stated to be as follows: C, ?9; C-D, ?2; D, 11; L, 1; size. Cat. No. 2270 . S, $5 ;$ C, 36 干.

The majority of the vertebræ are either represented or present in the type. Assuming the number of cervicals to be nine, all of them are represented $a$, position of ejected tooth; $b$, new tooth not yet protruded; $c$, germ tooth forming on inner side of alveolus; $d$, pulp-cavity; with the exception it is thought of the atlas and axis, possibly of the atlas only. From, and including, the first dorsal the vertebræ are present as a continuous series up to the twenty-second

'As described by Osborn. Crania of Tyrannosaurus and Allosaurus: Memoirs of the Am. Mus. Nat. Hist., new series, vol. I, pt. I, 1912. 
caudal inclusive, beyond which some displaced caudals belonging to the type specimen were recovered. Two cervico-dorsals may have been present.

Cervical Vertebra. The neck vertebræ of the type had suffered from surface exposure at the time the skeleton was discovered. They lay with the right side downward, and the centra and the majority of the left zygapophyses had disappeared through weathering. What remained intact beneath the surface of a short rock slope consisted mainly of neural spines, and right zygapophyses in proper relative position to each other. Eight vertebræ are represented in the series (Figure 14A) of which part of the right postzygapophysis is all that remains of the anterior one. Comparison with the cervical series of Tyrannosaurus as described by Osborn (1906), ${ }^{1}$ reliance being placed principally on the shape, length, and direction of the neural spines, and the form of the zygapophyses, has suggested the propriety of considering the series as inclusive of the third to the ninth cervical with the posterior one a cervico-dorsal. If the right postzygapophysial fragment in reality belongs to the axis instead of to the third cervical then the succeeding vertebræ would be numbered accordingly and the last of the series of eight would become the ninth and last cervical.

Presumably then seven cervical vertebræ are represented in the specimen out of a total of nine, the parts preserved being principally zygapophyses with their processes and neural spines of, it is thought, the third to the ninth vertebra both included, Figure 14A. With these, forming the posterior end of the series, are parts of what is considered to have been the anterior one of two cervico-dorsal vertebræ.

The cervical vertebræ, as determined, are represented by the following parts:

Third cervical;--fragment of the right postzygapophysis only.

Fourth, fifth, sixth, and seventh cervicals;--the right pre- and postzygapophyses, the neural spine, and the base of the right transverse process.

Eighth cervical;--the right prezygapophysis, the right and left postzygapophyses, and the right transverse process (with cervical rib, Figure 21B). Neural spine not preserved.

Ninth cervical;-the right and left prezygapophyses, the right and left postzygapophyses, the lower portion of the neural spine, and the right transverse process.

First cervico-dorsal;-- the right prezygapophysis and the base of the right transverse process. No neural spine preserved.

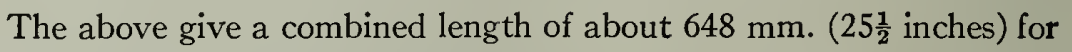
the seven cervical vertebræ represented.

In these vertebræ the neural spines are short, rather irregular in lateral outline above, laterally compressed, excavated below on their narrow front and back faces, and placed rather far back over the posterior

2 Tyrannosaurus, Upper Cretaceous carnivorous dinosaur (second communication); Bull. Am. Mus. Nat. Hist., vol. XXII, art. XVI, p. 287, fig. 3. 

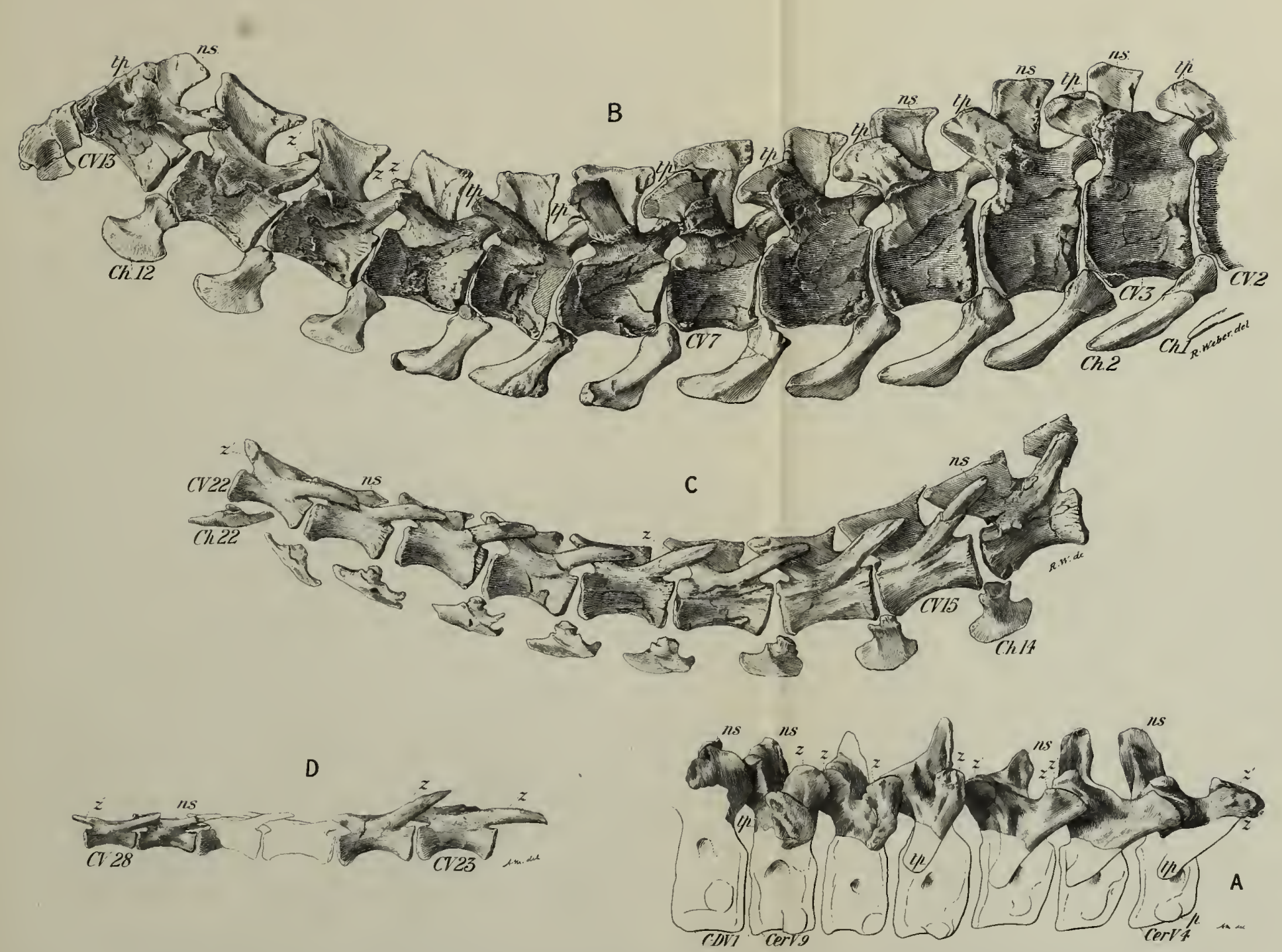

Figure 14. Cervical and caudal vertebræ of the type of Gorgosaurus; cervical $\frac{1}{8}$ and caudal $\frac{1}{3}$ natural size. A, cervical vertebræ, the fourth to the ninth, with the supposed cervico-dorsal vertebra (No. 10); the restored parts are unshaded; $B$, caudal vertebræ, the second to the thirteenth; $C$, caudal vertebræ, the fourteenth to the twenty-second; $D$, caudal vertebræ (found displaced) the twenty-third, twenty-fourth, twenty-sixth (in part), twenty-seventh, and twenty-eighth; $C$ - $D V$, cervicodorsal vertebra; $\operatorname{CerV}$, cervical vertebra; $C h$, chevron bone; $C V$, caudal vertebra; $n s$, neural spine; $p$, parapophysis; $t p$, transverse process; $z$, prezygapophysis; $z^{\prime}$, postzygapophysis. 


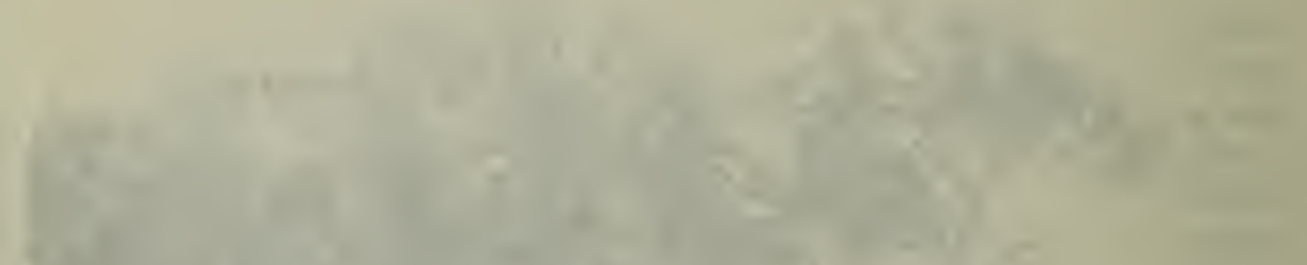

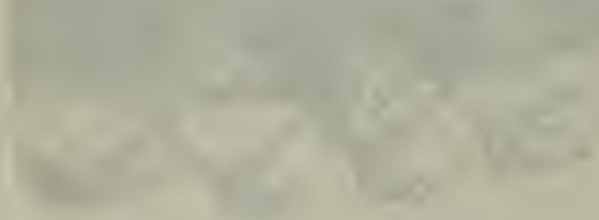

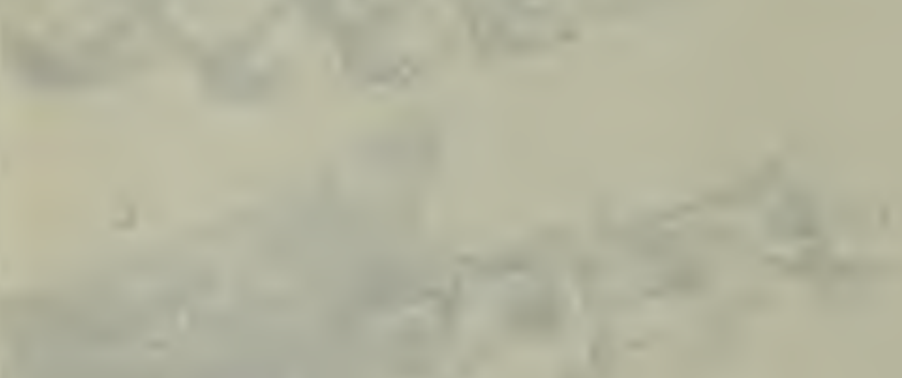

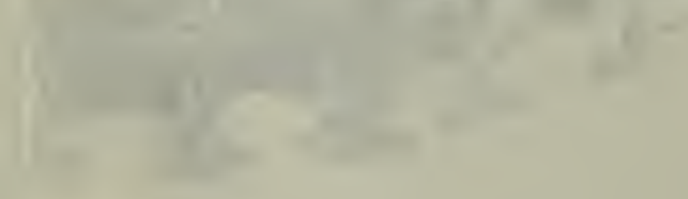

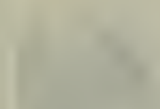

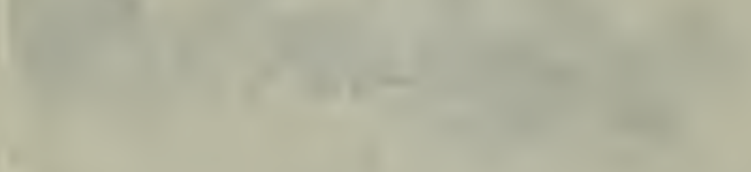
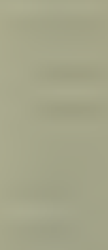

(n)

$\sqrt{2}+x^{2}$

(n)

$x^{2}$

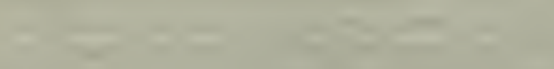

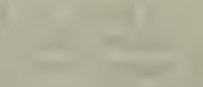

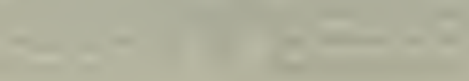

$$
\begin{aligned}
& =
\end{aligned}
$$
ran 
half of the centrum. Toward the base they increase rapidly in a fore and aft direction. In the type the spine is preserved to its full length in the fourth, fifth, and seventh vertebræ; that of the sixth is shorter, unduly so possibly on account of incomplete preservation distally; in the eighth and ninth the spine bases only are left. The zygapophyses, borne on strong, heavy processes are large, almost circular in outline, and are best seen in the specimen in the fourth, fifth, and sixth vertebræ where they and their processes have apparently been least affected by distortion (Figure 14A). A diapophysis is directed downward and backward from beneath the prezygapophysial process for articulation with the rib tubercle. The diapophysis in its entirety is preserved only in the eighth cervical where unfortunately it is crushed badly. It is this particular process to which the very complete rib, figured on page 33, was found attached. In the type specimen the right diapophysis of the ninth vertebra has been squeezed inward and pressed upward and those of the fifth, sixth, and seventh have been broken off, leaving an indication, however, of their true direction.

Dorsal Vertebre. The dorsal vertebræ of Gorgosaurus, eleven in number, have a slight gradual increase in size from the first to the last. In the type specimen they, in common with other parts of the skeleton, have suffered from lateral pressure but otherwise they are in a good state of preservation and succeed each other in their proper relative position forming a continuous series. The right rib of each vertebra is present and may be said to be almost in place in each case (Figure 7). Eight of the ribs of the left side are wholly or partially represented but most of them have been displaced (Figure 6). Between the eleventh dorsal vertebra and the first sacral is a vertebra which apparently does not belong to the dorsal series as no rib belonging to it has been found; it is for the present regarded as a lumbar.

The centra of the dorsal vertebræ are evenly excavated on the sides and inferiorly, and have slightly concave anterior and posterior articular surfaces the concavity of which, however, is probably accentuated by the crushing to which the vertebræ have been subjected. The height of the centra exceeds their length and is less than that of the neural arch and spine combined. Their breadth is less than their height, the outline as seen from in front or behind being a broad oval, but as all the centra are abnormally compressed in no case is the true breadth preserved. There is a gradual increase in the size of the centra in passing backward in the series with a corresponding increase in length and size generally of the neural spines. Broad diapophyses, directed outward and upward and backward, are given off from well up on the neural arch. Those of the right side, viz., the lower side of the skeleton as found, are bent upward toward the neural spines whereas those of the 
left side in the anterior dorsals have more nearly retained their normal direction. Most of the left diapophyses have apparently been shortened to some extent by pressure and toward the posterior end of the series they are bent downward and distorted. Those of the right side do not appear to have been much affected beyond being thrust upward; in the anterior dorsals their distal ends are seen above the neural spines in a left lateral aspect of the specimen as shown in Figure 6, ns.

In passing backward in the series the diapophyses appear to decrease slightly in length and size generally. These processes are broad at the base, narrow slightly outward, are vertically compressed, and strengthened beneath at midbreadth by a lamina of bone which runs outward toward the distal end of the process, and ends below in the posterolateral portion of the neural arch. Three right diapophyses viz., those of the fourth, fifth, and sixth vertebræ, appear to be nearly true in shape, and give the following approximate measurements: basal breadth, 95 $\mathrm{mm}$.; distal breadth, $70 \mathrm{~mm}$.; length, $140 \mathrm{~mm}$.

A deep cavity is present in the lateral faces of the centra above their midheight and anterior to the midlength.

The facet for the articulation of the head of the ribs is placed, for the first few ribs at least, on the neural arch near its anterior border. It is very plainly seen in the first three dorsals as shown in Figure 7 , at *.

The neural spines increase gradually in length backward in the series, those of the anterior dorsals being less upright than those that follow. Approximately the distance from the top of the spines to the upper surface of the diapophyses proximally in the eleven dorsal vertebræ is as given in the accompanying table of measurements.

Measurements of Dorsal Vertebra of Type.

\begin{tabular}{|c|c|c|c|}
\hline Vertebræ. & $\begin{array}{c}\text { Length (antero-pos- } \\
\text { terior) of centrum } \\
\text { at midheight. } \\
\text { Mm. }\end{array}$ & $\begin{array}{l}\text { Distance from top of } \\
\text { neural spine to mid- } \\
\text { length of centrum } \\
\text { below. } \\
\text { Mm. }\end{array}$ & $\begin{array}{l}\text { Distance from top of } \\
\text { neural spine to } \\
\text { upper surface of } \\
\text { base of diapophy- } \\
\text { sis. } \quad \mathrm{Mm} . \\
\end{array}$ \\
\hline $\begin{array}{l}\text { First...... } \\
\text { Second... } \\
\text { Third.... } \\
\text { Fourth... } \\
\text { Fifth..... } \\
\text { Sixth..... } \\
\text { Seventh... } \\
\text { Eighth... } \\
\text { Ninth.... } \\
\text { Tenth.... } \\
\text { Eleventh. }\end{array}$ & $\begin{array}{r}93 \\
97 \\
100 \\
102 \\
\ldots \\
\cdots \\
\cdots \\
\cdots \\
134 \\
150 \\
\end{array}$ & $\begin{array}{l}276 \\
278 \\
288 \\
290 \\
315 \\
\ldots \\
\ldots \\
295 \\
362 \\
368 \\
\end{array}$ & $\begin{array}{l}106 \\
108 \\
115 \\
115 \\
120 \\
127 \\
136 \\
140 \\
145 \\
155 \\
160 \\
\end{array}$ \\
\hline
\end{tabular}

The neural spines increase in fore and aft diameter distally. Above their midheight a rugosely surfaced marginal extension of the bone forward, upward, and backward is developed for the attachment of 
ligaments. On their side faces the spines are smooth in a narrow axial area sharply defined in front, above, and behind from the marginal zone which latter is horizontally furrowed by grooves of varying depth and distance apart. This marginal extension is slightly less in transverse thickness than that of the axial part of the spine and has an anterior and posterior face rendered rugose by deeply pitted projections and anastomosing channels running irregularly in a general vertical direction, Figure 15. In the type the distal ends of the spines in some of the dorsals
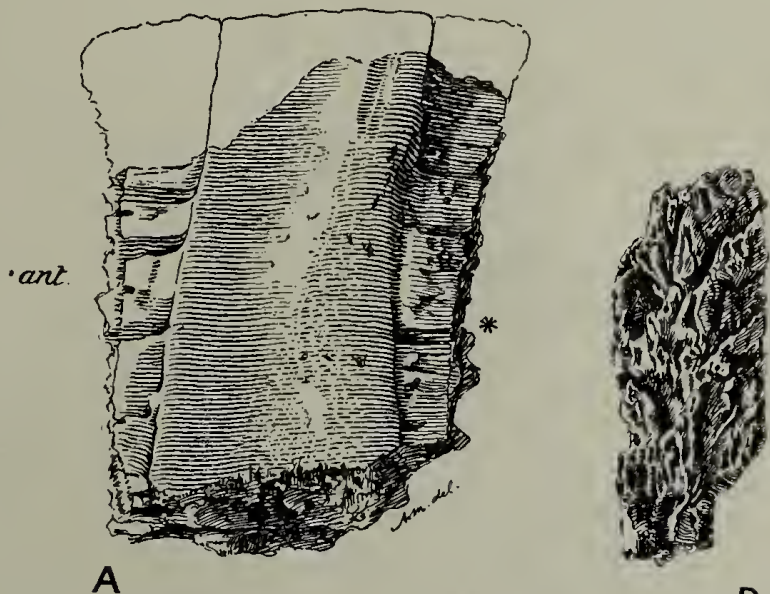

B

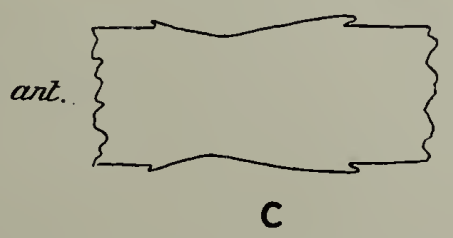

Figure 15. Distal end of neural spine of dorsal vertebra of Gorgosaurus; separate specimen; $\frac{1}{2}$ natural size. Cat. No. 350. $A$, left lateral aspect; $B$, anterior view; $C$, outline of transverse section at*, ant., anterior.

have increased to such an extent in an antero-posterior direction as to approach each other closely and even to effect a union. This distal enlargement of the neural spines occasioned by the development of rugose areas is most developed in the dorsal vertebræ, in the fifth to the ninth vertebra of this series in the type. The spines of the cervical vertebræ show like structural characters somewhat modified, and in the tail they are still less marked. During the preparation of the type specimen, the sandstone matrix between the upper ends of the neural spines of the dorsal vertebræ, more particularly from the fourth to the 
last, was found to hold small bony particles, which leads to the belief that there was a slight ossification of the fibrous tissue connecting the spines.

Sacral Vertebrce. The sacrum is entirely hidden on the left side of the type by the ilium.

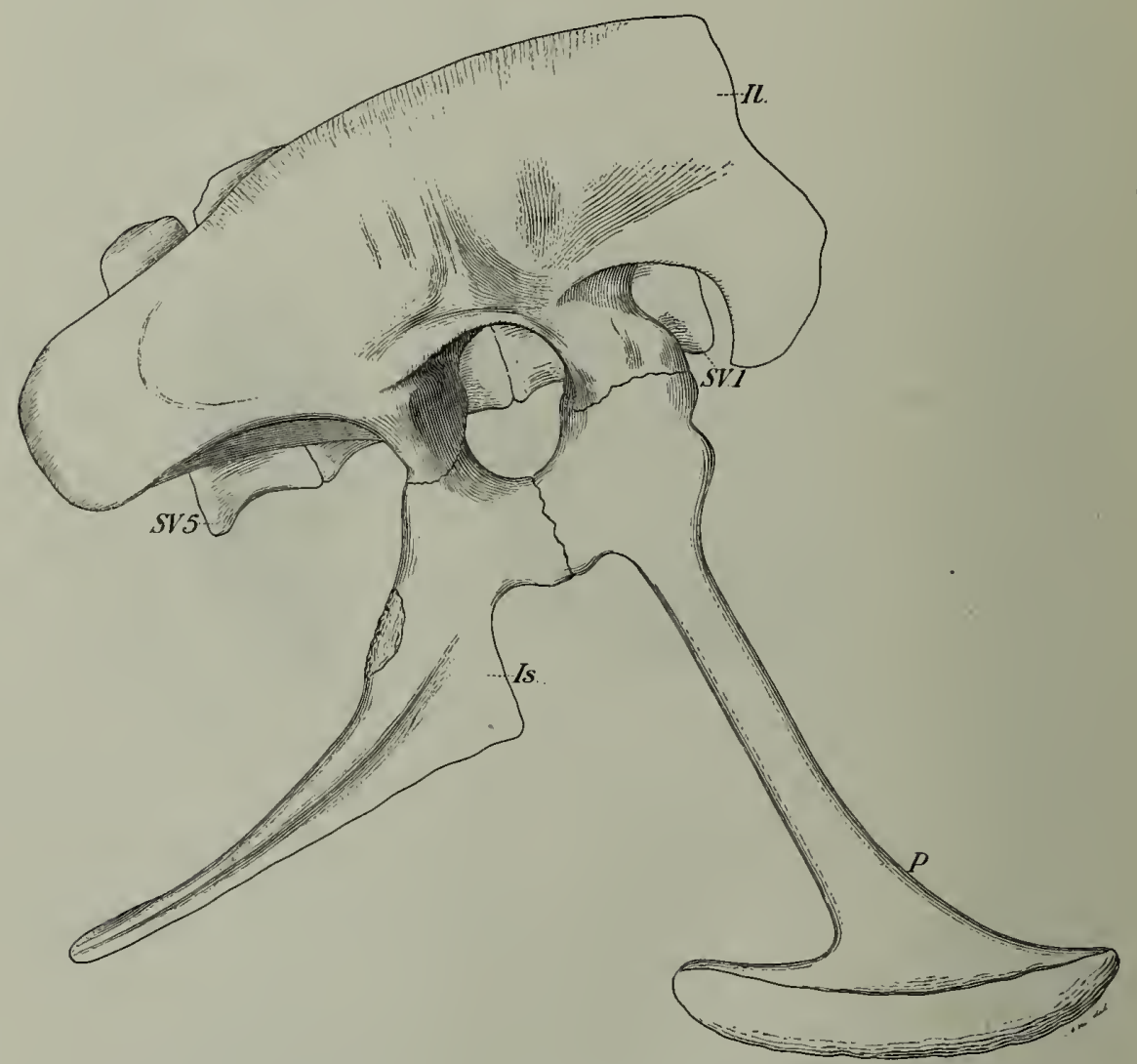

Figure 16. Pelvic arch of the type of Gorgosaurus; right lateral aspect; $\frac{1}{12}$ natural size. Il, ilium; $I s$, ischium; $P$, pubis; $S V_{1}-S V_{5}$, sacral vertebræ.

On the right side the whole of the lower portion of the ilium, including the acetabular region generally, has been shoved upward so as to disclose the coalesced centra of the sacral vertebræ to an unequal extent. Since the drawing reproduced in Figure 7 was made, the right limb of the type specimen has been lifted revealing much that had been hidden by the femur, tibia, and fibula. The centrum of the fifth sacral vertebra is seen and that of the fourth to near its anterior margin which is hidden beneath the pedunculate union of the ilium and ischium (Figure 16). Within the acetabulum the centra of the third and second vertebræ are 
revealed, the former for about half its length in front, the latter for nearly its full length. These two centra have been flattened by the head of the right femur, but their junction with each other can be made out a little behind the centre of the acetabulum. The broad contact of the ilium with the pubis covers the centrum of the first sacral from its union with the second to near its anterior end. Five sacral vertebræ are thus revealed and it has been possible to obtain fairly accurate measurements giving the relative length of their centra.

Measurements of Sacrum of Type.

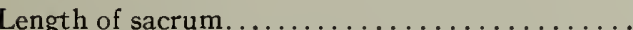

Length of centrum of first vertebra at midheight (approx.) .............. 138

Length " " "second " " "

Length " " " third " " " $\ldots \ldots \ldots \ldots \ldots \ldots \ldots \ldots \ldots, 130$

Length " " " fourth " " "

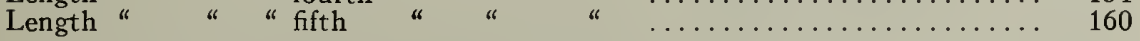

The centra of the sacral vertebræ are concave on the sides and beneath. A transverse process connecting with the ilium is seen in the type in the first, fourth, and fifth vertebræ, but that of the second and third is hidden by the ilium. The process of the first vertebra is broad and long and is given off from the upper part of the centrum; in the type it is bent upward and flattened and was seen only when the right femur was moved. Those of the fourth and fifth sacrals are narrower and apparently shorter, and proceed in each case from the middle of the centrum in its upper part; they also are crushed and distorted in the specimen (Figure 7). The lower edge of the surface of contact of the process of the fifth sacral with the ilium is very clearly defined. The upper portion of this surface is seen at $S 5$ in Figure 39 (inner surface of separate left ilium) and denotes an attachment area of considerable size, as in Tyrannosaurus, in fact there is a general agreement in the position and size of these areas as seen in the separate ilium of Gorgosaurus and the sacrum of Tyrannosaurus as figured by Osborn (op. cit. 1906).

The only other parts of the sacrum visible in the type are the distal ends of the neural spines seen between and at the level of the superior border of the ilia. Near the midlength of the ilia above, the space between these bones has been reduced by pressure to about one-third of an inch, but their distance apart increases both toward the front and rear. The neural spines of the first four sacrals are co-ossified distally, but a space occurs in front of the top of the fifth spine separating it from the fourth. This distal co-ossification of the spines would lead one to expect to find them united at a lower level forming a more or less continuous plate such as is found in Tyrannosaurus.

Caudal Vertebre. From displaced caudals belonging to the type, determined as the twenty-third, twenty-fourth, twenty-sixth (posterior 
end of centrum only), twenty-seventh, and twenty-eighth, and from a tail of another individual (see page 29), we have knowledge of thirtyone caudal vertebræ. Judging from the rate of taper in the more posterior vertebræ it is estimated that five more vertebræ completed the tail giving a full number of thirty-six caudals.

The tail is almost equal to one-half the total length of the animal and must have played an important part in preserving the creature's balance; it was probably dragged for a small part only of its distal length. That the tail was incapable of much flexion is apparent from the greatly increased length of the zygapophyses, and the extent to which they interlock at and behind its midlength. It is probable, however, that the degree of rigidity was not as great as in the tail of the slender and contemporaneous Ornithomimus altus Lambe, if to that species properly belonged, as is supposed, the peculiarly shaped caudal vertebræ with greatly elongated, horizontal, and flattened prezygapophyses described and figured by the writer in $1902 .{ }^{1}$
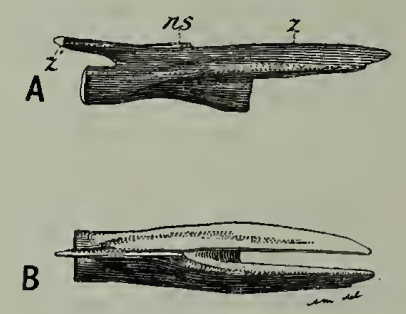

Figure 17. Caudal vertebra of Ornithomimus altus Lambe; $\frac{1}{3}$ natural size. A, right lateral aspect; $\mathrm{B}$, superior aspect; $n s$, neural spine; $z$, prezygapophysis; $z^{\prime}$, postzygapophysis.

In general proportions the anterior caudal vertebræ are stout and about as high as long (Figure 14). In passing backward they soon assume a lengthened, cylindrical form as their diminution in length is less rapid than in height. The neural spines, the transverse processes, and the chevron bones are short, resulting in a tail which, in life, must have been in its proximal half nearly as broad as high, becoming more cylindrical, or circular in cross-section, toward its end, a tail which would be quite different in shape from the high, laterally compressed tail of Trachodon, and probably resembling in proportions that of some of the existing terrestrial lizards such as the carnivorous Tupinambis nigropunctatus of South America and the European Lacerta ocellata.

In the type skeleton the caudal vertebræ with their chevron bones are in place up to and including the twenty-second. The twenty-third, twenty-fourth, twenty-seventh, twenty-eighth, and part of the centrum of the twenty-sixth were discovered displaced separately in the matrix so that all the vertebræ of the tail in the type are known up to the twentyeighth inclusive except the twenty-fifth and the greater part of the twenty-sixth.

1 Geol. Surv., Can., Cont. to Can. Pal., vol. III, pt. II. New genera and species from the Belly River series (Mid-Cretaceous). 
A separate specimen, obtained from the Belly River formation on Red Deer river in 1915 and thought to be referable to Gorgosaurus, consists of caudal vertebræ in place in a splendid state of preservation from what are probably the sixteenth to the thirtieth. In this specimen most of the chevron bones are in place including the one that came between the thirtieth and thirty-first vertebræ. Judging from the rate of taper of the centra in this and in the type specimen about thirtysix caudal vertebræ were probably present in Gorgosaurus, and on this assumption the tail is restored to this vertebral length in Figure 49.

In following backward in the caudal vertebral series the centra from being slightly higher than long in the most anterior vertebræ become by gradual transitions considerably longer than high in the more posterior ones, the reduction in height being more rapid than in length. In the twenty-eighth vertebra, the most posterior one found in the type skeleton, the height of the centrum (anterior articular face) to its length is in the proportion of 1 to $2 \frac{3}{4}$ (Figure 18).

The vertebral centra are concave on the sides and below. With their proportionate lengthening the lower surface becomes more decidedly curved and encroaches more on the side faces. The anterior articular faces appear to be moderately.concave, the posterior ones plane or very slightly concave. In the twentyseventh and twenty-eighth verte-
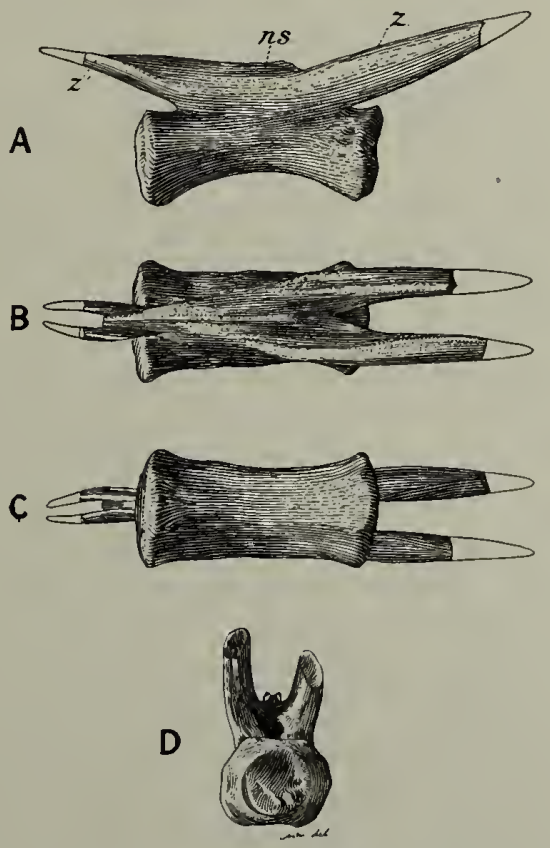

Figure 18. Twenty-eighth caudal vertebra of the type of Gorgosaurus; $\frac{1}{3}$ natural size. $A$, viewed from the right side; $B$, from above; $\mathrm{C}$, from below; $\mathrm{D}$, from behind; $n s$, neura! spine; $z$ prezygapophysis; $z^{\prime}$, postzygapophysis.

bræ, which have not suffered at all from lateral pressure the anterior face has a broad, bevelled peripheral border surrounding a well-defined central concave surface which in the twenty-seventh is markedly concave but in the twenty-eighth is only slightly depressed. In both vertebræ the posterior articular face is bevelled around the edge and plane toward the centre.

The neural spines are short, deep from front to back, thin across, flat on the sides, and end above in a horizontal edge. In those of the 
more anterior caudals the height is about equal to the length of the centrum. In most of the spines the upper anterior angle is produced slightly forward giving the anterior face a concave outline in lateral aspect. In passing back, in the tail, the spines decrease in height and, concurrent with the proportionate lengthening of the centra, add to their antero-posterior depth. This increase in depth is attained principally at the distal end where the posterior angulation is produced backward beyond the line of the end of the centrum causing the narrow hinder edge of the spine to face obliquely downward.

Concurrent with the lengthening of the centra, and the anteroposterior extension of the neural spines and chevrons there is a striking prolongation of the prezygapophysial processes. Up to the eleventh caudal vertebra each prezygapophysis (facing inward and upward) is at the end of the process, but at the twelfth the process begins to extend forward beyond the zygapophysial facet and in the vertebræ that follows the prolongation is rapidly increased, each process extending far forward parallel with the neural spine of the preceding vertebra. In the twentyeighth vertebra the length of the prezygapophysial process is nearly equal to that of the centrum. When the process extends beyond the prezygapophysis the latter faces directly inward and appears on the inner side of the process as a small slightly elevated, oval surface.

The postzygapophyses in the anterior caudals face outward and downward, and occur at the base of the neural spine posteriorly. In following backward the neural spines decrease in height and up to the twentieth vertebra still rise above the level of the postzygapophyses. In the vertebræ that follow, however, the reduced neural spine, sunk to the level of the postzygapophyses, combines with the latter to form a stout backwardly directed, centrally placed process which interlocks with the pair of prezygapophysial processes of the succeeding vertebra. In the eighteenth caudal there is a slight prolongation of the bone backward beyond the postzygapophysis on each side of and past the back termination of the neural spine. This double prolongation, which increases to some extent in the vertebræ following the eighteenth, has the appearance, when viewed from above, of a bifurcation of the central, composite postzygapophysial process. The postzygapophysial articulating facet on each side of this process faces directly outward.

In the anterior caudal vertebræ the prezygapophysial processes are directed upward at an angle of about 35 degrees, but in those that follow they gradually become less inclined. These processes are laterally compressed in a moderate degree, the greater diameter being nearly vertical, in which respect they differ from the much flattened corresponding processes of Ornithomimus, already referred to, with a greater transverse diameter sometimes nearly horizontal (Figure 17). The 


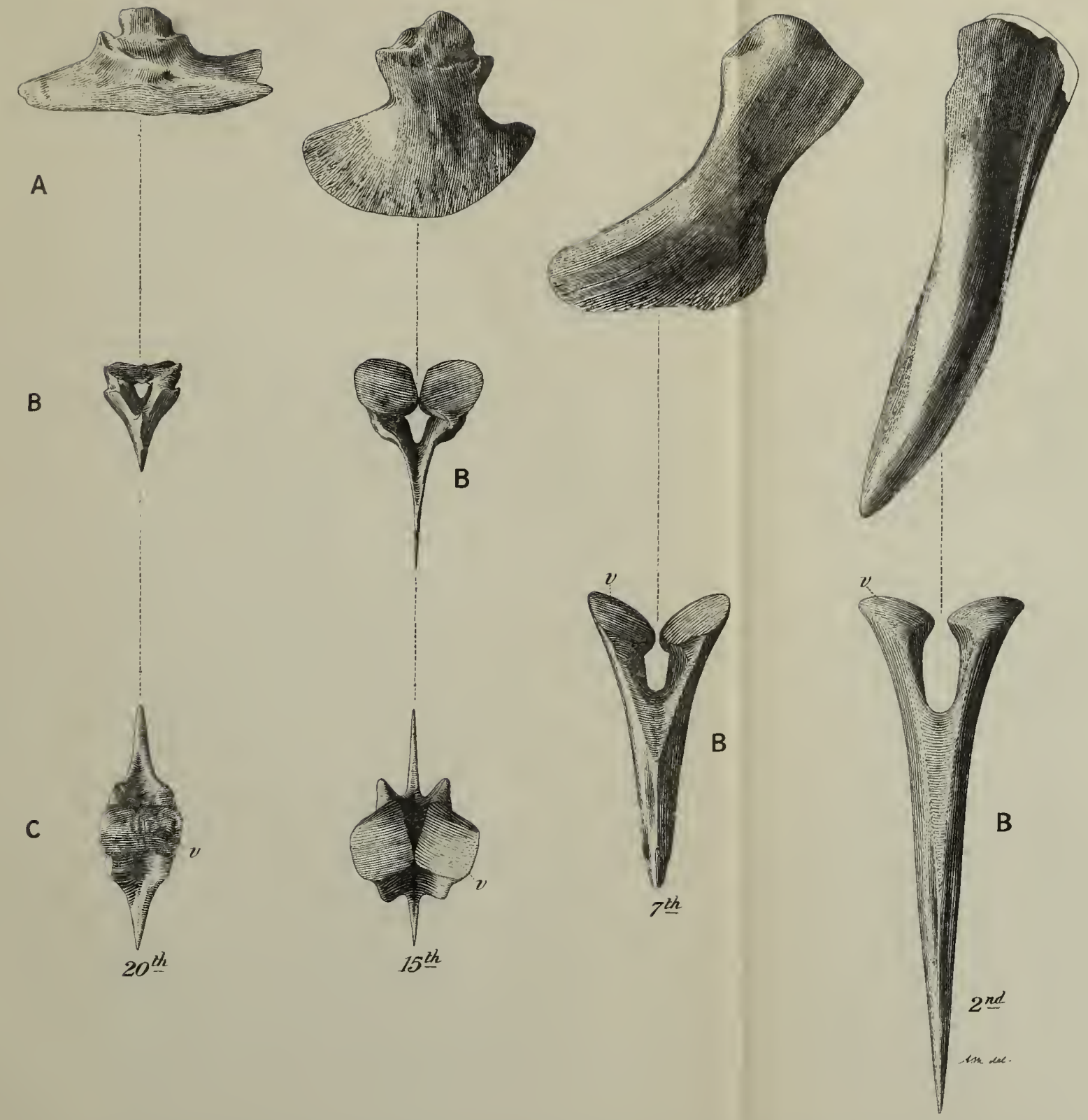

Figure 19. Second, seventh, fifteenth, and twentieth chevrons of type of Gorgosaurus; $\frac{x}{3}$ natural size. $A$, right lateral aspect; $B$, posterior aspect; $C$, superior aspect; $v$, surface of contact with vertebra. 

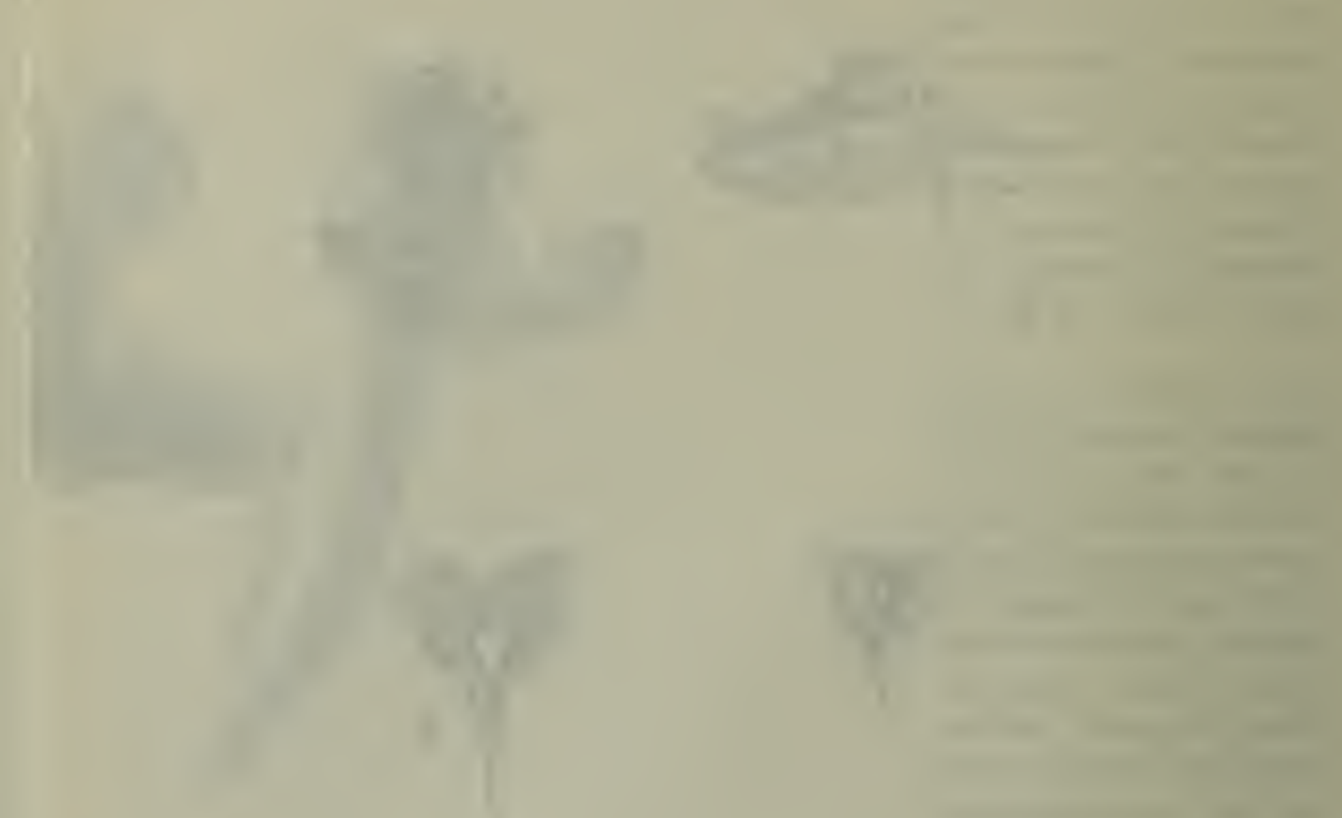

(n)
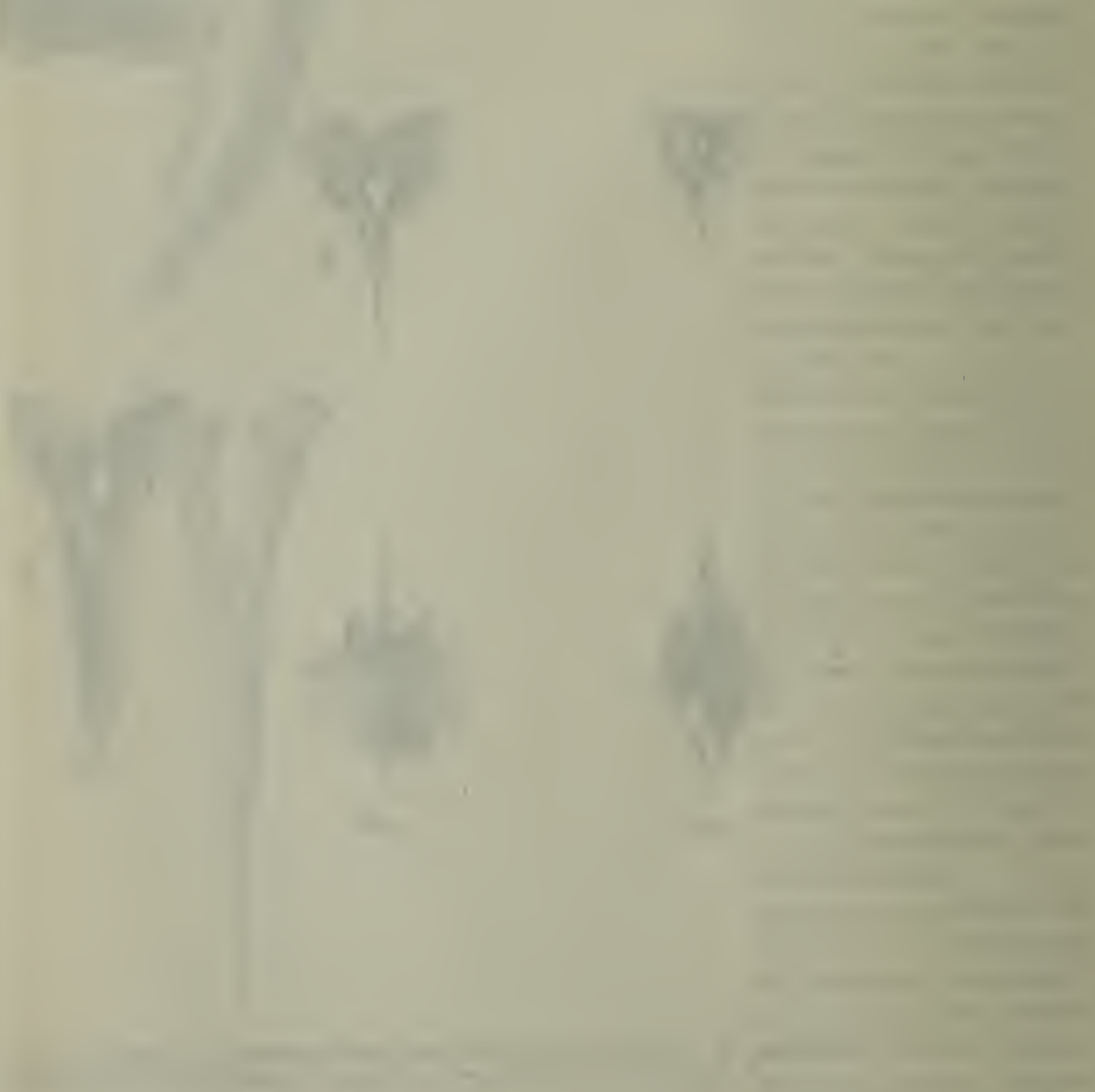
transverse processes of the caudals are short, broad, thin vertically, and come to a rather square ending distally. They diminish gradually in size in passing backward in the series and cease with the fourteenth vertebra on which a slight protrusion only of the bone represents the last process (Figure 14).

\section{CHEVRONS.}

The chevron bones are intervertebral, short, and change much in shape in passing backward in the series; they begin between the first and second caudal vertebræ and continue to at least the thirty-first caudal. The changes in shape in the chevrons are due principally to a distal enlargement of the bone, which, becoming pronounced first on the posterior face near the beginning of the series, is soon increasingly developed on the anterior face also, forming a keel, and finally, in the hinder half of the tail, is prolonged equally in front of and behind the shaft of the bone (Figure 19). Concurrent with the increasing fore and aft extension of this distal foot there is both an actual and a relative decrease in the length of the shaft which, in its maximum reduction in the smaller posterior chevrons, is little more than a rounded articulating surface, for intervertebral contact, on a constricted neck rising centrally from the foot. The lower edge of the chevrons, as the foot developed, is parallel with the longitudinal axis of the tail. As the depth of the chevrons decreased, in passing backward in the series, so did their anteroposterior distal extension increase; at first deeper than broad, in lateral aspect, they shorten to a "meat-chopper" shape near the middle of the tail, and farther back resemble miniature sleigh-runners in form. This shape in the distal chevrons no doubt indicated that posteriorly the tail dragged, and the extent to which it came in constant contact with the ground can be gauged by the degree of distal expansion found in these bones. The hind feet of Gorgosaurus are those of a land animal, and the form of the tail, and particularly of the chevrons in its hinder half-the bony parts that would be nearest the ground and which would be influenced most by the tail's contact with hard surfaces-also indicate a terrestrial habitat. The tail in Trachodon and its kindred is deer, and laterally compressed-suitable for propulsion in water; the chevron bones are long, and slender distally, quite unlike those of Gorgosaurus. When the formation of the tail in the Theropoda generally is better known it will probably be found that the chevron bones resemble those of Gorgosaurus in their main features. In some of the Jurassic Sauropoda, notably in Diplodocus, the "foot" of the posterior chevron bones is proportionately even more longitudinally extended in a horizontal direction than those of Gorgosaurus, a fact strongly in favour of these immense dinosaurs (Diplodocus and allied genera) having been land rather than swamp reptiles. 
Second Chevron:

Length (distance from proximal end to distal extremity) , . . . . . . 227

Breadth (antero-posterior) at midlength..................... 40

Thickness (transverse) across articular facets......................... 70

Seventh Chevron:

Distance from middle of proximal end to middle of lower margin of distal foot 145

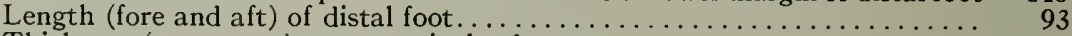

Thickness (transverse) across articular facets $\ldots \ldots \ldots \ldots \ldots \ldots \ldots \ldots \ldots \ldots \ldots \ldots . \ldots \ldots$

Fifteenth Chevron:

Distance from middle of proximal end $t$, middle of lower margin of distal foot 88

Length (fore and $\mathrm{aft}$ ) of distal foot $\ldots \ldots \ldots \ldots \ldots \ldots \ldots \ldots \ldots \ldots \ldots \ldots$

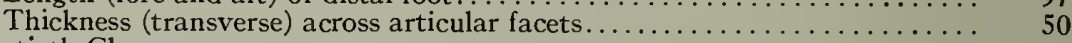

Twentieth Chevron:

Distance from middle of proximal end to middle of lower margin of distal foot 47

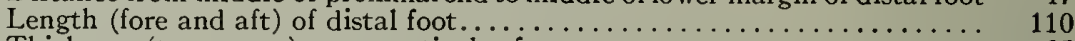

Thickness (transverse) across articular facets.................... 35

RIBS.

Cervical Ribs. The ribs of the anterior cervicals are short and compact, those of the more posterior ones are relatively large and greatly lengthened.
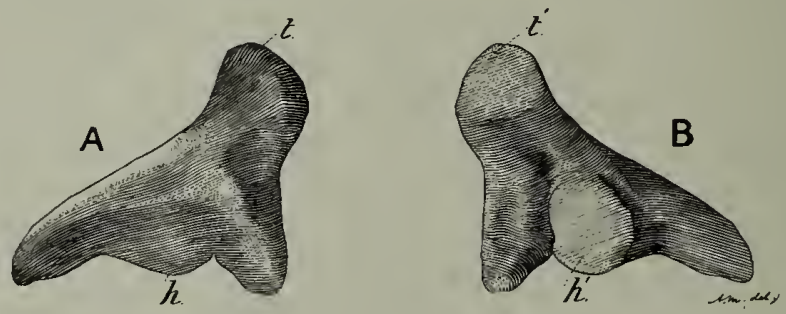

Figure 20. Anterior right cervical rib; $\frac{1}{3}$ natural size. A, exterior view; B, interior view; $h$, capitulum; $h^{\prime}$, capitu ar facet; $t$, tuberculum, $t^{\prime}$, tubercular facet.

In the type specimen five cervical ribs and part of a sixth are preserved; all are double headed. One of these was attached to the right transverse process of the eighth vertebra (Figure 21) and the others occurred scattered in the matrix near the neck. Of these latter one appears to be the mate of the one found attached (Figure 7) and two, judging from their correspondence in size and shape, are a pair also and probably belonged to the sixth vertebra (Figure 7). The remaining rib is very short, is from the right side, and was probably attached to the axis or the third vertebra (Figure 20). The rib, represented by the fragments, was on the left side, was also short and is thought to be the mate of the other short rib.

The very short right rib is complete and with it is the distal end of a transverse process to which the facet of the tubercle has remained in contact. This rib (Figure 20) is double headed, triangular in lateral 
outline, with an anterior height about equal to its inferior length; it is moderately thick for its size. Its shortness is in marked contrast to the lengthened ribs of the more posterior vertebræ of the neck. The
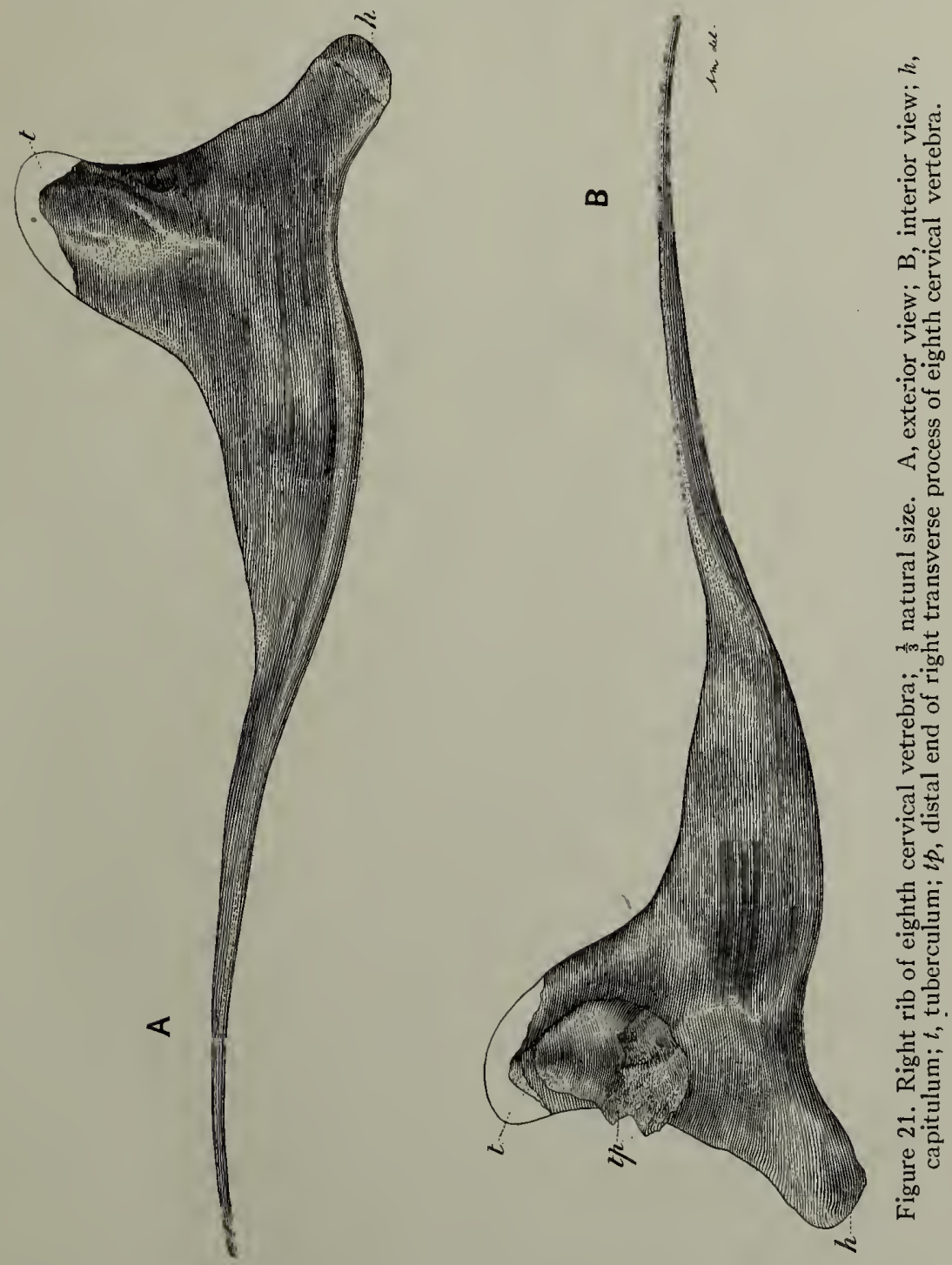

portion of the rib extending backward from the head is extremely short; it is narrow, curves slightly downward, is laterally compressed and obtusely pointed behind. There is an extension of the bone for.ward from the head, from which and from the head rises a broad neck bearing 
the tubercle. This forward expansion gives the rib its maximum depth. The tubercular and capitular surfaces of attachment are of about the same size, well-defined, flat, and nearly circular in outline.

\section{Measurements of Right Anterior Cervical Rib.}

Length from anterior edge of tubercle to posterior end $\ldots \ldots \ldots \ldots \ldots \ldots \ldots,{ }_{107}$

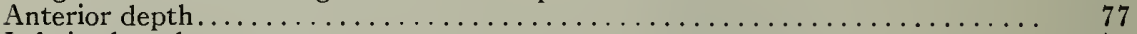

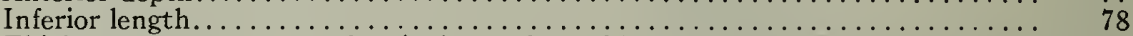

Thickness at upper edge of articular surface of head and at lower part of tuber-

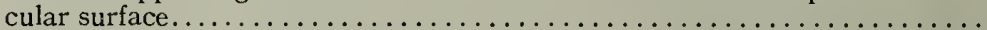

The rib fragment already referred to, consists of the posterior half of the rib from which the tubercular portion and the lower front extension have been broken off; it was found on the rock surface beneath where the neck partly protruded and had suffered from weathering. So far as a comparison is possible it agrees in size and shape with the specimen shown in Figure 20.

The right rib of the eighth cervical vertebra (Figure 21), which may be considered typical of the more posterior cervical ribs as regards shape, is broad at the base, narrows rapidly backward, and becomes very slender in its distal half length. Anteriorly it is thin and plate-like; the attenuated backward extension retains a slight lateral compression so as to be oval in cross section. The lower anterior angulation forms the head, and in this respect these large posterior ribs differ from the small anterior ones in which the capitular facet is placed farther back. In lateral aspect the front edge of the rib is shallowly excavated, the broad anterior half is deeply concave above and convex below, and the slender distal half bends slightly downward. For a short distance behind the head the lower outline is concave with a thickened border which appears on the inner side of the rib as a ridge above which the bone to the front edge and to the tubercle is thin. A slight inner thickening also occurs as a strengthening ridge directed upward toward the tubercle and bounding the thin anterior area behind. For some distance behind the head the lower border is bent outward and also remains moderately thick. The capitular facet is not clearly defined in the right rib of the eighth vertebra nor is it distinctly marked in the pair which are thought to belong to the sixth vertebra (Figure 7, CR6). When in place on the vertebra the general direction of the rib is downward and backward with the head more advanced than the tubercle.

Measurements of the Right Rib of the Eighth Cervical Vertebra.

Length in a straight line from the lower anterior end to the distal extremity.....

Distance across the anterior border.............................. 135

Depth from the tubercle to the concavity of the lower margin behind the head... 109

Depth at midlength of lower border.............................. 23

Thickness midway between the tubercle and the lower margin...............

Thickness above the lower margin behind the head ................... 15 
Thoracic Ribs. The thoracic ribs in Gorgosaurus are eleven in number on either side, and are long, slender, and double headed (Figures 22,23 , and 24). They lengthen from the first to the fourth, or possibly the fifth which is not fully preserved, and shorten rapidly to the eleventh. They are strongly curved near the vertebral end and flatly curved for the remainder of their length downward. The heaviest and strongest part of the ribs is in the neighbourhood of the tubercle which is separated from the head by a long, straight, laterally compressed neck. At and outward for a short distance from the tubercle the ribs have a somewhat inverted L-shaped cross section. With an increasing slenderness downward they become subquadrangular in cross section, then sub-circular, and finally narrowly oval near their termination with the greater diameter apparen tly directed inward and forward.

The laterally compressed neck increases in depth from the head to beneath the tubercle. In its downward and inward direction from the tubercle it inclines slightly forward to articulate with the body of the vertebra. Seen from above the neck is straight; in side view it shows a tendency to

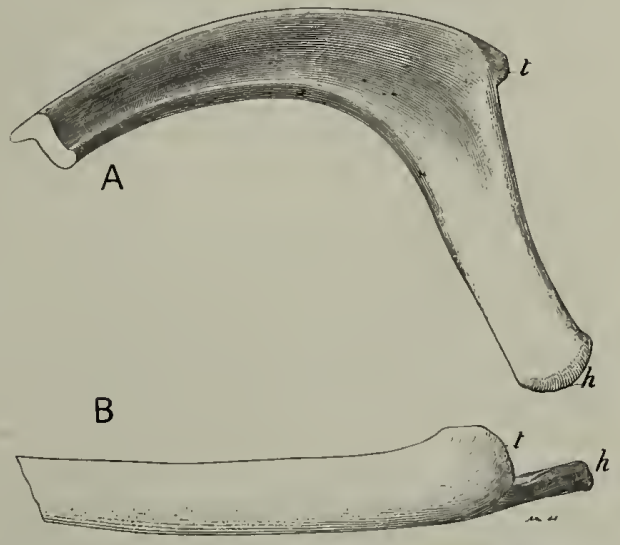

Figure 22. Right rib of third dorsal vertebra of type of Gorgosaurus; $\frac{1}{6}$ natural size. A, anterior view; $\mathrm{B}$, superior view; $h$, head; $t$, tubercle.

bend slightly upward near the head. There is little, if any, increase in the size of the bone at the head whose articular facet is gently convex with a long oval outline of which the greater diameter is vertical.

The tubercle is developed postero-dorsally and extends backward horizontally, its breadth greatly exceeding its depth. It is continued outward along the shaft, for about one-fourth of the distance from the tubercle to the lower end of the rib, as a flange giving the bone a broad upper surface nearly at right angles to the deep anterior face and resulting in the inverted L-shaped cross section which adds greatly to the strength of the rib. Here the dorsal surface is nearly flat from side to side, the anterior face is slightly concave, being shallowly and longitudinally grooved, and the postero-ventral surface is deeply excavated.

With the cessation of the flange and their diminution in depth the ribs becone sub-quadrangular in cross section with the dorsal and ventral faces nearly equal and the posterior face broader than the anterior 
one, each face being slightly grooved or fluted in the direction of the bone's length with the exception of the dorsal and posterior faces which remain somewhat flat. The upper rib surface is broadest near the tubercle.

The articular facet of the tubercle is convex in an antero-posterior direction, and faces downward, inward, and slightly backward; its depth is about one-fourth its breadth measured along the curve.
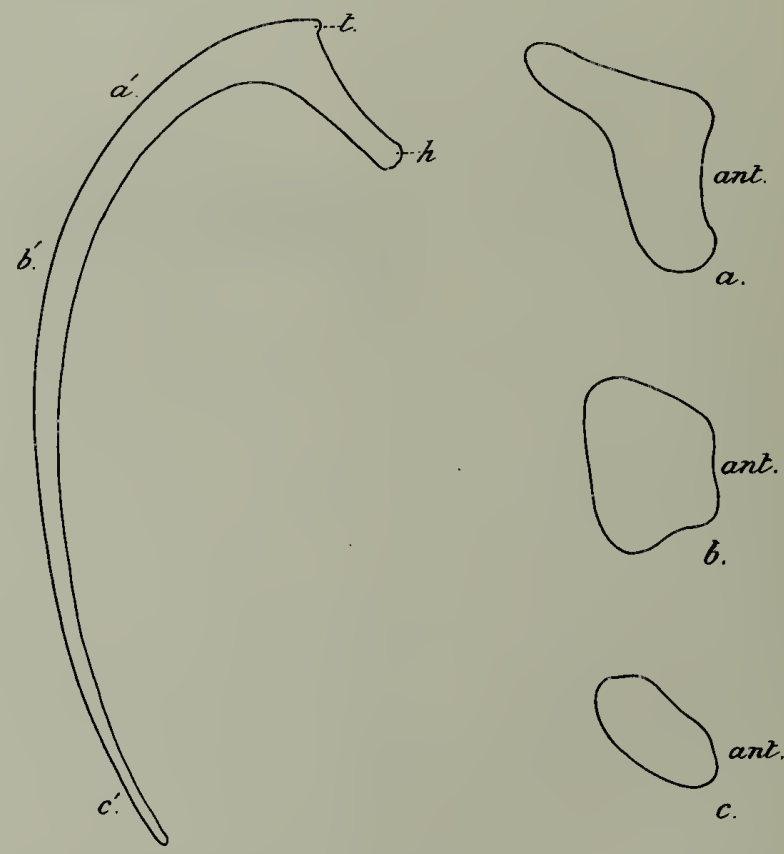

Figure 23. An anterior rib, the third dorsal, of the type of Gorgosaurus; $\frac{1}{12}$ natural size. $a, b$, and $c$, outlines of transverse sections of the same at $a^{\prime}, b^{\prime}$, and $c^{\prime}$ respectively; $\frac{1}{2}$ natural size. $a n t$, anterior; $h$, head; $t$, tubercle.

In the type all the right ribs are preserved and articulate with their respective vertebræ or are only slightly displaced. They have, however, been bent backward on each other, but with little distortion of their natural curve (Figure 7). The majority of them have suffered somewhat from pressure and some of them, as indicated in the accompanying table of measurements, are imperfect at the lower end. The second, third, and fourth are complete in all respects. The first and fifth are thought to be complete but their lower ends are hidden by the matrix beneath the abdominal ribs. The tenth and eleventh appear to be fully preserved. 
On the left side the greater part of eight ribs and a fragment of the shaft of one are preserved as shown in Figure 6. They are well preserved but all of them have been displaced more or less from their vertebræ.

The changes in the shape of the ribs outward and downward from the tubercle are illustrated in Figure 23 by outlines of cross sections of one of the best preserved of the ribs (the third? ? *, Figure 6) of the left side. This rib has suffered least of all the ribs of the type from distortion and is apparently quite normal in shape.

Measurements in mm. of the Right Thoracic Ribs of the Type.

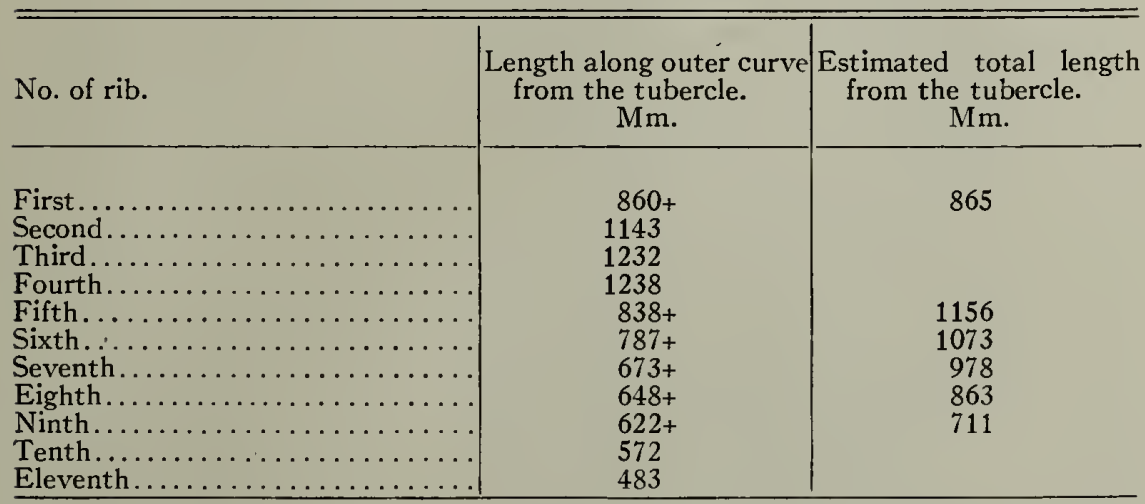

The breadth of the dorsal face of the third right rib, $195 \mathrm{~mm}$. out from the tubercle, is $45 \mathrm{~mm}$., a similar measurement, $143 \mathrm{~mm}$. from the tubercle, in the ninth rib is $41 \mathrm{~mm}$.

At their midlength the dorsal face of the ribs is about $28 \mathrm{~mm}$. broad with a slight diminution in the hinder ones.

The distance in a straight line from the tubercle to the head in the more anterior ribs is about $200 \mathrm{~mm}$.

The length of the first left rib, complete to the lower end, measured along the curve from the tubercle is about $865 \mathrm{~mm}$. $50 \mathrm{~mm}$.

The average height of the head in the more anterior ribs is about

At the time the drawing reproduced in Figure 7 was made the right hind limb completely hid the eighth rib and most of the ninth, tenth, and eleventh. Since then the limb has been lifted, disclosing fully not only as much as is preserved of these hinder ribs but also the anterior end of the ilium and the acetabular region generally.

Abdominal Ribs. In Gorgosaurus abdominal ribs are present forming a cuirass which extends from the sternum back to the distal end of the pubic bones, and whose maximum breadth is equal to about three-fourths of its length. 
The ribs occur in a longitudinal series and curve outward and backward from the midline of the cuirass. They alternate to the right and left and overlap at their inner ends. Each rib consists of two parts,

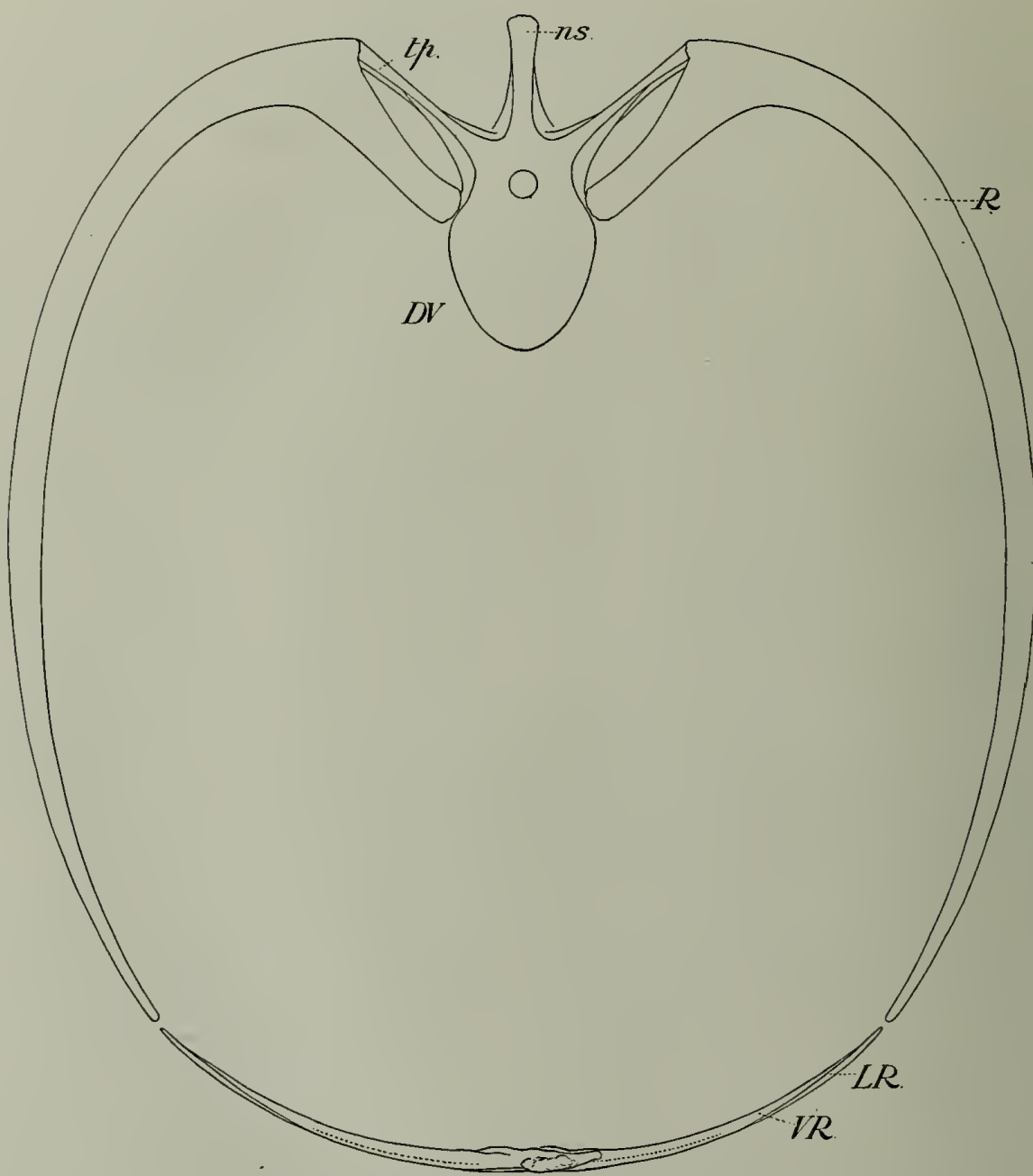

Figure 24. Restored transverse section of trunk at third dorsal vertebra: $\frac{1}{9}$ natural size. $D V$, dorsal vertebra; $n s$, neural spine; $R$, left thoracic rib; $t p$, transverse process; $V R$, abdominal rib.

an elongated bone flattened inwardly for the overlap, and a shorter, slender, rod-like bone which is closely applied to the outer end of the larger one. During life the ribs were no doubt bent upward at the outer end but as preserved in the specimen they lie flattened in one plane. 
In the type the greater part of the right half of the cuirass is preserved, presenting to view its ventral suriace; with it occur a number of overlapping inner ends or heads belonging to the ribs of the left side. The left half of the cuirass had been exposed to the air when the skeleton was discovered and weathered fragments only of the greater part of it were obtained. The number of ribs of the right side, wholly or partially preserved, and following each other closely in regular sequence and in place in the specimen, is seventeen (Figure 25).

Near the sternum was found a displaced rib length (Figure 7, VR1) which is interpreted as being the right half of a double rib formed by the co-ossification of a left with a right hand rib; this double rib is thought to have belonged to the extreme anterior end of the cuirass and to have been No. 1 of the ribseries. Among the fragments belonging principally to the left side of the cuirass, is one which appears to be part of another double rib, forming a single median piece, which, judging from its curvature and size was, if not the last, very

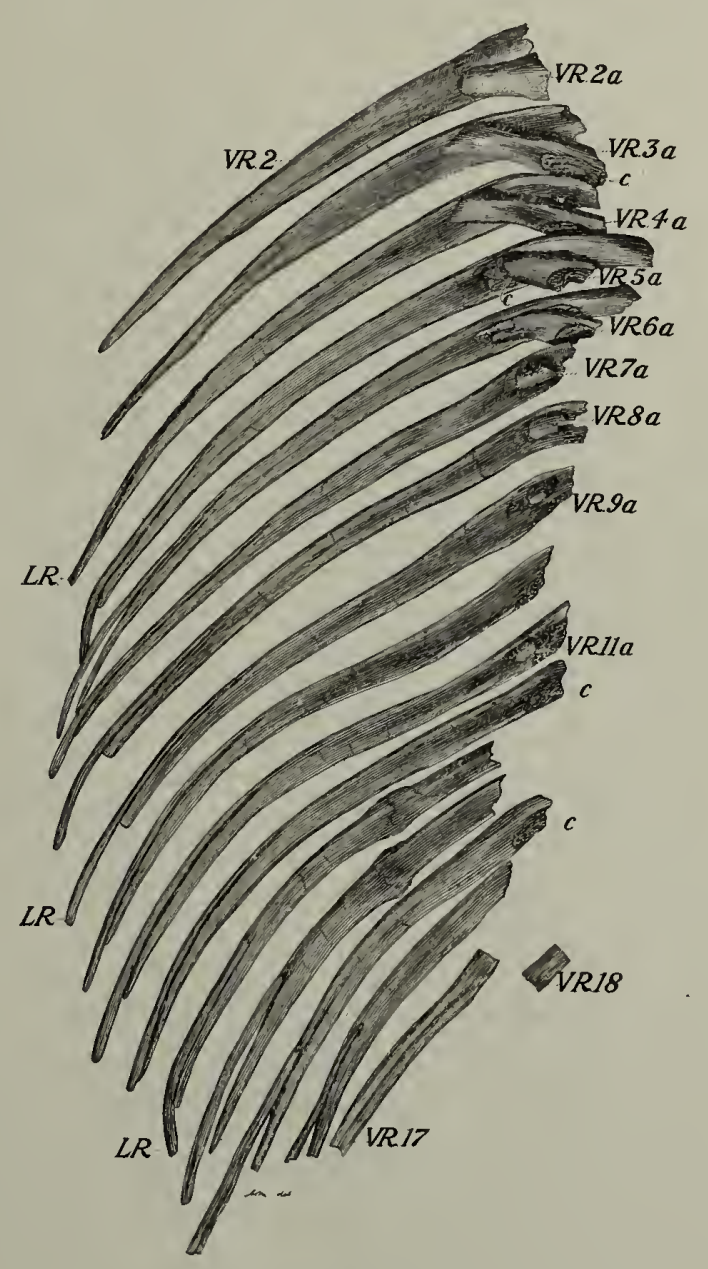

Figure 25. The abdominal ribs of Gorgosaurus as preserved in the type; ventral aspect; 1 natura size. $c$, surface of attachment; $L R$, lateral rib-bone; $V R 2-17$, second to seventeenth right rib; $V R 2 a-10 a$, inner ends of left ribs. close to the last of the series. These two ribs, additional to the seventeen found in place, raise the number to nineteen which may be taken as the full number of ribs on either side in the series, although of this there can be no certainty at present; they are introduced as the first and last 
ribs in the restoration drawing of the cuirass (Figure 27). Forming part of the abdominal rib series of a carnivorous dinosaur in the Geological Survey collections from the Edmonton formation of Alberta (Red Deer river) are two double ribs, one large and moderately bent with a greatly increased median breadth (fore and aft) due to co-

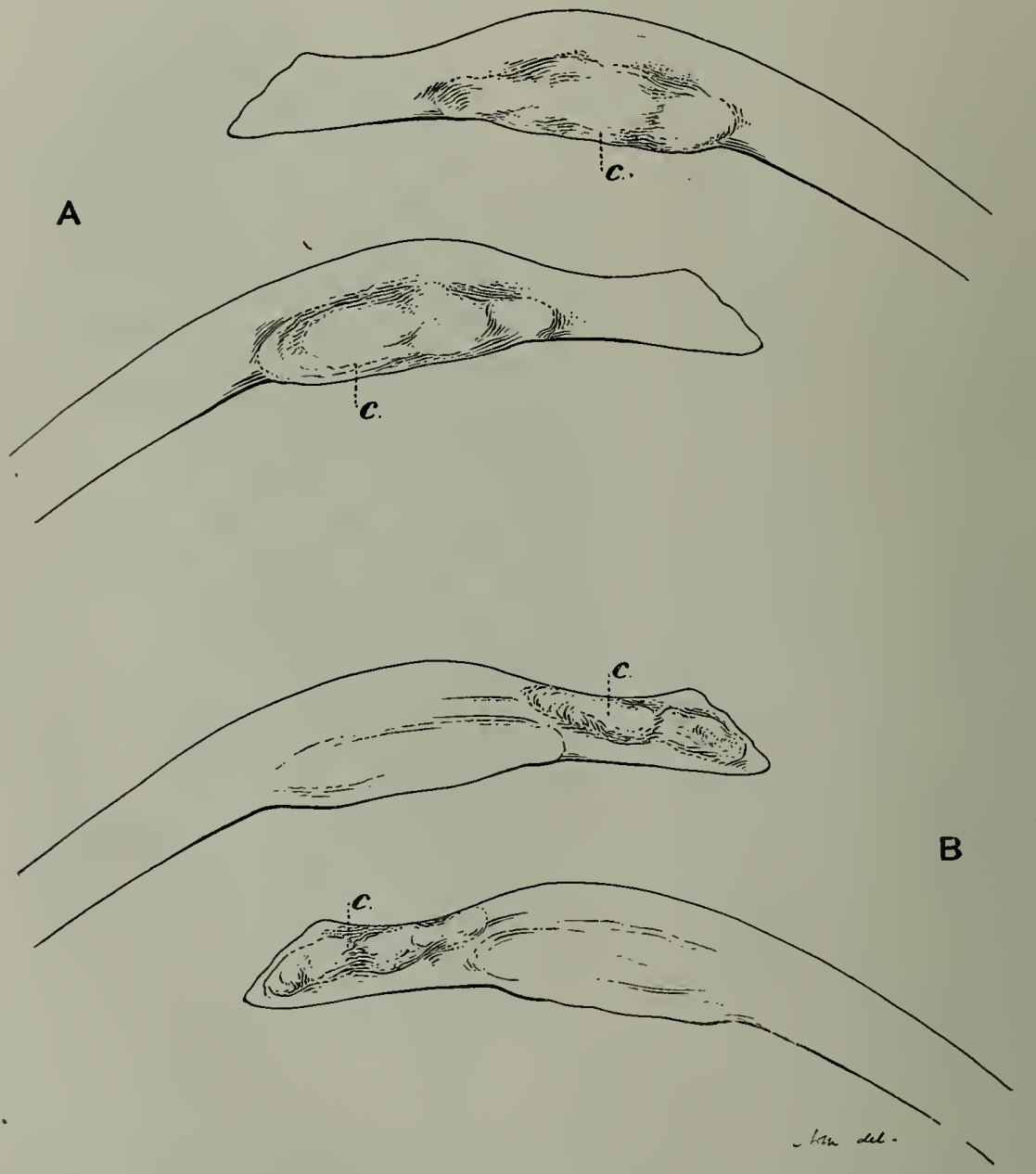

Figure 26. Heads of abdominal ribs of Gorgosaurus to show surfaces of attachment; $\frac{1}{4}$ natural size. A, right and left ribs, ventral aspect; $B$, dorsal aspect of the same; $c$, surface of attachment.

ossification, the other small and curved rapidly backward from the centre, where there is little evidence of the conjunction of separate bones, the former evidently from the front of the rib series, the latter from the back. Co-ossification of some of the ventral ribs is also found in Tyrannosaurus. 
In the type of Gorgosaurus there are preserved in place with the right ventral ribs the inner ends, some complete, others fragmentary, of nine left ribs in the anterior half of the cuirass, disclosing the amount

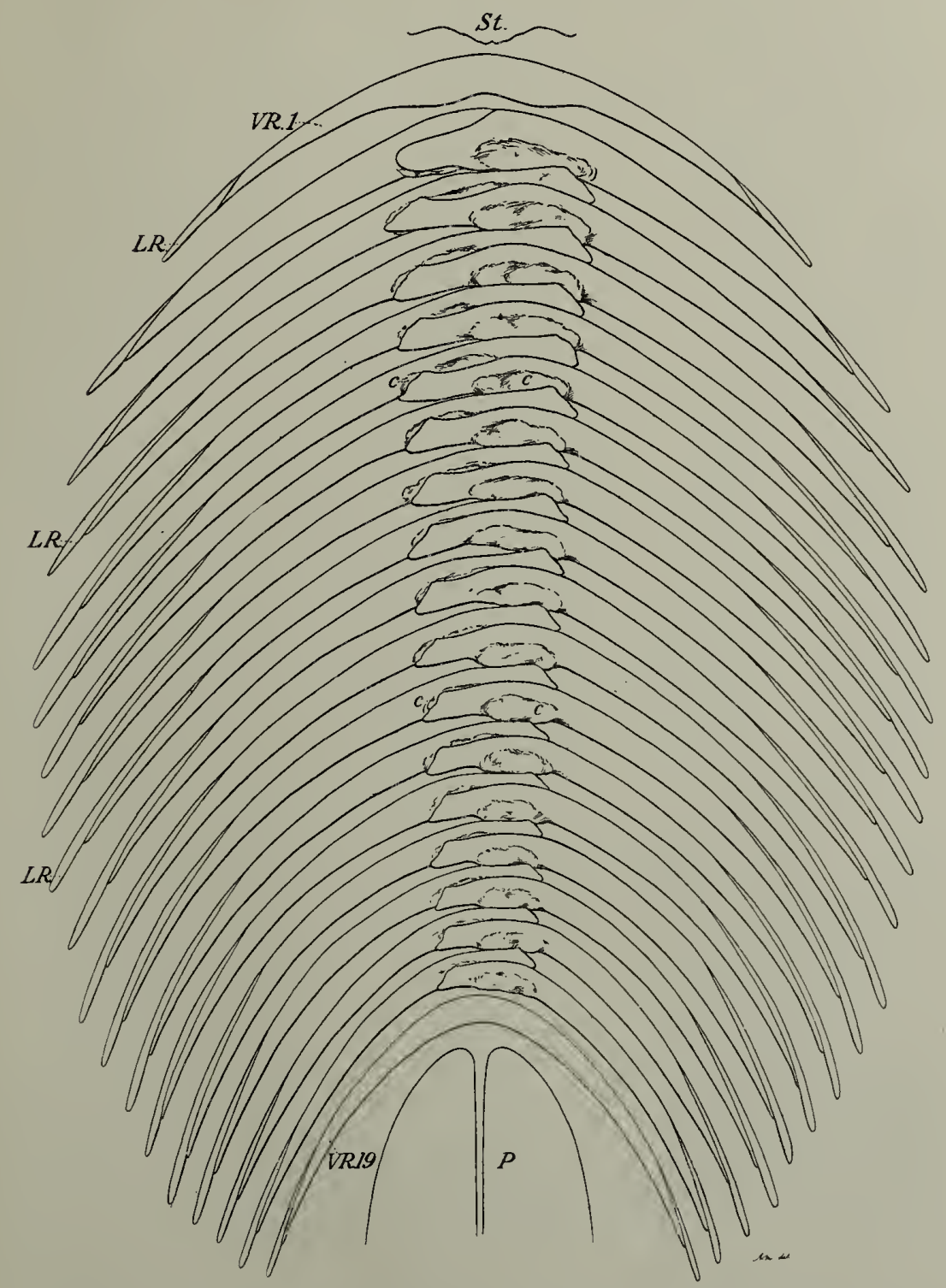

Figure 27. Restoration of abdominal ribs of Gorgosaurus; ventral aspect; $\frac{1}{9}$ natural size. $c$, surface of attachment; $L R$, lateral rib bone; $P$, pubis; $S t$, sternum; $V R$, abdominal rib. 
and manner of the inner overlap, and the position of the longitudinal middle line of the cuirass throughout its length, assuming that the cuirass was bilaterally symmetrical. With the above data it has been

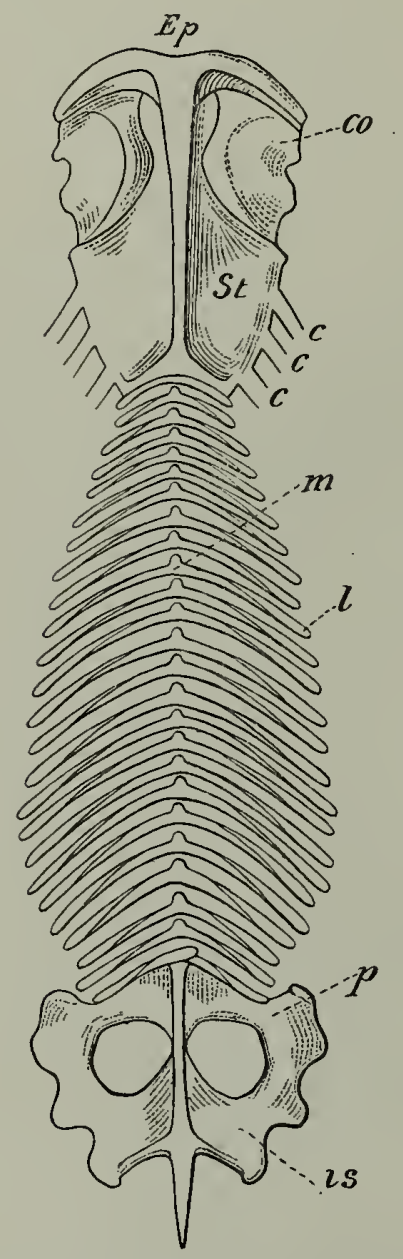

Figure 28. Abdominal ribs of Sphenodon (Hatteria) punctatum Gray. (After Gagenbaur). Co, coracoid; Ep. episternum; Is, ischium; $m, l$, median and lateral pieces of ventral ribs; $P$, pubis; $S t$, sternum. face anteriorly to the lower face posteriorly of the rib in front, rugose surfaces marking the areas of attachment. The upper anterior surface of attachment is situated near the ribs termination: it is thus on the opposite side of the longitudinal midline to which the rib belongs and entire cuirass of Gorgosaurus as given in Figure 27.

The greatest breadth of the cuirass is slightly in advance of its midlength and the anterior end is broader than the posterior one. As already stated it is probable that there were at least nineteen composite ribs (main piece + lateral one) in each half of the series including in this number the coossified half lengths. They increase in length from the first to the fifth. The next two, the sixth and seventh, are about as long as the fifth. Behind the seventh there is a gradual decrease in length to the nineteenth, which appears to have been of about the same length as, or perhaps slightly shorter than the first. In passing backward in the series, however, there is a progressive increase in the backward curve of the ribs, resulting in a considerably diminished breadth in the posterior end of the cuirass as compared with the anterior end.

The central overlap of the ribs decreases in passing backward in the series concomitant with a lessening in their breadth (antero-posterior). In the more anterior ribs the overlap of any two of them is about one-fifth of their combined transverse curve, and this decreases to about one-ninth in the posterior ribs.

In the interlocking of the inner ends of the ribs, the anterior border of each rib reaches beneath the posterior border of the one immediately preceding it from the other side, and each rib is attached by its upper

possible, therefore, to reconstruct the 
consequently the surface to which it is attached on the lower face posteriorly of the preceding rib, is at some distance from that rib's inner termination on the side of the midline to which the rib belongs. Therefore, each rib has two separate rugose surfaces of attachment, one on the upper face near the front border, the other on the lower face near the hinder border (Figures 25, 26, and 27).

The rugose areas of attachment generally have the form of an irregular, elongated oval which is at times broken up into two or three minor surfaces of variable size.

It is probable that there was considerable play between the ribs, obviating a rigidity in the cuirass and securing an amount of flexibility of service probably in connexion with the animal's breathing, and suggestive also of the creature's frequent assumption of positions which brought the abdomen in contact with hard objects such as the ground when resting, or vegetation through which a passage had to be forced.

The ribs are quadrangular in cross section at their midlength, curve evenly backward, and taper gradually to a blunt point. There is a gradual diminution in the breadth (antero-posterior) of the ribs in passing backward in the series. Near their inner ends they become flattened and here reach their maximum breadth with a thin, protrudent posterior edge. The rib heads themselves bend slightly backward, are flat and narrow, and terminate abruptly. As already mentioned, each rib at the median overlap is twisted downward in front so as to bring its anterior border beneath the posterior border of the rib in front and effect an intercostal union.

At the distal end the ribs are grooved infero-anteriorly for the reception of the slender rod shaped bones which lie against them. These latter are more attenuated proximally than distally where they are rather bluntly pointed. Their length is greatest at the midlength of the series where they are about half the length of the ribs to which they are applied and beyond which they project for a short distance.

Whereas in Gorgosaurus and some allied Cretaceous genera a limited number of ventral ribs are co-ossified to form a single median piece supporting a shorter, slender piece at each end, in Sphenodon the majority of these ribs have united in the midline and consist of a central transverse length and two slender outer bones (Figure 28). The ribs of the Cretaceous rhynchocephaloid reptile Champsosaurus have a median and two lateral pieces. 
Measurements of Abdominal Ribs in Type.

Length of fifth right rib (exclusive of slender lateral bone) measured along its

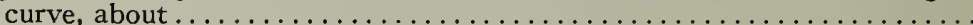

Length of sixth right rib similarly measured, about. .

Breadth of second right rib at right end of inner overlap...............

"
" third
" fourth

From the fourth rib back to the tenth the slender lateral bone extends beyond the larger rib piece for about the average distance of $32 \mathrm{~mm}$. In the more posterior ribs the distance decreases backward in the series to about $20 \mathrm{~mm}$. The lateral overlap in the supposed first rib is short, but in the next two or three ribs it increases rapidly to the maximum at the greatest breadth of the cuirass.

\section{STERNUM.}

A somewhat distorted, thin, curved plate of bone, with an undulatory, bilaterally symmetrical outline, is apparently the sternum, or the ossified portion of it if that element was originally partly cartilaginous (Figure 29). It is composed of a right and left half in contact at their inner edge, and occurred in the type pressed against and around the centrum of the first dorsal vertebra. Near it, at a distance of a few inches, lay the slender bone described on page 39 and regarded as the right half of a ventral rib from far forward in the series, probably the first.

These supposed sternal bones together, in normal position, form a plate more than twice as broad as long with an upper (interior) rather rough, concave surface, and a lower, smoother, convex one.

The right sternal bone has a moderately concave upper surface and appears to be normal in transverse curvature; from front to back it is rather flat. The left bone of the pair has been pressed inward from the left so that its upper surface is at about right angles to that of its mate instead of continuing to the left the normal, slight transverse curvature of the pair. It has been shifted in position so as to underlap the right one to some extent along the midline of contact, and has also been bent inward at right angles to itself near its outer end. 

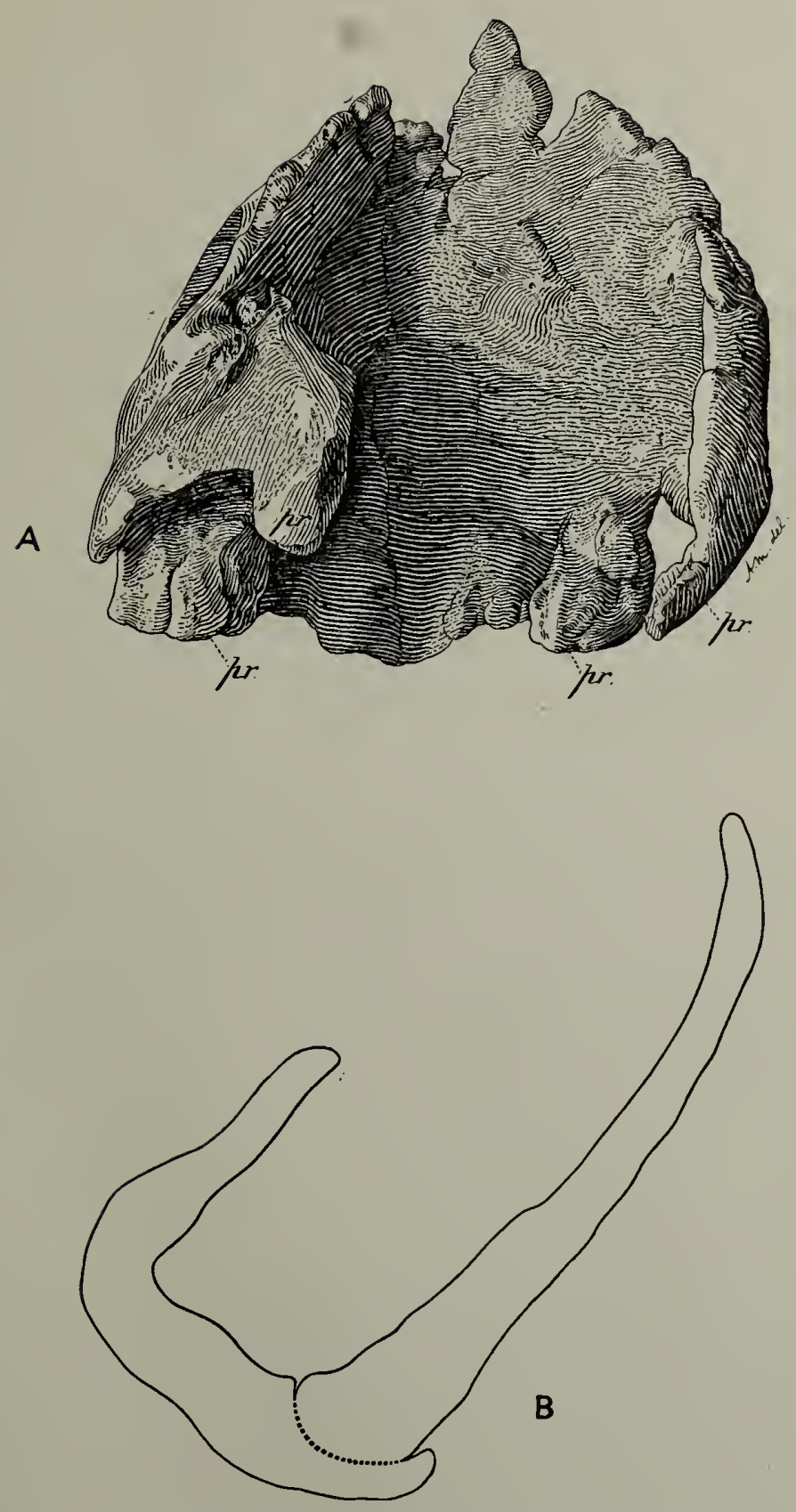

Figure 29. Sternum of type of Gorgosaurus; $\frac{1}{2}$ natural size. A, view from above; $\mathrm{B}$, outline of transverse section; $p r$, process for attachment of sternal rib. 
These bones are thickest near the inner line of contact whence they thin slightly outward; the free edges are rounded. There appears to have been a firm attachment of the pair to each other. In each there are corresponding indentations of the edge, one on the lateral back border, and one, rather shallow, behind, as well as some minor emarginations of varying depth and width, principally along the front edge, some of which may be partly due to or accentuated by breaks. In front a surface for contact with the coracoid may be indicated by the outline at $a$, Figure 30. On the outer side of each of the two indentations of the hinder border in each bone, there is a decided projection, conspicuously thick in the inner one, thinner and longer in the outer one, which may mark the position of two pairs of sternal ribs, if indeed the proximal ends of the ribs are not partially preserved.

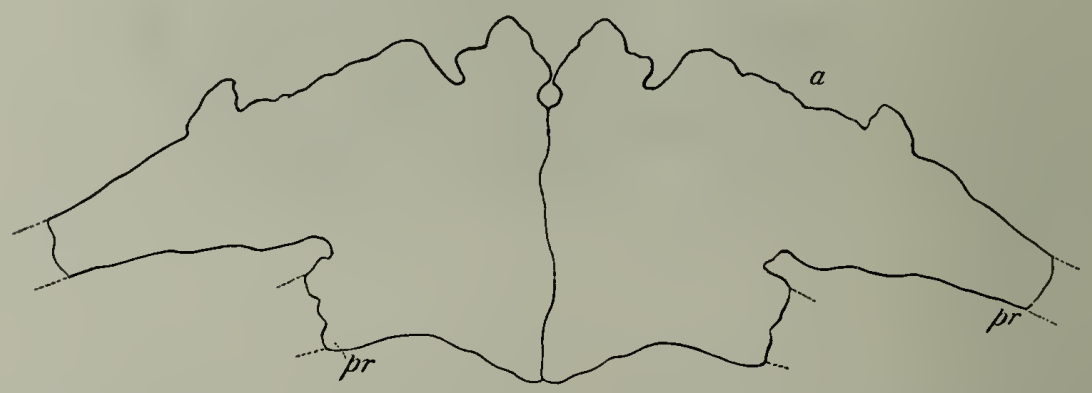

Figure 30. Plan of sternum of Gorgosaurus; $\frac{1}{4}$ natural size. pr, process for attachment of sternal rib.

Measurements of Right Sternal Bone.

Mm.

Maximum breadth along curve of upper surface................ 170

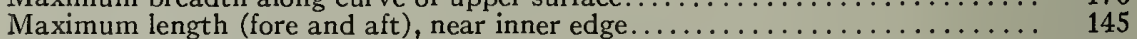

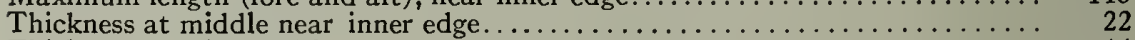

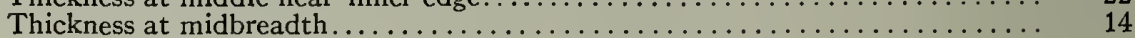

\section{PECTORAL GIRDLE.}

Scapula. The scapula is a long, thin bone, very narrow for the greater part of its length, and expanded at both ends (Figure 31). It consists of an elongated blade and a short lower portion which extends forward abruptly from the base of the blade. The expansion of the blade upward is gradual. In lateral outline the blade is nearly straight in front, slightly concave behind, and flatly convex across the top. In its slender lower half it has an ovoid transverse section narrowing forward, and somewhat flattened on the inner side and behind. It is thickest at its narrowest part, the neck, and thins gradually upward as it broadens. 
Below the neck the scapula expands slightly backward, but mainly forward where the bone is thin with a sweeping, semi-circular anterior outline. The posterior border of the lower expansion is short and consists principally of the upper two-thirds of the glenoid cavity, the remainder of the cavity being supplied by the coracoid. The bone ends inferiorly, with a slight anterior contraction in breadth, in a sinuous sutural union with the coracoid.

Coracoid. This bone is relatively large, thin for the most part, and broader than long. In lateral outline it is somewhat four-sided with the lower front angle rounded off and the lower back one produced causing the hinder margin to be concave (Figure 31).

The scapula and coracoid are thickened in the neighbourhood of the glenoid cavity and for a short distance downward from it along the emarginated posterior curve of the coracoid. Elsewhere in both elements, with the exception of the relatively thick neck of the scapula, the bone is thin.

The foramen in the coracoid is not far from the upper edge of that bone and is a little behind its midbreadth. It slants decidedly forward in passing through to the inner side.

The glenoid cavity is shallowly concave, higher than wide, with a well defined peripheral rim. As stated above it is mainly within the confines of the scapula.

The slight curvature which the scapula no doubt had over the anterior ribs is indicated only in the lower part of the blade where the bone has been sufficiently strong to resist the pressure which has flattened the scapula and coracoid practically into one plane, forcing the coracoid away from the inward bend which it naturally had toward the longitudinal midline of the body below. The effect of pressure is strongly marked in the type in the upper portion of the blade where it crosses the ribs (Figure 7). The coracoid was convex externally and concave internally when undistorted, the concavity of the inner surface passing up into the lower expanded part of the scapula, but in the type specimen the flattening of these bones has effaced their natural curvature to a great extent.

The surface of the bone in both the scapula and the coracoid is smooth for the most part but slight striations are present on the exterior of the upper part of the blade of the scapula running in the direction of the length of the bone; also a roughness on the lower border of the backwardly produced infero-posterior angle of the coracoid suggests the position of its probable union with the sternum.

In the type specimen the left scapula and coracoid were not found. 
Measurements of the Scapula and Coracoid.

capula and coracoid am.

Combined length of scapula and coracoid along the middle of each bone...... 1086

Scapula, length from middle of upper end to middle of scapulo-coracoidsuture.. 876

breadth at upper end.............................. 175

breadth at one-fourth of the length up from the middle of the scapulocoracoid suture................................. 56

thickness at same point........about................. 40

Coracoid, length................................................. 210

Length of scapulo-coracoid suture.................................. 166

FORE LIMB.

The fore limb of Gorgosaurus is slight and extremely short, its length being a little less than one-fourth of that of the powerful hind limb (Figure 31). In the type specimen it was found above the glenoid cavity having attained that position by the rotation of the limb upward in its socket, the head of the humerus remaining beside the glenoid cavity (Figure 7). The humerus, with its inner surface directed almost backward and its front face nearly outward, lay behind and parallel to the shaft of the scapula. The fore arm was bent downward and backward, the ulna and radius remaining together. The hand had been forced back on the fore arm so as to have the palm facing outward and the digits half closed on themselves. The arm was thus doubly bent, at the elbow and at the wrist, and this position has been retained in the mount, care having been taken to keep the component parts in the position in which they were found relative to each other, sufficient matrix being left to hold them securely in place. The limb is in an abnormally raised and unnatural position, but apart from this the bones are in their proper relative position and their full number is probably present (see carpus, p. 52).

There are two fingers to the manus of Gorgosaurus (Figures 31, 35 , and 36) which were interpreted by the writer as being Nos. II and III, and so described and figured by him in the Ottawa Naturalist of January 1914. Prior to the discovery of Gorgosaurus the fore arm and the hand were unknown in any Cretaceous carnivorous dinosaur. Dr. Charles W. Gilmore in his paper "On the fore limb of Allosaurus fragilis" " of the Jurassic makes an interesting comparison of the fore foot in Triassic, Jurassic, and Cretaceous Theropods from which it appears that a reduction of the digits began and progressed from the outer side of the hand. In the specialization of the fore limb the greatest known reduction in the size of the limb itself and in the number of the digits was reached in Gorgosaurus. The writer is of the opinion that the two digits previously numbered II and III (original description) are the first and second, as suggested by Gilmore, and they are referred to as such in the present description.

1 Proc. U.S. Nat. Mus., vol. 49, November, 1915. 


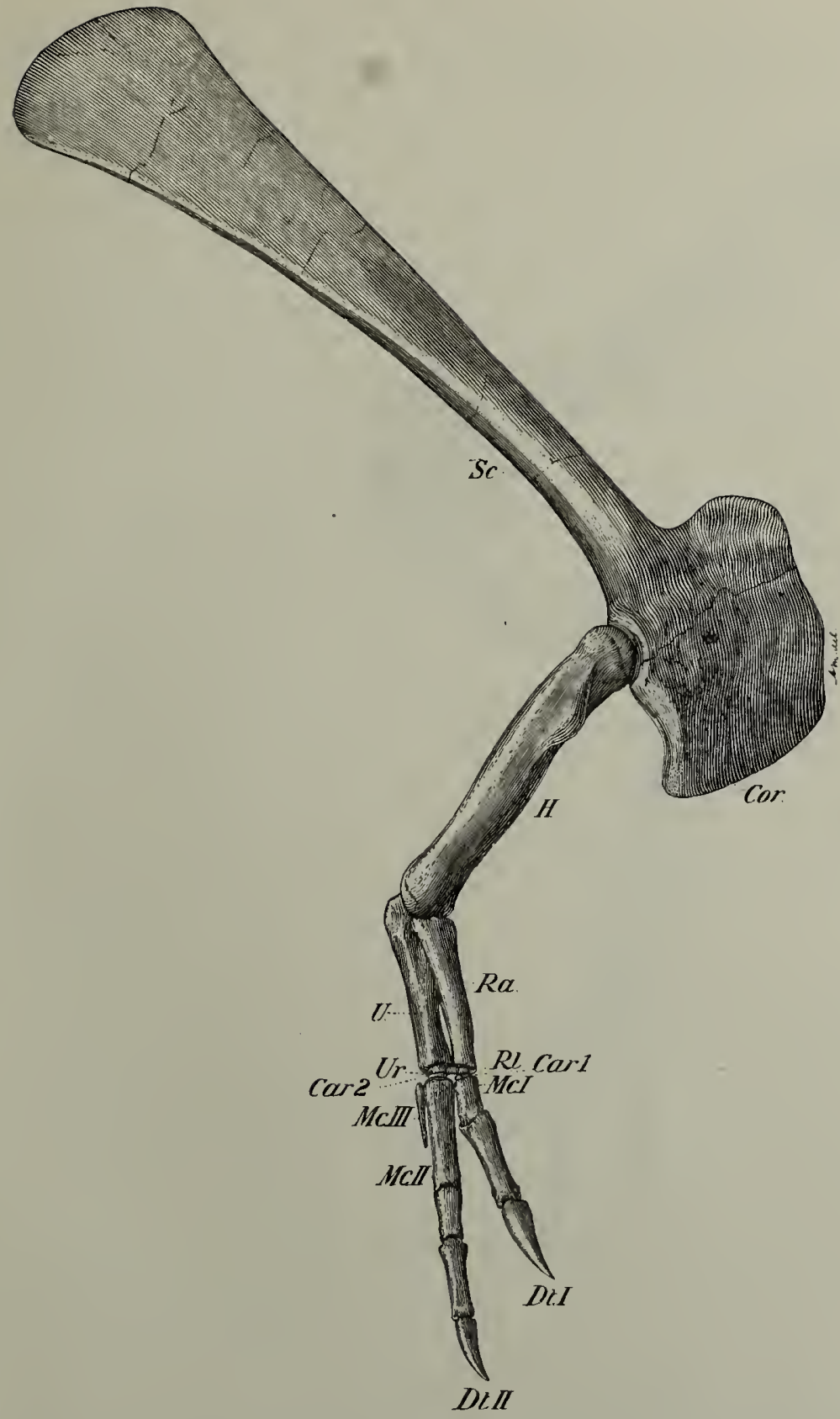

Figure 31. Right fore limb of type of Gorgosaurus libratus; $\frac{1}{8}$ natural size. Car, carpal; Cor, coracoid; $D t$, digit; $H$, humerus; Int intermedium; $M c$, metacarpal; $R a$, radius; $R l$, radiale; $S c$, scapula; $U$, ulna, $U r$, ulnare. The coracoid is shown in perspective retreating from the observer. 
At the time the description of the right manus of Gorgosaurus was written the sandstone matrix had not been removed from the left side of the specimen and the hope was expressed that the left arm and hand

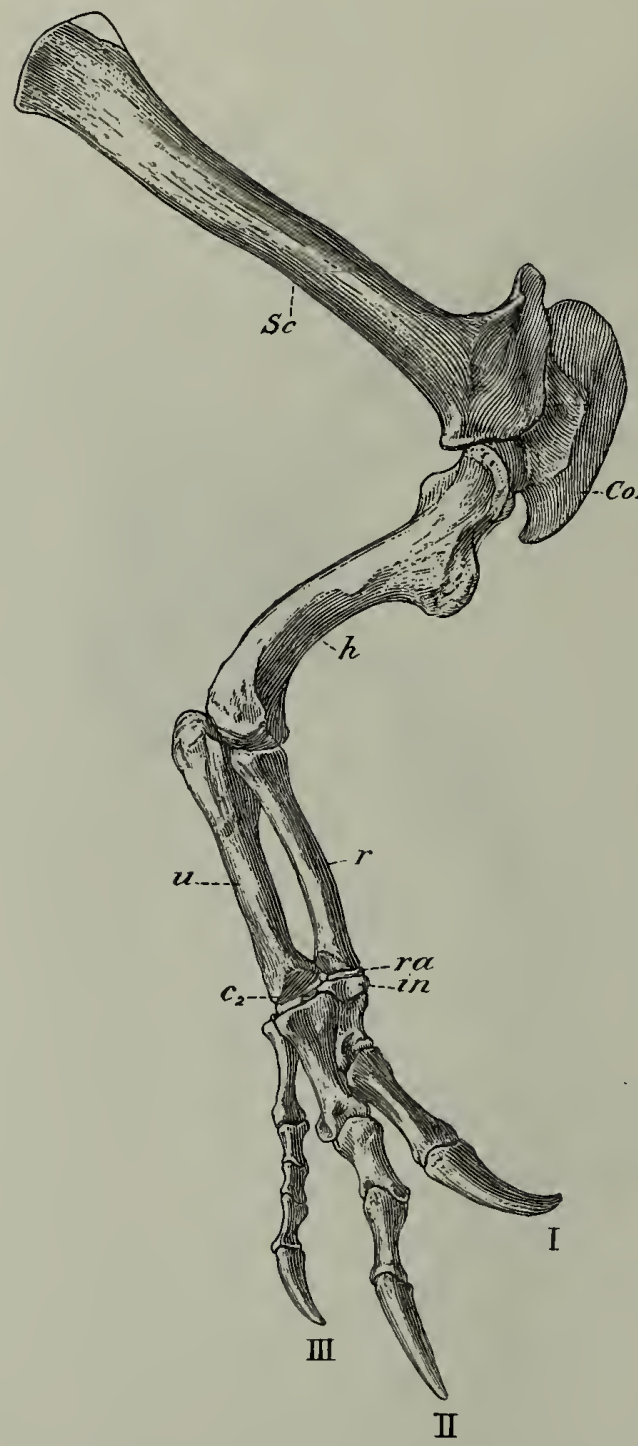

Figure 32. Right fore limb of Allosaurus fragilis Marsh (After Gilmore); $\frac{1}{8}$ natural size. $C_{\mathbf{2}}$, carpale two; cor, coracoid; $h$, humerus; in, intermedium; $r$, radius; $r a$, radiale; $S c$, scapula; $u$, ulna; I, II, and III, digits one, two, and three. would be found. This hope was, however, not realized except to the extent of recovering some of the parts of that limb viz., the distal half of the radius, fragments which may belong to the ulna, small pieces of phalanges, and phalanges $1 \mathrm{I}$ and 2 II.

The presence of the complete right fore limb in the type specimen of Gorgosaurus, revealed for the first time the phalangeal formula of the manus of a Cretaceous carnivorous dinosaur, the relative size of the component parts of the limb, and the size of the manus in comparison with the rest of the limb, as before the discovery of Gorgosaurus the humerus only was known in the single genus Tyrannosaurus.

Humerus. The humerus of Gorgosaurus is short and subcylindrical (Figure 31). In its upper half it is decidedly curved with the posterior face concave. The lower half is nearly straight but has a slight bend in the opposite direction. There is a slight constriction of the shaft near either end. The breadth is greatest at the proximal end; distally the greatest diameter is 
about equal to that of the shaft at midlength. A high, thin, radial crest, directed forward, runs down the external side of the anterior face from near the proximal end of the bone to about its midlength. In the specimen this crest has been bent down on to the anterior face which, the bone being hollow, has given way and been crushed inward. There is a concavity in the surface of the front face immediately above the distal end. A slight groove across the distal end, in a fore and aft direction, marks the division of the inner, apparently larger, ulnar condyle from the radial condyle on the outer side. The condylar surface of the distal end faces slightly inward in consequence of which the general direction of the forearm would be inward, to some extent. Beneath the head, which appears to occupy the whole of the proximal end, there is a low rugose angulation extending downward for a short distance on the inner side of the posterior face.

Radius. The radius is a short, stout bone a little less than one-half the length of the humerus (Figure 31). It is somewhat quadrangular in cross section with the distal end smaller than the proximal one. The transverse diameter is least a short distance above the lower end. In its lower half the front and side faces are decidedly flattened. It terminates above and below in rather flat articular surfaces, the upper one triangular and somewhat convex with the apex of the triangle pointing inward and a litttle backward, the lower one oblong, with the greater diameter transverse, and shallowly excavated at the centre for the radiale. Distally the front and outer faces are rugosely striated in the direction of the bone's length, also a little more than one-fourth up from the distal end a prominent interno-posterior angulation is roughened for muscular attachment.

Ulna. The ulna is longer than the radius (Figure 31). It is largest proximally where it is triangular in cross section, broadest in front with the anterior face hollowed out for the close approximation of the radius, and angulated behind where a stout olecranon process increases the height of the bone posteriorly. It is narrowest near the lower end and expands little distally. A shallow concavity in and toward the back of the lower articular face denotes the relative position of the ulnare. In its lower half length the anterior face of the bone is flattened.

Both the radius and ulna are somewhat crushed proximally in the type so that measurements taken here are not exact, the transverse diameters being exaggerated and the antero-posterior ones less than normal.

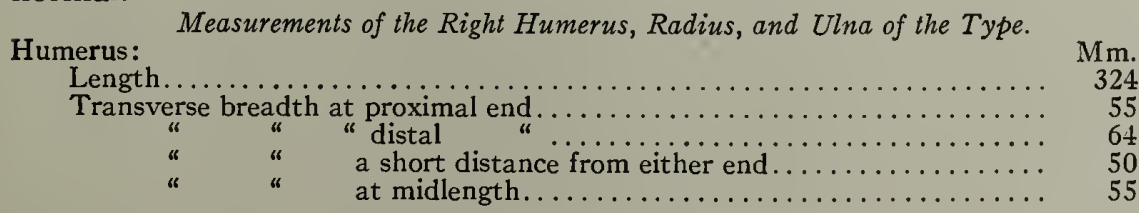


Radius:

$\mathrm{Mm}$.

Length.......................................... ${ }_{156}$

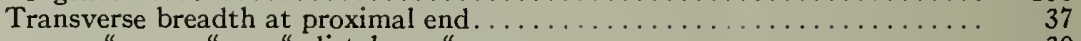

Ulna : " " "

Length........................................ 180

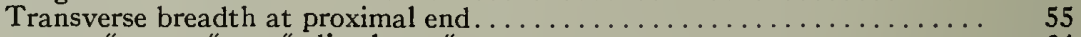

" " " distal " $\ldots \ldots \ldots \ldots \ldots \ldots \ldots \ldots \ldots \ldots \ldots \ldots \ldots, \quad 34$

" " midlength............................ 29

Although differing decidedly in many respects from that of both Allosaurus (Figure 32 ) and Tyrannosaurus ${ }^{1}$ the humerus of Gorgosaurus, as might be expected, resembles more closely that of the Cretaceous Tyrannosaurus of the higher geological horizon.

In comparison with the fore limb of Allosaurus (Figure 32) that of Gorgosaurus is relatively much smaller, the reduction in length being due principally to the extreme shortness of the ulna and radius, the latter bone in Gorgosaurus being less than half the length of the humerus.

Carpus. Five bones are preserved in the carpus in the type, constituting probably the full number of the ossified elements. These

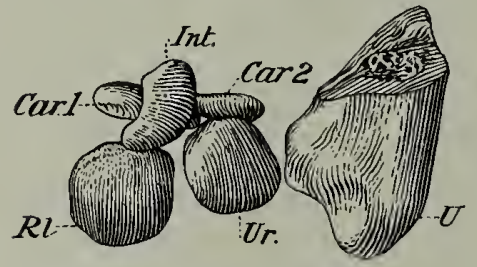

Figure 33. Carpal bones of the right manus of the type of Gorgosaurus; $\frac{1}{2}$ natural size. Car 1-2, carpale 1-2; Int, intermedium; $R l$, radiale; $U$, ulna; Ur, ulnare. bones are the radiale, the ulnare, a probable intermedium, and carpalia 1 and 2. All of these bones are vertically compressed and have rounded outlines (Figures 33 and 35). The radiale and ulnare lie side by side and are larger than the others. The radiale is slightly larger than the ulnare and is almost in place beneath the radius; the ulnare has shifted only a distance of its own diameter from its proper position at the distal end of the ulna. The supposed intermedium is smaller than the radiale and ulnare and lies in front of them in about the same plane but slightly overlapping the radiale; it appears to have been oval in outline with an emargination on one side. The position of this bone suggests its being the intermedium and forming with the radiale and ulnare a proximal row of three. Of the two remaining bones one is the smallest of the five, is bean-shaped, and has not been distorted nor injured in any way; it lies against the front edge of the ulnare and is regarded as carpale 2. The other is in advance of the radiale and is between the intermedium and the upper, outer part of the proximal articular surface of metacarpal I and is probably carpale 1 ; it is partly hidden, and is crushed and otherwise damaged but it is considerably larger than carpale 2 .

\footnotetext{
1 Tyrannosaurus, Upper Cretaceous carnivorous dinosaur (second communication) by Henry Fairfield Osborn. Bull. Am. Mus. Nat. Hist., vol. XXII, p. 293, fig. 8.
} 
The reduction of metacarpal III and its close contact proximally with metacarpal II renders it probable that a carpale 3 was not developed.

Since the original reference to the carpus of Gorgosaurus was made in 1914, the ulnare has been disclosed raising the known number of carpal elements from 4 to 5 ; the bone then referred to as the largest of the four is the one now regarded as the radiale.
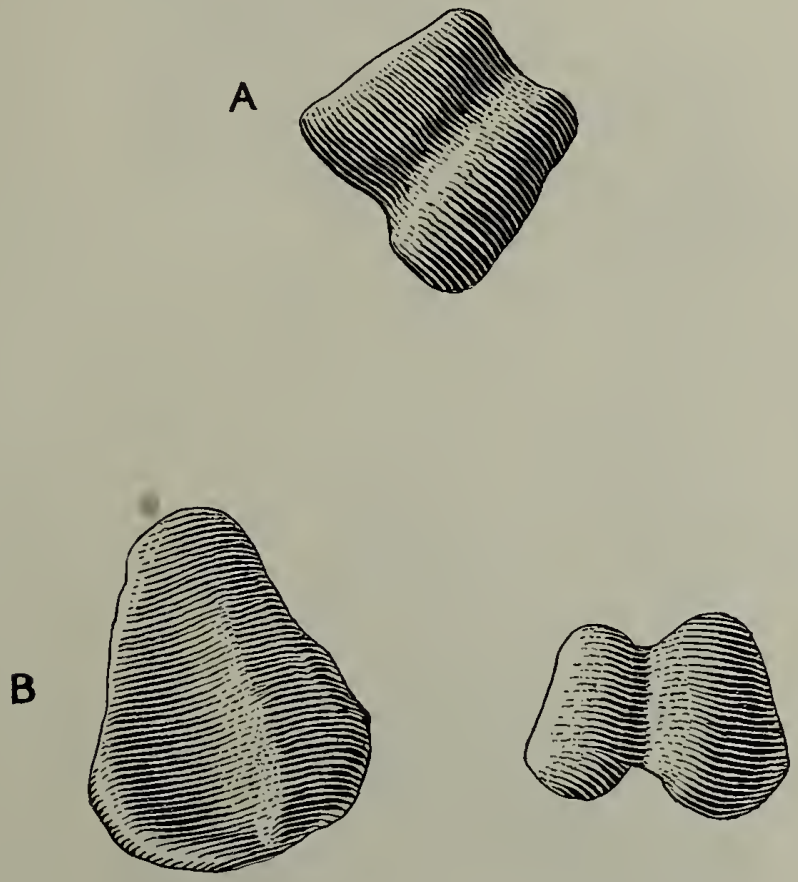

C

Figure 34. Left manus of type of Gorgosaurus; natural size. A, distal articular end of proximal phalanx of digit I; B, proximal articular end of the same phalanx; $\mathrm{C}$, distal articular end of metacarpal I of right manus of type reversed to represent the corresponding part (missing) in the left manus.

Metacarpus. There are three metacarpals, of which No. I is very short, No. II is double the length of No. I, and No. III is vestigial being represented by a short, slender bone, slightly curved and tapering to its distal end (Figures 31 and 35). Metacarpal $\mathrm{I}$ is at the distal end of the radius, metacarpal II has been shifted slightly from the end of the ulna, and metacarpal III lies along the outer side of metacarpal II in the distal two-thirds of that bone's length.

Metacarpals I and II are grooved at the distal end. In the short, stout metacarpal I the groove is narrow, deep, and nearer the inner side, so as to divide the end unequally (Figure $34 \mathrm{C}$ ), the outer articulating 


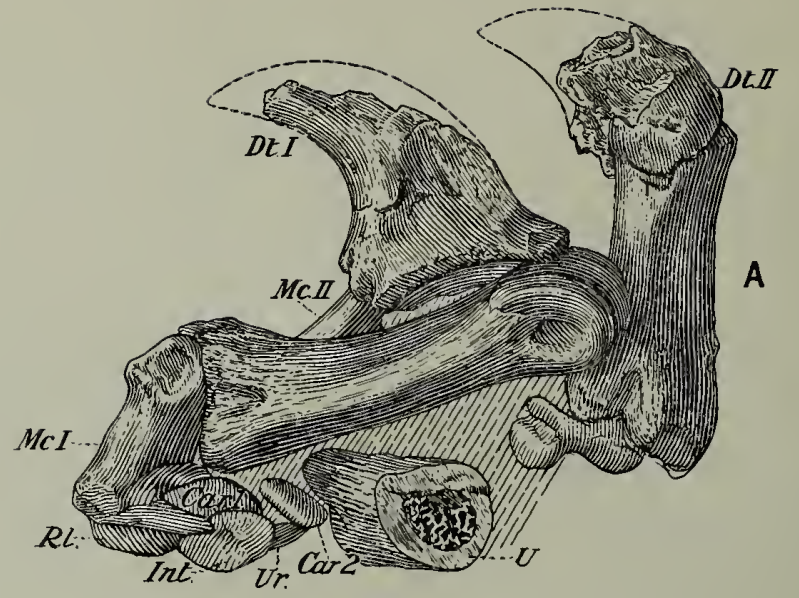

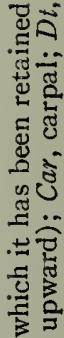

$\Xi E$

뭄

马्ट

氙客

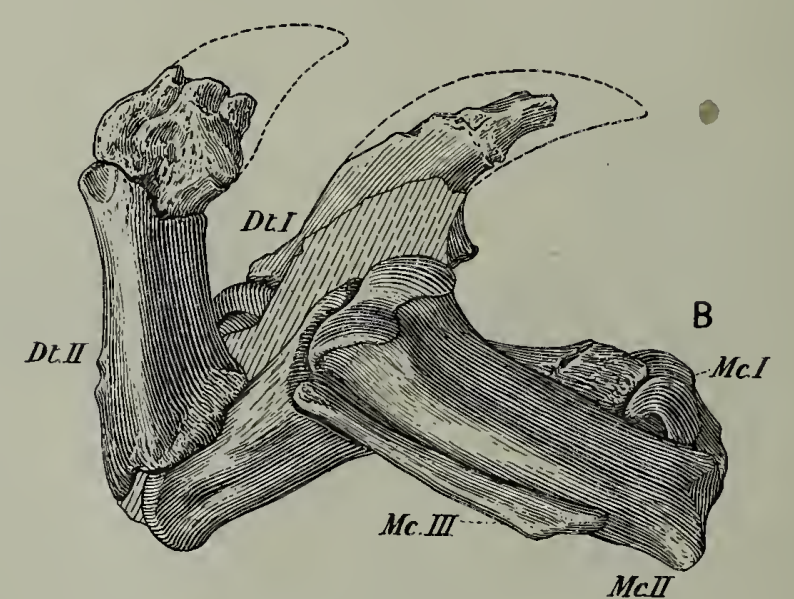

$\forall$

둥ㅎํ

更

.

证

记

o

च匹

.

m

ต.

讯

눙

8 용

岩出

玹

․․ㄹ

范

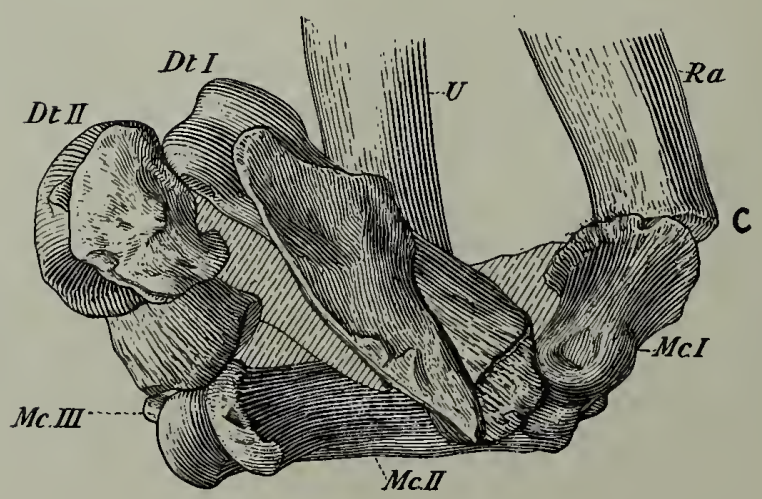

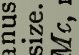

हृत ह

赵要

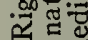

जा ह ह

ம்.

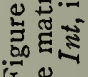

I. $.5: \frac{0}{7}$ 
facet being the larger of the two and extending farther forward than the other. Both facets curve down and back on to the lower surface of the bone. In the long metacarpal II the groove is broad, shallow, and centrally placed, the convex articulating surfaces running well down beneath the bone. The proximal ends of these two metacarpals are not clearly seen but they appear to have been plane or slightly concave surfaces.

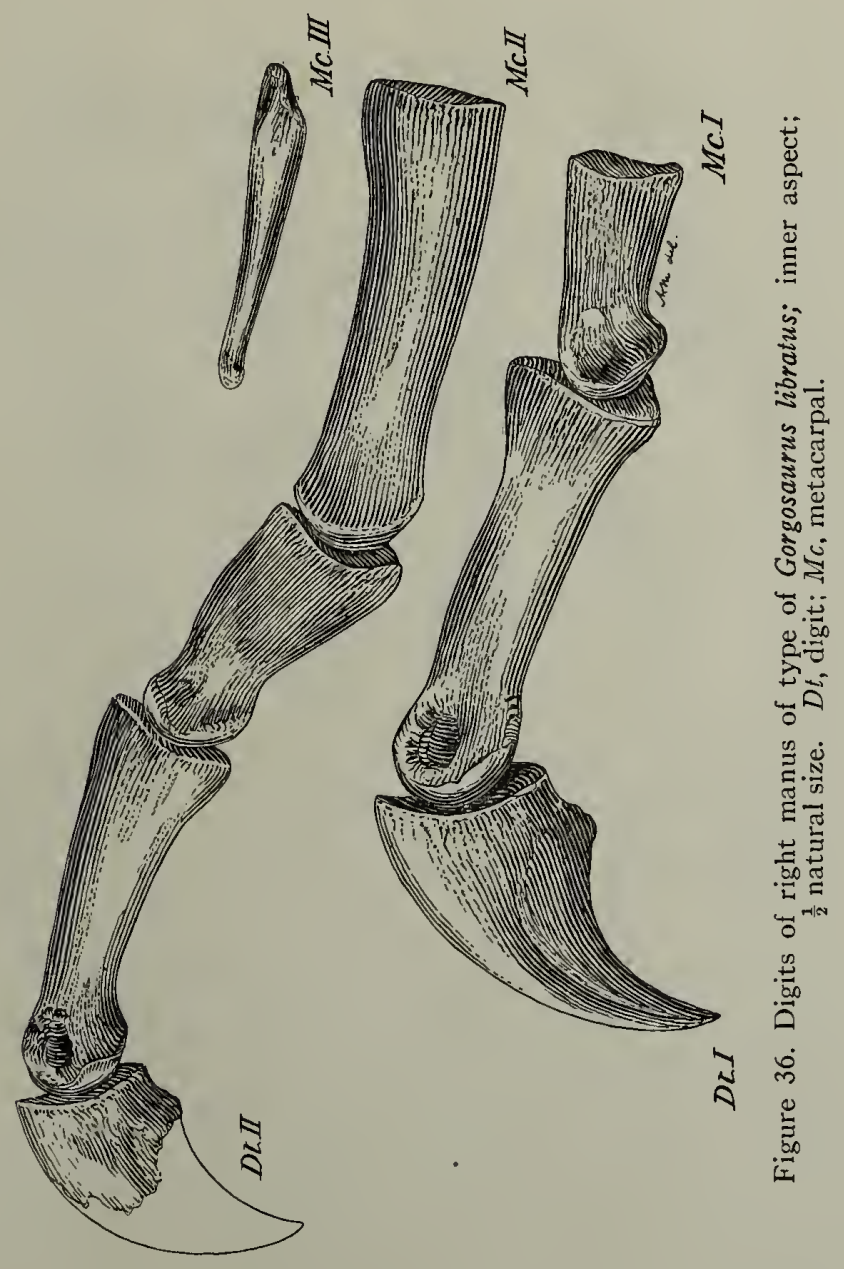

Phalanges. The phalangeal formula is 2 I, 3 II (Figures 31, 35, and 36). The two phalanges of digit I consist of an elongated first, and a comparatively large, laterally compressed, curved, and sharply pointed ungual. In digit II the first phalanx is short, the second long, and the distal 
one claw-shaped and smaller than the ungual of digit I. In the first phalanx of digit I there is a deep pit on each side of the distal end. In the phalanges of digit II these pits are shallow but more pronounced in the second than in the first. In the corresponding part of metacarpal I circular depressions are present deeper on the outer than on the inner side, but they are not developed at all in metacarpal II.

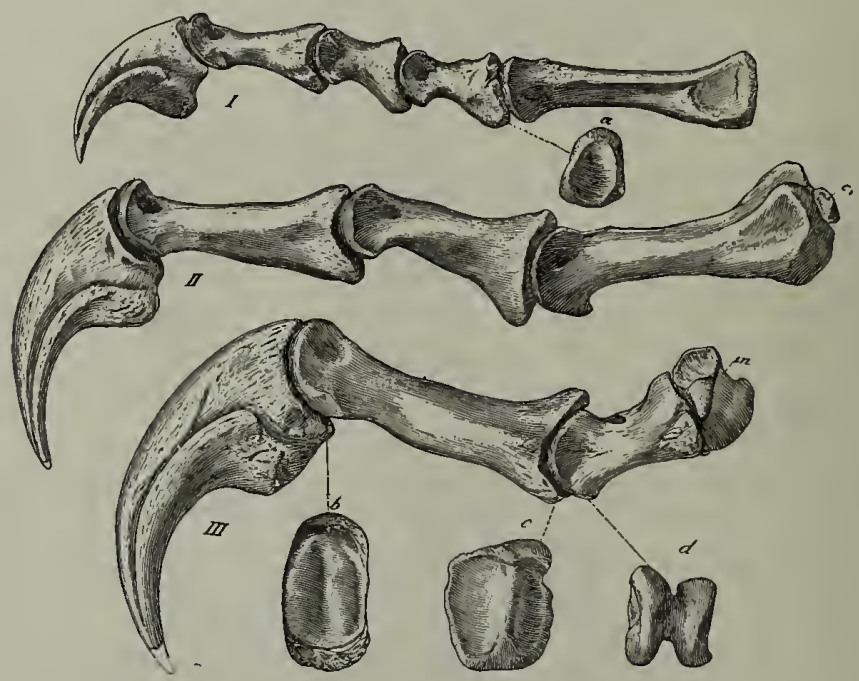

Figure 37. Digits of right manus of Allosaurus fragilis Marsh (after Gilmore); $\frac{1}{4}$ natural size. $a$, proximal articular end of the proximal phalanx of digit III; $b$, proximal articular end of ungual of digit I; $c$, proximal articular end of proximal phalanx of the left foot; $C_{2}$, carpale two; $d$, distal articular end of metacarpal I; in, intermedium; I, II, and III, digits one, two, and three.

In the first phalanx of digit $\mathrm{I}$, and in the first and second of digit II, a broad central groove is present at the distal end, and the articulating surfaces face well downward. Proximally a low vertical ridge is developed, dividing the end into equal concave surfaces, except in the case of the first phalanx of digit I where the ridge is oblique running downward and outward across the end of the bone, and dividing it unequally to fit the unequal facets of the distal end of metacarpal I (Figure 34). As a consequence when digit $I$ was rotated downward it was thrown inward with a spreading effect to the hand. A similar construction is noticed by Gilmore in the manus in Allosaurus fragilis ${ }^{1}$ Figures 32 and 37.

1 On the fore limb of Allosaurus fragilis, by Charles Gilmore. Pro. U.S. Nat. Mus., vol $49,1915$. 
Metacarpal I:

Measurements of Metacarpals and Phalanges of Type.

Length.

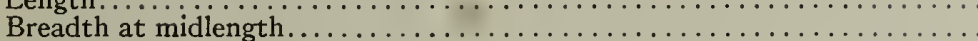

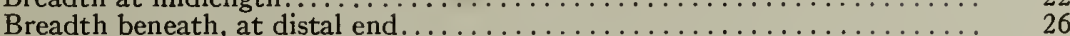

Metacarpal II:

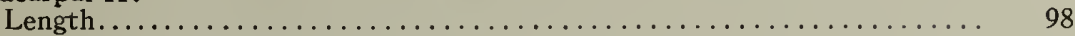

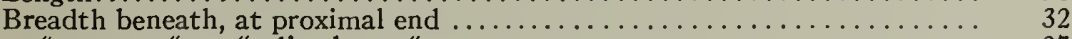

Metacarpal III:

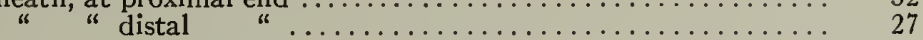

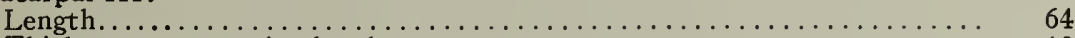

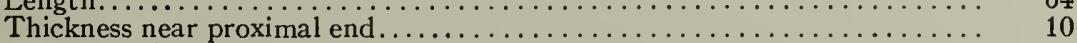

First Phalanx of Digit I:

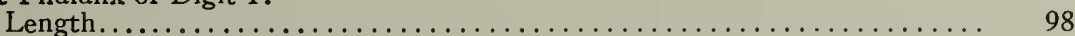

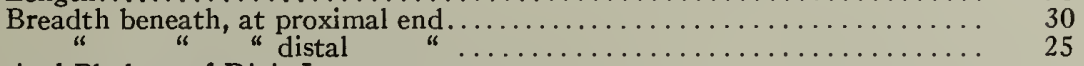

Terminal Phalanx of Digit I:

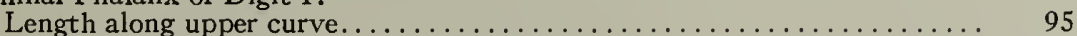

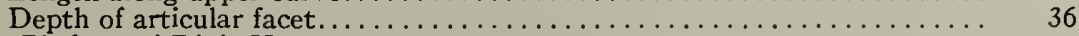

First Phalanx of Digit II :

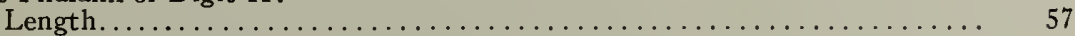

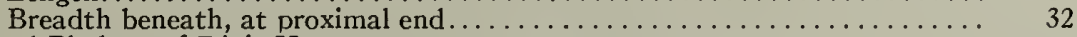

Second Phalanx of Digit II:

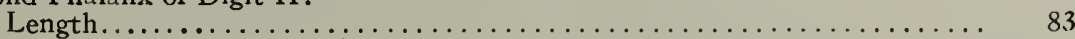

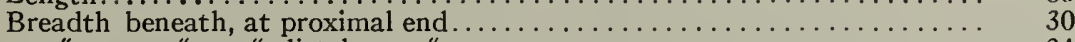

PELVIC GIRDLE.

Ilium. The ilium, the largest bone of the pelvis, is more than twice as long as high, and extends farther behind the acetabulum than it does to the front. It is thin tranversely except in the acetabular region where it is relatively heavy and robust. It is much deeper at the front end than behind, the greater anterior depth being due principally to a hooked downward extension of the lower margin. The post-acetabular portion is strengthened on the inner side by a heavy downwardly turned flange running obliquely upward and backward from the ischiadic peduncle giving this part of the bone the appearance of being deeply grooved below longitudinally. In lateral outline the superior border is rather flatly convex, the anterior one irregularly undulating, and the short posterior one evenly rounded.

The bone as a whole has an inclination inward in its upper part, most noticeable above the acetabulum, where over a considerable area the surface is outwardly concave. The superior border for some distance on either side of its midlength is bent inward.

The pubic peduncle is the heaviest part of the bone. From a heavy neck with smooth concave sides and front face it increases in size rapidly downward, providing below an extensive very rugose surface, nearly as broad as long, for the articulation of the pubis. Posteriorly it expands, principally on the inner side, and is shallowly excavated transversely by the broad upwardly curved surface of the acetabulum.

The ischiadic peduncle is slender in comparison with the robust pubic one. It reaches downward to the same extent, and has the same 
transverse thickness but is narrow from front to back furnishing an irregularly roughened and relatively small surface for articulation with the ischium.

The iliac surface of the acetabulum, maintaining a nearly uniform breadth throughout its semicircular curve, is slightly narrcwe: between

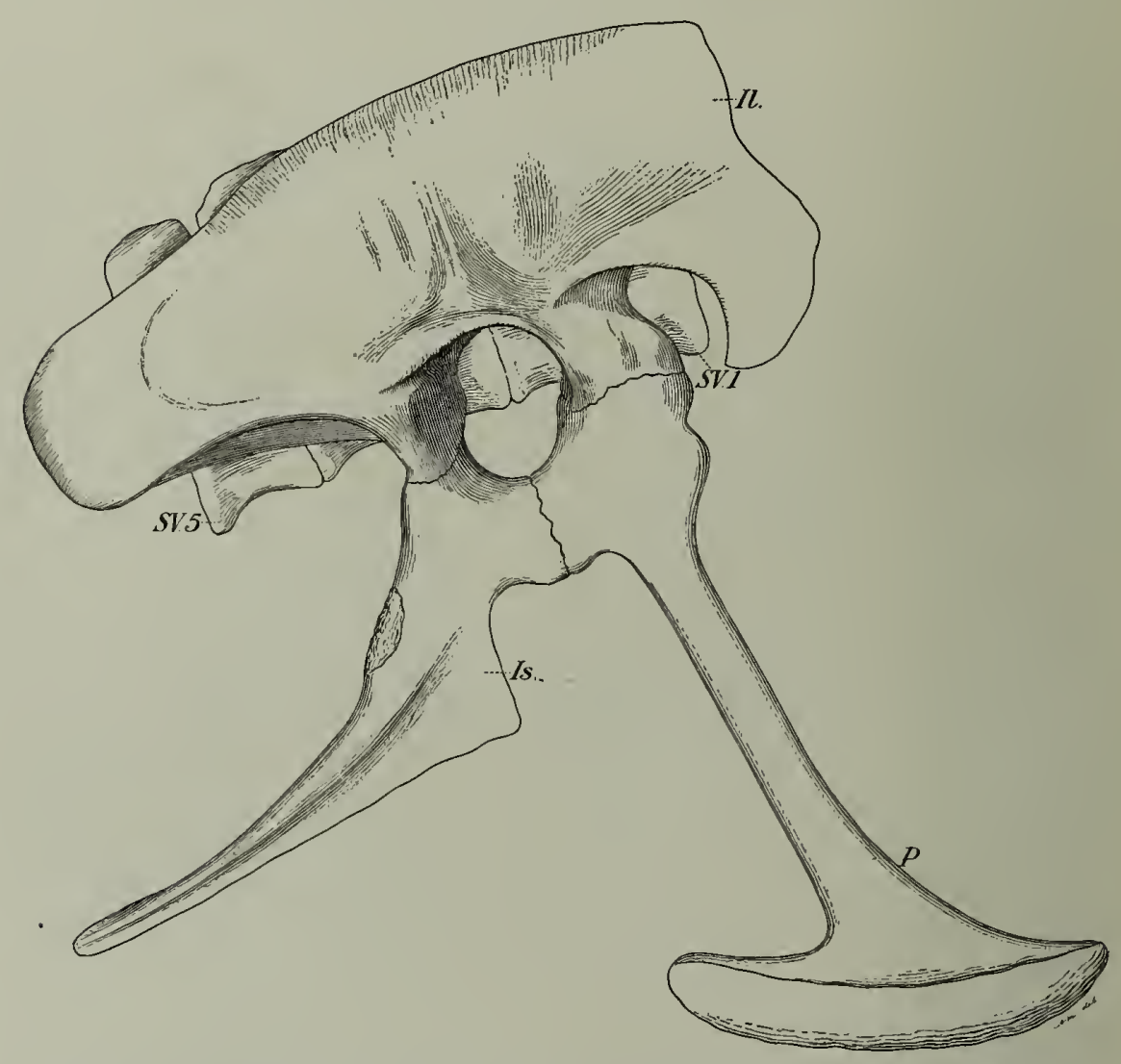

Figure 38. Pelvic arch of the type of Gorgosaurus libratus; right lateral aspect; $\frac{1}{12}$ natural size. $I l$, ilium; $I s$, ischium; $P$, pubis; $S V_{1}-S V_{5}$, sacral vertebræ.

the peduncles; both within and without it comes to a sharp, projecting edge. Anteriorly this surface is decidedly excavated transversely; posteriorly it is flat and faces to some extent outward giving the acetabular opening a slightly backward direction when viewed from without.

For a short distance downward from the superior border along the greater part of its length, the surface of the ilium both internally and externally is striated for muscular attachment, the direction of the 
striations being in a general way at right angles to the border and convergent toward the acetabulum. The general external protrusion of the

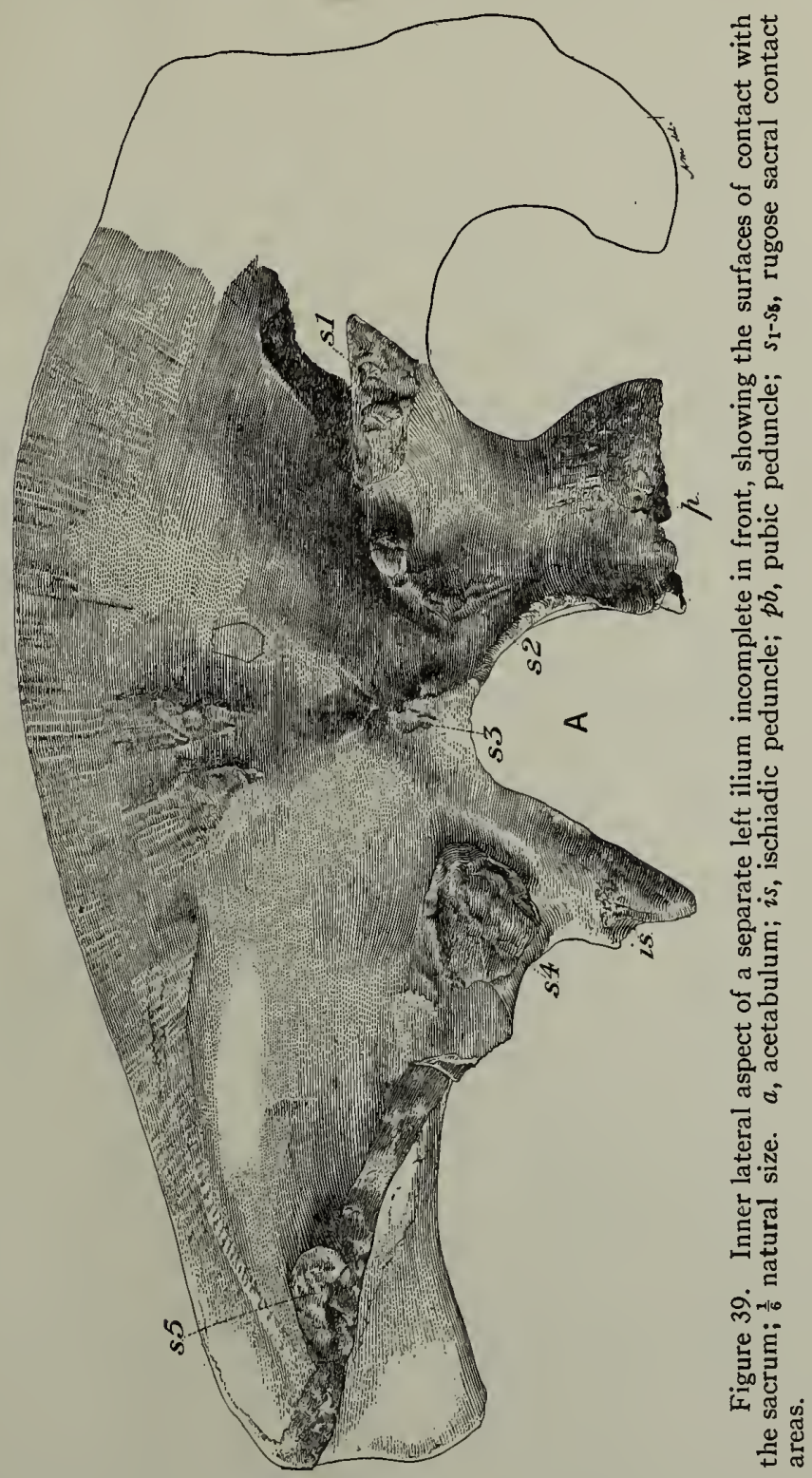

bone above the acetabulum is continued forward as a smooth rounded ridge which merges into and thickens the lower margin of the anterior alar extension behind the hook. Behind the acetabulum the lower 
margin is thickened in like manner externally but less conspicuously so, the chief strengthening below being supplied by the downwardly turned inner flange ${ }^{1}$ already mentioned.

In the type of Gorgosaurus the ilia, which are in place and conceal the greater part of the sacrum, have not been disturbed with a view to revealing their inner surface. The configuration of the inner side is shown, however, in a well preserved and nearly complete, separate left ilium apparently belonging to this species and figured on page 59 .

In this specimen five very distinctly preserved rugose surfaces indicate the position and extent of the contact of the transverse processes of the five sacral vertebræ with the ilium as shown at $s_{1-5}$ in Figure 39 . The location of the anterior surface of contact $\left(s_{1}\right)$ and of the two last ( $s_{4}$ and $s_{5}$ ) agrees with the position of the distal end of the transverse process of sacrals 1,4 , and 5 , as seen in the type. Of these roughened areas, the anterior one is above and in line with the front end of the pubic peduncle, and consists of an extensive horizontal surface in combination with a vertical one extending upward and forward. The second area, at a slightly lower level and in line with the posterior face of the pubic peduncle, is smaller, very rugose, and of irregular shape. The third is above the middle of the acetabulum, near its border, and is less definitely circumscribed; at some distance above it are two rugosities, placed side by side, which appear to be an upward extension of this area interrupted by a smoothness of the surface of the bone. The fourth area is rather large and occurs on the upper, posterior part of the ischiadic peduncle: The fifth, also large, is near the posterior end of the ilium. It extended from above the inner strengthening flange, broken off in this specimen, downward to the lower border as seen in the type. These surfaces of contact agree in a general way with those of Tyrannosaurus as indicated by Osborn's figure of the sacrum ${ }^{2}$ of that genus.

Measurements of Left Ilium of Type.

Extreme length $\left(38 \frac{6}{8}\right.$ inches) $\ldots \ldots \ldots \ldots \ldots \ldots \ldots \ldots \ldots \ldots \ldots \ldots \ldots \ldots \ldots$

Length in front of middle of upper margin of acetabulum. . . . . . . . . . . . . .

Length behind middle of upper margin of acetabulum . . . . . . . . . . . 527

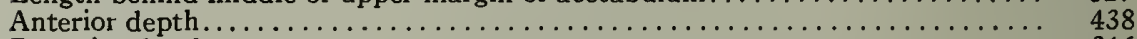

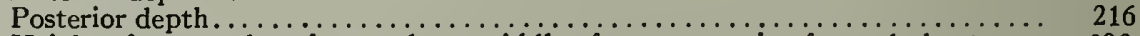

Height of upper edge of crest above middle of upper margin of acetabulum..... 393

Height of upper edge of crest above lower end of ischiadic peduncle........ 470

Height of upper edge of crest above middle of ilio-pubic suture . . . . . . . . 457

Extreme outer horizontal width of acetabulum .................... 216

\footnotetext{
1 This inner flange, due to distortion, occupies a lower and more outward position than it should in the right ilium of the type (Figure 7). What appears on the outer surface as an "overhanging flange running horizontally at midheight "(original description, p. 7 of this memoir) is best described as the outer, lower posterior border of the bone.

2 Tyrannosaurus, Upper Cretaceous carnivorous dinosaur (second communication); Bull. Am. Mus. Nat. Hist., vol. XXII, art. XVI, fig. 5.
} 
Width of surface of acetabulum-

Above, at middle of curve................................. 90

Below, anteriorly............................................... 97

Below, posteriorly (slightly oblique) $\ldots \ldots \ldots \ldots \ldots \ldots \ldots \ldots \ldots \ldots \ldots, 110$

Ilio-pubic surface of contact-

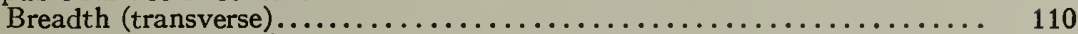

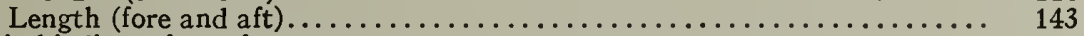

Ilio-ischiadic surface of contact-

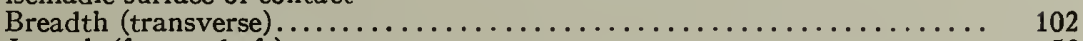

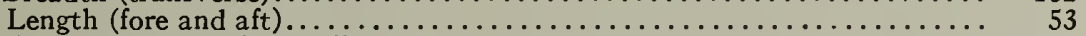

Width of acetabulum, internally................................. 196

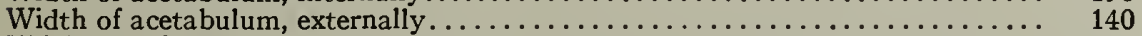

Thickness of crest-

At upper edge of rugose surface of attachment of process from 1st sacral

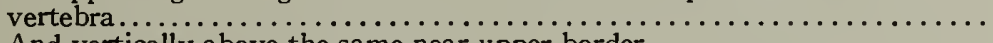

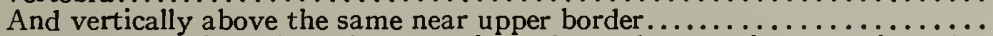

At smooth surface above lower surface of attachment of process from 3rd

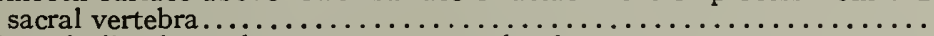

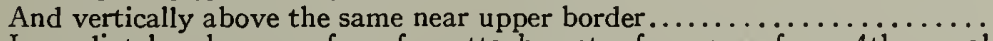

Immediately above surface for attachment of process from 4 th sacral

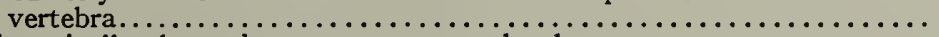

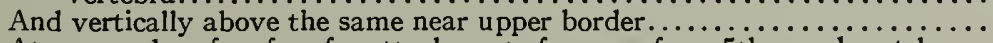

At upper edge of surface for attachment of process from 5 th sacral vertebra..

Pubis. This bone (Figures 7 and 38 ) is expanded proximally to make extensive connexions with the ischium behind and the ilium above. Contracting rapidly it is prolonged downward as a long narrow shaft which expands suddenly below to form a large, backwardly and forwardly extended "foot." The front half of its upper surface is in sutural contact with the ilium, and the hinder half forms the lower anterior quarter of the acetabulum, its contribution to this opening being equal to that of the ischium. The contraction of the bone to form the shaft is gained by an incurve of the anterior border and, more particularly, by a deep emargination of the posterior border, at the lower end of the ischiadic suture, corresponding with the concavity in the outline of the ischium on the other side of the suture. The shaft is straight and retains practically the same breadth downward until it expands rapidly into the distal foot. In its downward direction it inclines slightly forward, meeting the foot, whose axial length is nearly horizontal, at less than a right angle. The foot extends backward to a greater extent than it does forward and is remarkable for its size, being more than twice as long as the maximum breadth of the bone proximally. Its lower outline, in lateral aspect, is broadly rounded. The lower surface, facing obliquely outward, is somewhat convex throughout, defined by a well marked angulation above, and roughened in marked contrast to the smoothness of the shaft.

The pubic bones incline inward from above, come together a little above the midlength of the shaft, and then continue downward in contiguity. Where they meet a prominent rugosity is developed increasing the transverse diameter of the bone. Above the union the shaft is oval 
in cross section with the greater diameter fore and aft. Below the rugosity the inner surface of the shaft and of the foot is flattened, and the two bones are closely applied to each other apparently without co-ossification.

\section{Measurements of the Right Pubis of Type.}

Extreme length in a straight line from the middle of the iliac suture to the lower,

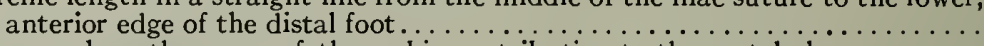

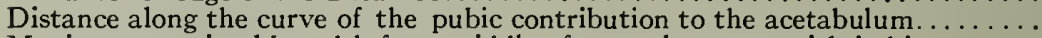

Maximum proximal breadth from middle of sutural contact with ischium to an-

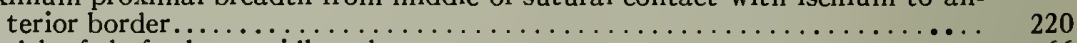

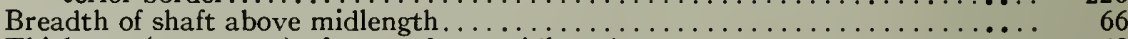

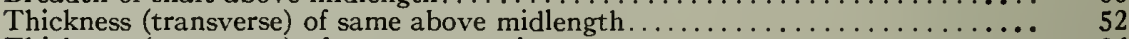

Thickness (transverse) of same at rugosity . . . . . . . . . . . . . . . . . . . 86

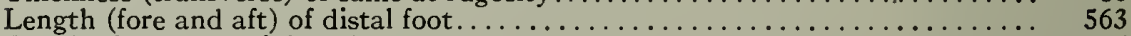

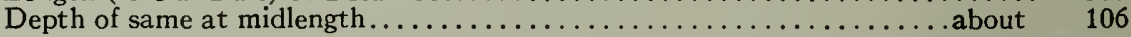

Ischium. The ischium (Figures 6, 7, and 38) is the smallest of the three elements of the pelvis; it is much shorter than the ilium, and is shorter than the pubis by about one-quarter of the latter's length. The bone curves downward and backward with a fairly regular concave posterior border as seen in lateral aspect. It is broad proximally, becomes slender in its distal half, and is narrowly rounded at its termination. Above it contributes to one-quarter of the surface of the acetabulum, and meets the pubis in a suture of considerable length whose direction is vertical beneath the middle of the acetabulum. Posteriorly above its sutural surface for contact with the ilium is deeply concave to receive the terminal edge of the narrow peduncle. Its anterior border, a little below the middle of its proximal half-length, is produced forward in an obtusely pointed expansion which adds greatly to its breadth and beyond which the bone narrows rapidly downward. Bordering the acetabulum the bone is massive, along the posterior margin it is thickened and rounded, but elsewhere it is relatively thin. On the posterior border, a short distance below the iliac suture there is a very distinct, oval, rugose area denoting muscular attachment. The distal ends of the ischia come together for an undetermined distance apparently without co-ossification.

\section{Measurements of Right Ischium of Type.}

Length in a straight line from middle of iliac suture to distal end.......... ${ }_{762}^{\mathrm{Mm}}$.

Distance along the curve of the ischiadic contribution to the acetabulum....... 127

Length of sutural contact with the pubis (vertical) $\ldots \ldots \ldots \ldots \ldots \ldots \ldots \ldots \ldots \ldots$

Breadth of sutural contact with pubis across lower surface of acetabulum....... 48

Breadth from anterior proximal emargination to posterior border.......... 150

Breadth from point of anterior expansion to posterior border . . . . . . . . . 210

Breadth at midlength of posterior border. . . . . . . . . . . . . . . . .

Breadth near distal extremity $\ldots \ldots \ldots \ldots \ldots \ldots \ldots \ldots \ldots \ldots \ldots \ldots \ldots \ldots \ldots \ldots \ldots \ldots . \ldots \ldots$

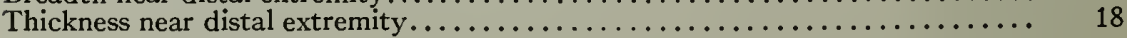

In Figure 7 the lower border of the left ischium shows beneath that of the right one, and in Figure 6 the whole of the left ischium is seen with 
the upper border of its mate of the right side in view above it. In these two figures both pubic bones also are partly seen.

\section{HIND LIMB.}

The great length of the hind limb-one of the notable features of the genus -is contributed to somewhat equally by the femur, the tibia, and fibula, and the much lengthened foot (Figures 6, 7, and 49). The
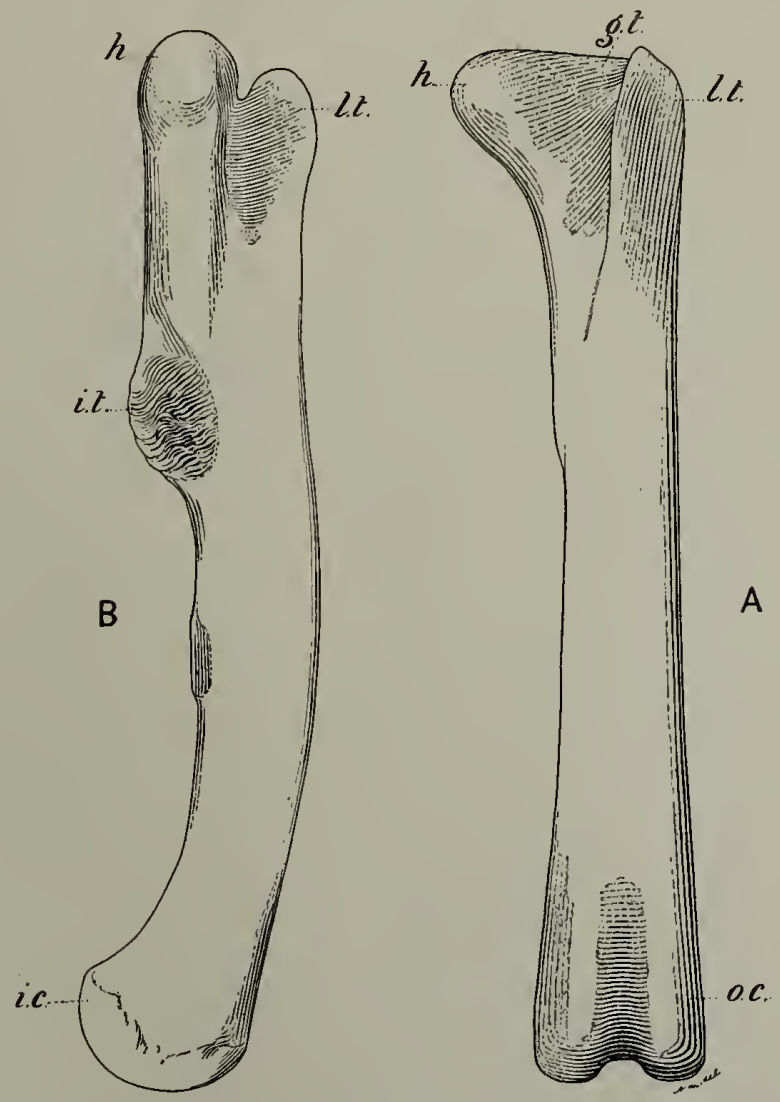

Figure 40. Femur of separate left limb of Gorgosaurus, Cat. No. 350. A, anterior view; $B$, inner view; $\frac{1}{9}$ natural size. g.t., great trochanter; $h$, head; i.c., inner condyle; i.t., inner trochanter; l.t., lesser trochanter; o.c., outer condyle.

femur is slightly longer than the tibia but not quite as long as the foot (metatarsal III + digit III). The upward trend of the head of the femur threw that bone slightly outward. As the body of the animal was bulky below the hips this obliquity of the thigh bones was necessary to allow of their free forward movement. During locomotion the knee 
was considerably bent, the articular surfaces of the knee and ankle indicating the amount of flexure at these joints as represented in Figure 49. The outer condyle of the femur apparently reached lower than the inner one so that the ankle was more under the body and the feet closer together than would otherwise have been the case with an outwardly inclined femur -in other words the animal was bow-legged. A straddling gait is not suggested by the limb bones. The footprints would be in two rather close parallel lines.

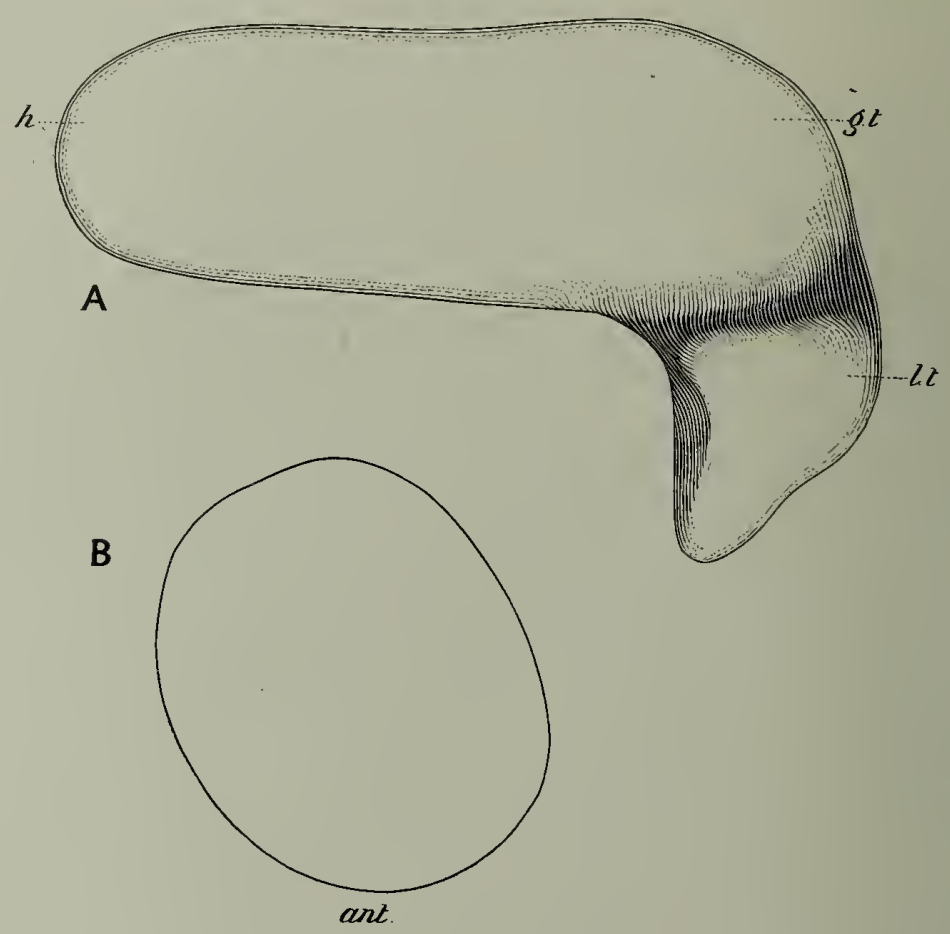

Figure 41. View from above, $A$, and outline of transverse section of shaft at mid-length, B, of femur shown in Figure $40 ; \frac{1}{3}$ natural size. ant, anterior; other lettering as in Figure 40 .

Femur. This (Figures 40 and 41 ) the longest and most robust bone of the hind limb has a large head, a strong, thick, forwardly bent shaft, and well developed condyles of which the outer one appears to be slightly the larger. The shaft is nearly circular in cross section at midlength, below which its curvature is greatest.

The head is lengthened inward, and is set almost at right angles to the shaft with a slight inclination upward and ?forward. Its articular surface is well rounded, and there is no indication of a neck. The greater trochanter is on a level with the head whose upper surface is continuous 
with that of the trochanter without apparently any intervening demarcation. The lesser trochanter is conspicuous on the anterior border of the outer face and rises nearly to the height of the greater trochanter with a free upper end. The inner trochanter is well developed and occurs rather high up on the inner face posteriorly a short distance above the midlength of the bone. A shallow depression extends upward for some distance on the anterior face of the shaft from between the condyles, and on either side of the depression the bone is angularly protrudent. The condyles are extended backward, and the intercondylar groove is deep. A short distance below the midlength of the bone, and in line with and considerably below the inner trochanter there is a small rugose area for muscular attachment. The general surface of the shaft is smooth.

The posterior face of the femur at its proximal end is broadly rounded from the articular surface of the head outward. The anterior face from the lesser trochanter inward is concave. The lesser trochanter is triangular in cross section, narrowing to the front where it ends in a free vertical edge directed inward and forward. It has a flat anteroexternal surface which rounds rapidly backward to the broad convexity of the posterior surface of the bone. Its inner surface is concave in continuation of the broad transversely concave surface of the anterior face. The upper end of the lesser trochanter is separated from the greater trochanter by a deep, narrow groove running in an internoexternal direction.

Tibia. The tibia (Figures 42 and 43 ) is slightly shorter than the femur and is expanded at both ends, distally in a transverse direction, and proximally from back to front to a less extent. The bone in lateral aspect is rather straight in its upper half length, and bends slightly forward below the middle. The shaft is flattened antero-posteriorly so as to be broadly oval in cross section in its main mid-portion. On the upper surface two small tuberosities, separated by a shallow groove, slightly overhang the posterior face. Proximally a heavy process, for muscular attachment, is developed from the inner half of the front face. It extends forward with a curve outward and greatly increases the antero-posterior thickness of the bone at the upper end. It comes to a vertical angulation in front, is convex on its inner side and concave externally, the convexity being continued outward in the remainder of the front face of the bone.

A large cnemial process directed outward and slightly forward occurs on the antero-external border. It is laterally compressed, conspicuously protrudent, and comes to an irregular vertical edge with a rugose anterior surface and a smooth, concave posterior one. It bounds outwardly the lower end of the upper concavity of the front face and is in advance of the fibula when that bone is in position. Following downward from the cnemial process there is a decided angulation which defines 
anteriorly a narrow external flattening of the shaft marking the downward contact of the fibula. Distally the tibia in its expansion thins laterally, and is transversely concave anteriorly and convex posteriorly. Anteroinferiorly it is transversely concave at midbreadth and convex to either side, fitting closely to the astragalus with which it apparently becomes conjoined. The posterior face distally is broadly angulated in a vertical direction on the inner side of its midbreadth, the face of the bone on each
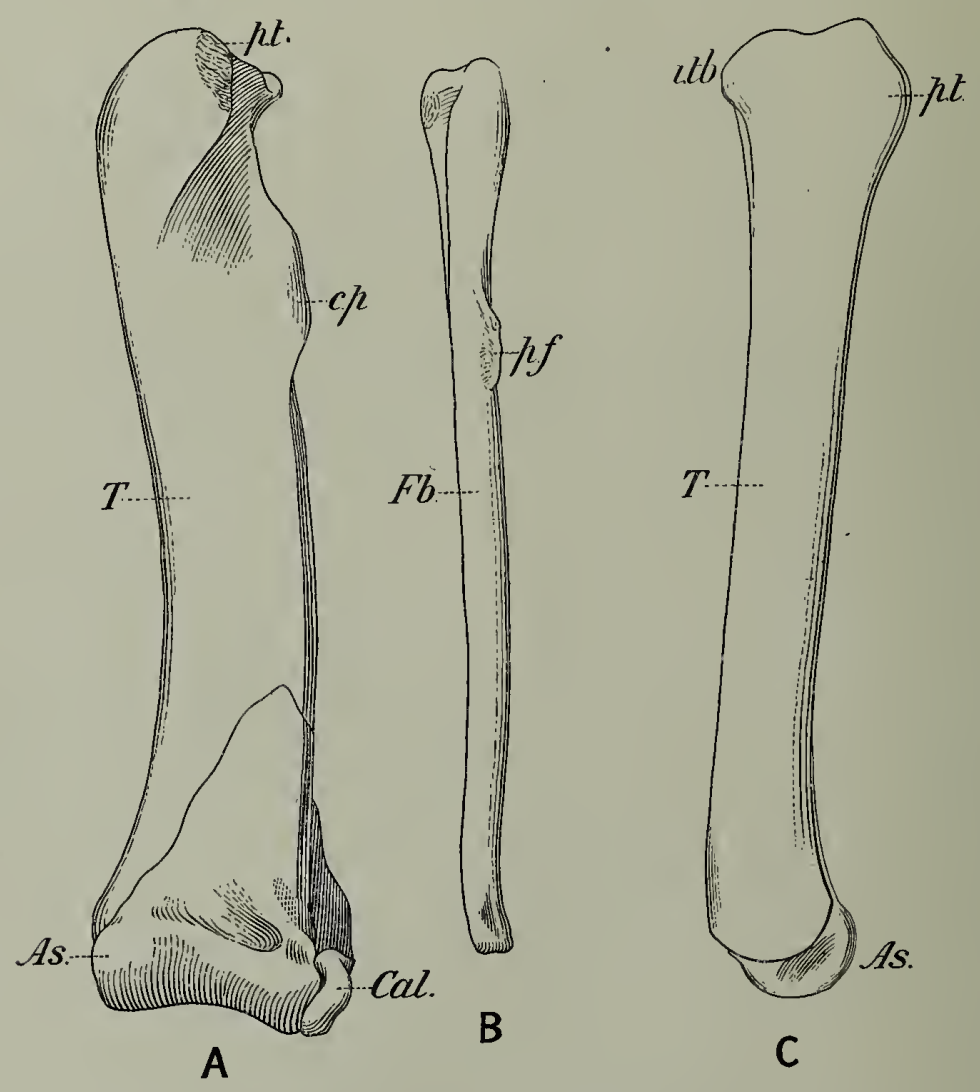

Figure 42. Tibia and fibula, with astragalus and calcaneum, of separate left limb of Gorgosaurus, Cat. No. 350 . A, anterior view of tibia; B, inner view of same; C, anterior view of fibula; $\frac{1}{9}$ natural size. As, astragalus; Cal, calcaneum; c.p., cnemial process; $F b$, fibula; $i$. $t b$, inner tuberosity; p.t., process of tibia; $p$.f., process of fibula; $T$ tibia.

side being flattened with a slope forward to the lateral border. Outwardly the bone is extended behind the calcaneum and the distal end of the fibula. Distally the anterior face is transversely concave in its contact with the astragalus, becoming flat where it fits against the 
posterior faces of the calcaneum and the fibula. Proximally a small rugosely striated area on the external posterior border of the outer tuberosity marks the contact of the upper end of the fibula at this point.

In Gorgosaurus, as well as in Dryptosaurus (Albertosaurus) of the Edmonton formation of Alberta, the tibia has a breadth below equal to
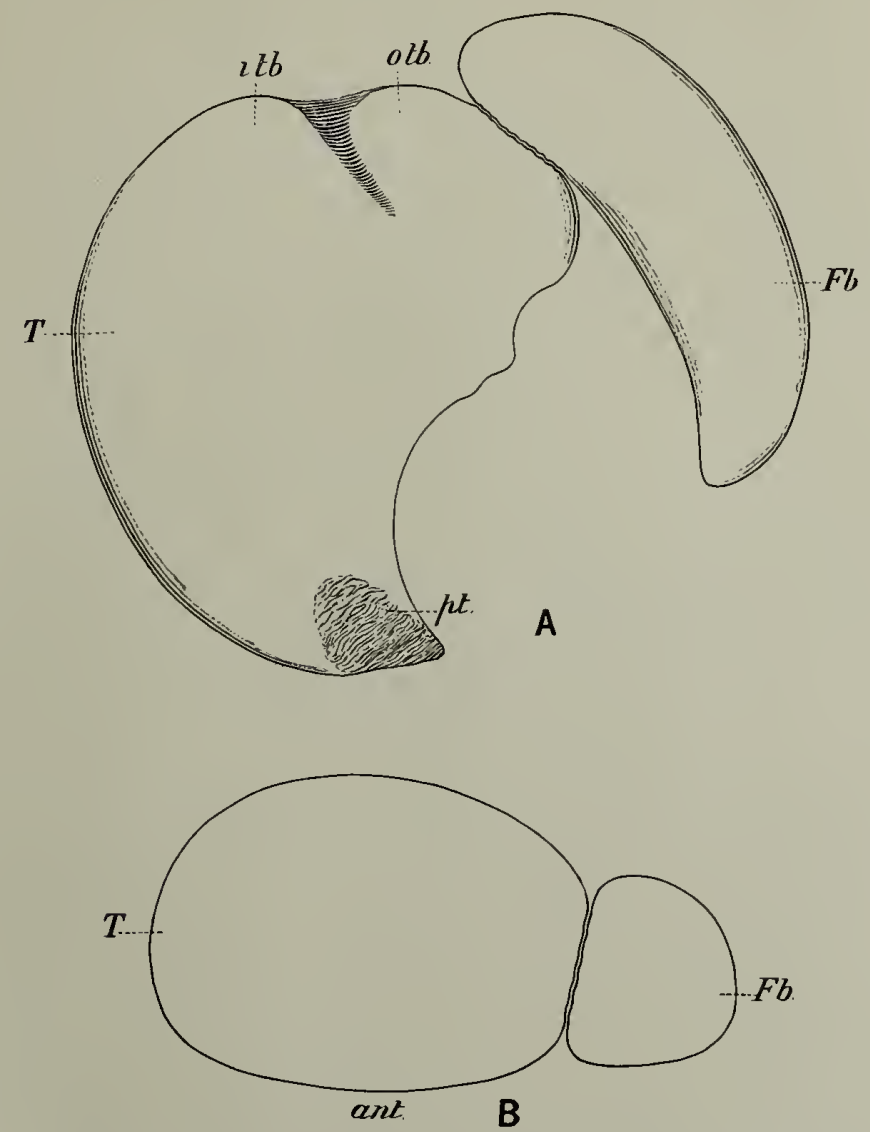

Figure 43. View from above, A, and outline of transverse section of shaft at midlength, B, of tibia and fibula shown in Figure $42 ; \frac{1}{3}$ natural size. ant, anterior; o.tb, outel tuberosity; other lettering as in Figure 42.

the combined breadths of the astragalus and calcaneum. In Ornithomimus altus the tibia is equal to the astragalus only in breadth and does not extend behind the calcaneum.

Fibula. The fibula (Figures 42 and 43 ) is a long, nearly straight bone with a slender shaft increasing slightly in diameter from below upward. It is small distally and expands antero-posteriorly at its 
proximal end. It is closely applied to the tibia for the greater part of its length, is in contact also with the ascending process of the astragalus, and rests below on the calcaneum in advance of an extension outward of the border of the tibia. Its length is slightly less than that of the tibia. The chief noticeable features of the fibula are its 'slenderness and its very close lateral application to the tibia and astragalus.

Proximally the bone is subcrescentic in transverse outline, concave on the inner side and broadly convex outwardly. The narrow upper surface is flat. At midlength the shaft is subcircular in cross section, rounded except on the inner side which is broadly flattened, the anteroposterior diameter being the greater. The distal end is convex below, and subovate in cross section narrowing backward. Proximally the inner face is antero-posteriorly concave to near its upper termination where the bone suddenly thickens to a flat, or only slightly concave surface flush with the front and back borders of the bone. On the anterior face, at a distance of one-third of the length of the bone from the upper end, a small protrudent rugosity is developed which, when the fibula is in place, constitutes a downward continuation of the cnemial process of the tibia. At the upper end a small roughened surface is present on the inner face posteriorly marking the application of the bone to the outer tuberosity of the tibia. The inner face of the bone is flattened throughout its length except in its expanded concave portion above. When in position the fibula articulates with the tibia posteriorly above, is free for a short distance above the cnemial process, then passing downward behind and closely against that process it is applied externally to the shaft of the tibia and distally lies against the flattened outer edge of the ascending process of the astragalus and the front face of the tibia externally.

\section{Measurements of the Femur. Tibia, and Fibula of the Type.}

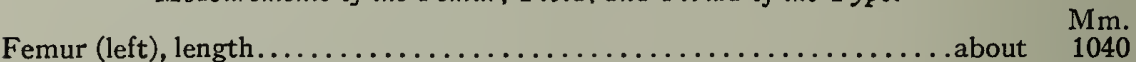

Antero-posterior diameter of shaft at midlength..................... 136

Tibia +astragalus (left), length....................................... 1000

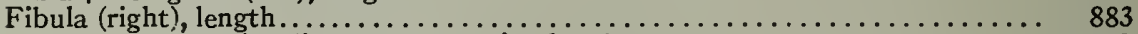

Antero-posterior diameter at proximal end ............................... 180

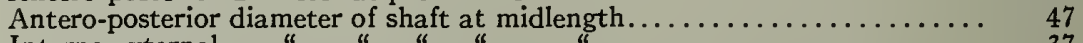

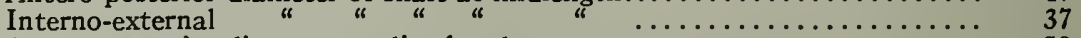

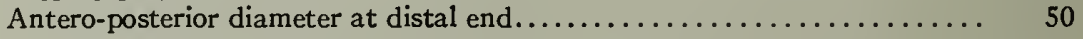

Measurements of the Femur and Tibia of Separate Left Hind Limb, Cat. No. 350.

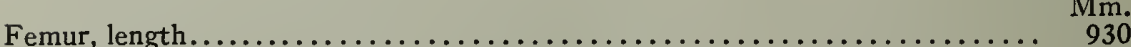

Distance from inner surface of head to outer surface of greater trochanter.. 242

Antero-posterior diameter of shaft at midlength.................. 133

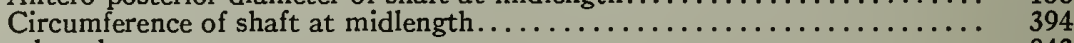

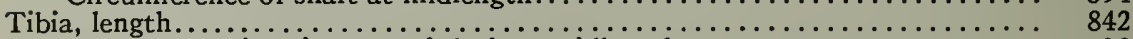

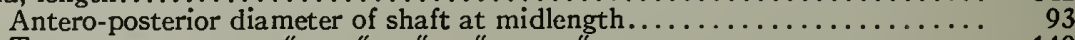

Transverse " " " " $\ldots \ldots \ldots \ldots \ldots \ldots \ldots \ldots, 140$

Length including astragalus...................................... 882

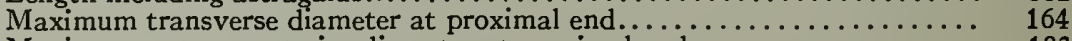

Maximum antero-posterior diameter at proximal end.................... 183

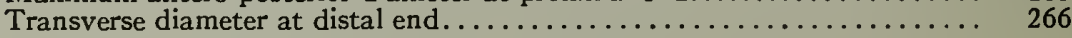


Tarsus. The ossified elements of the tarsus are five in number, viz., the astragalus and calcaneum forming a proximal row, and three flattened bones in a distal row.

The construction of the tarsus seems to be verysimilar in all essential particulars to that of the smaller and relatively slender Ornithomimus altus Lambe, from the Belly River formation of Red Deer river, Alberta, ${ }^{1}$ in which there are three tarsalia forming a distal transverse row.

Astragalus. The astragalus (Figure 42) is very large in comparison with the other bones of the tarsus and consists of a main portion curving from beneath to the front of the distal end of the tibia, and a broad ascending process applied to the anterior face of that bone. It is higher than broad, thin below in comparison with its breadth, and much thinner in the ascending process. The main lower portion is tumid anteriorly and inferiorly on either side of a wide constriction so as to have somewhat the shape of an hour glass when viewed from the front. The constriction is most pronounced nearer the fibular than the inner side in consequence of which the inner tumidity is broader and less steeply sloped than the other. Its upper surface, on which the distal end of the tibia rests, is concave in an antero-posterior direction, and concavely excavated transversely on either side of the midbreadth where it is evenly and broadly convex. Its posterior border is overhung by the tibia. The surface against which the calcaneum fits is concave and larger than the free inner surface which is flat or only slightly concave.

The ascending process is nearly as broad at the base as the main portion from which it springs. It is triangular in outline in anterior aspect, narrowing rapidly upward, mainly from the inner side, and becoming very thin above. Its outer edge is rugose and flattened for the close approximation of the fibula in continuation downward of the fibular contact surface on the shaft of the tibia. The anterior face is set back from the rotund lower portion of the bone, is conspicuously excavated at the middle below, and is further defined by a well marked groove traversing its base from side to side.

That the main portion of the astragalus became co-ossified with the tibia is probable. In Ornithomimus altus the union of these two bones is well illustrated by the distal end of a left tibia, from the Belly River formation (Geological Survey, Cat. No. 199), to which the astragalus is attached by partial fusion. In this specimen there appears, however, to have been no co-ossification between the ascending process of the astragalus and the tibia.

Calcaneum. This bone (Figure 42) is closely applied to the outer side of the lower portion of the astragalus in advance of the tibia. It is narrow transversely and longer than high. In lateral aspect it is flattened

\footnotetext{
${ }^{2}$ Geol. Surv., Can., Cont. to Can. Pal., vol. III, quarto, pt. II, 1902, p. 50, fig. $11 .$.
} 
above and behind, is deepest toward the back, and is rounded below and in front in a nearly semicircular curve. Its upper surface is short, broadest behind, and excavated to receive the distal end of the fibula. Behind its articulation with the fibula it meets the tibia in a surface which slopes evenly downward and backward, with a slight inclination inward, becoming narrower below. The inner face is convex in its contact with the astragalus. The combined lower and front surface is convex transversely and conforms to the curve of the astragalus. The outer, free surface is flat or slightly concave with a raised front border; anteriorly its separation from the rounded surface of the front end is accentuated by a well marked groove passing downward behind the marginal ridge. The inner and posterior borders of the lower surface are extended to definitely underlap the astragalus and tibia respectively.

Measurements of the Astragalus and Calcaneum of Separate Left Hind Limb, Cat. No. 350.

Astragalus:

$\mathrm{Mm}$.

Maximum, height................................ 300

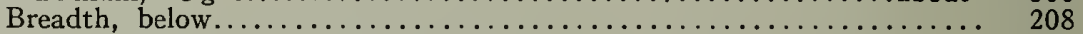

Distance from anterior face of outer rotundity to posterior border....... 100

Distance from anterior face of inner rotundity to posterior border......... 93

Calcaneum:

Distance from anterior face of median constriction to posterior border...... 80

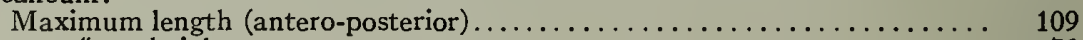

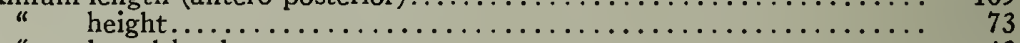

breadth, above............................. 43

Distal Tarsalia. The three distal tarsals, Nos. 2,3, and 4, are flattened, somewhat disc shaped bones, occurring in a transverse row above metatarsals, II, III, and IV. In the type specimen they have been subjected to pressure which has caused a certain amount of distortion and displacement so that it is difficult to determine their true shape and exact normal position, especially as in the two limbs the pressure has not affected them equally.

So far as can be judged from available data, these tarsals were of nearly equal size, were flush behind with the posterior border of the upper surface of the metatarsals, but in the case of Nos. 2 and 4 apparently did not reach fully to the anterior border of metatarsals 2 and 4 . Tarsale 3 , applied to the reduced proximal end of metatarsal III, overlapped metatarsals II and IV on either side. Nos. 2 and 4 covered the greater part of the upper end of their respective metatarsals.

In the left foot of the type tarsale 2 is not resting on the top surface of metatarsal II but, with the flexion of the ankle, seems to have left that surface and to have been crushed against the inner anterior rotundity of the astragalus (Figure 7, tar. 2). Tarsale 3 is over metatarsal III and extends laterally for a short distance over metatarsals II and IV. Tarsale 4 covers the greater part of metatarsal IV; it is thickest, apparently normally, at the back externally and thins toward the front and inwardly. 
In the other foot of the type two of the distal tarsals are preserved, viz., Nos. 3 and 4 , but No. 2 is missing. The two preserved are much distorted and appear as represented in Figure 44 with their antero-posterior diameter reduced and with a decided displacement in the case of No. 3 inward.

In a hind limb, presumably of Gorgosaurus, obtained from the Belly River formation on Red Deer river in 1915 , the three of the distal elements of the tarsus are preserved.

The distal tarsals in Gorgosaurus appear to have been soft bones and it is probable that cartilage entered largely into the formation of the ankle joint.

Metatarsus. The metatarsus of Gorgosaurus is composed of five bones of which all are present and in place in both feet in the type. Metatarsals II, III, and IV (Figures 44 and 45) are the principal, fully functional ones, are conspicuously elongated, and fit closely against each other throughout their length except for a short distance distally where II and IV bend away from No. III leaving its distal end free, the separation being best seen in a posterior view. Metatarsal I is greatly reduced and is represented distally only by a very short bone which is attached to the inner side of the posterior face of No. II at the latter's midlength. Metatarsal $\mathrm{V}$ is vestigial and consists of a slender, short bone representing the proximal end only of this element. Reference to the composition of the metatarsus of Gorgosaurus was included in the writer's original description of the genus and species published in 1914.
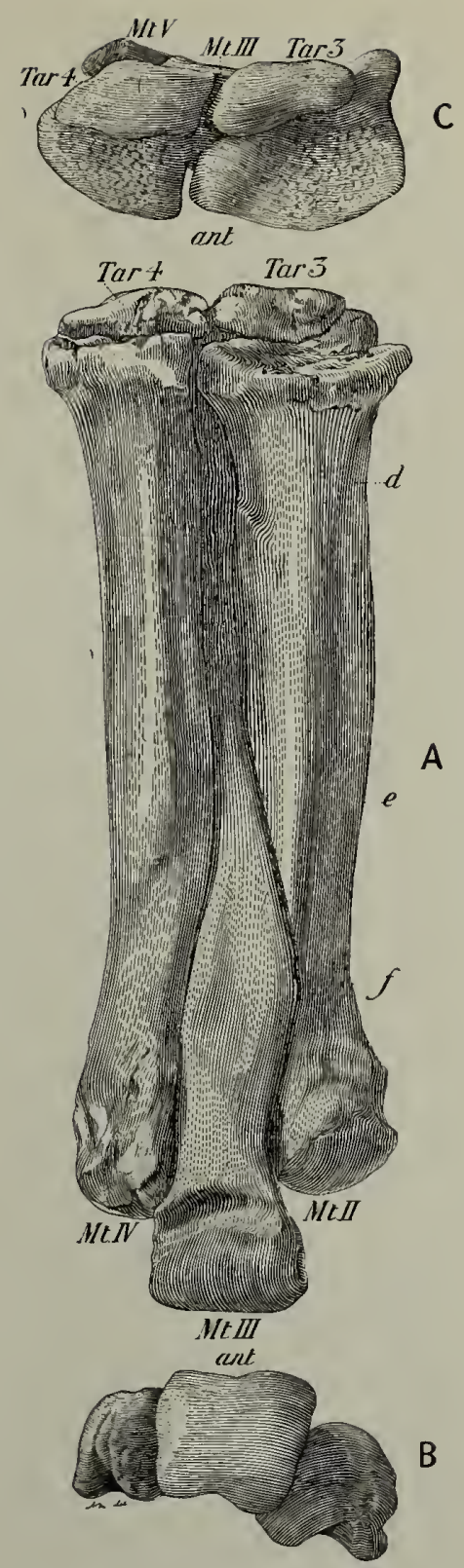

Figure 44. Metatarsals II, III, and IV of the right foot of the type of Gorgosaurus; $\frac{1}{6}$ natural size. A, anterior view; $B$, lower aspect; $C$, upper aspect; ant, anterior; $d, e, f$, position of transverse sections given in Figure 45; $M t$, metatarsal; Tar, tarsal. 
Metatarsals II, III, and IV are principally notable for their length and the manner in which they are closely applied to each other, as in the extremely slender Ornithomimus altus Lambe, in which these elements have apparently reached a maximum of elongation. Nos. II and IV are robust bones, with heavy shafts, and expanded proximal ends. Metatarsal III is considerably longer than Nos. II and IV, and extends

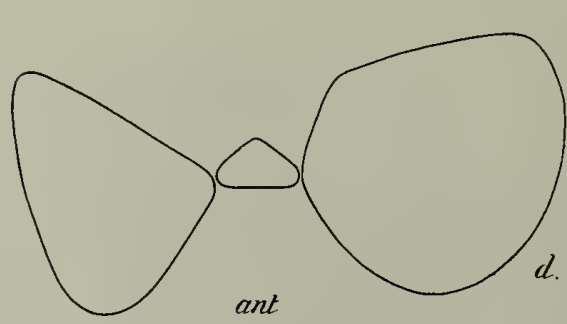
for some distance beyond them distally, at the same time reaching farther forward; No. IV is slightly longer than No. II. Metatarsal III is attenuated above and attains its greatest size in its lower half length, the distal end being larger than that of either of the other two. Proximally it is crowded backward

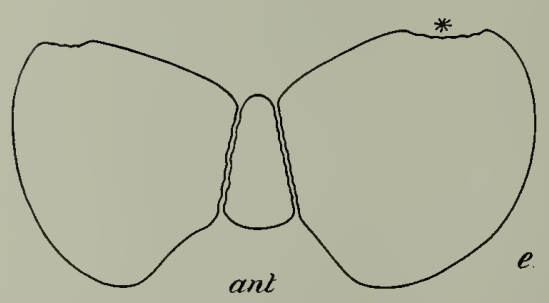
between Nos. II and IV and is here seen only when viewed from behind. Passing downward between II and IV, and visible to about the same extent in both an anterior and posterior aspect of the metatarsus, it gains a more forward position in its distal half, II and IV closing behind it and practically concealing it in a back view. With

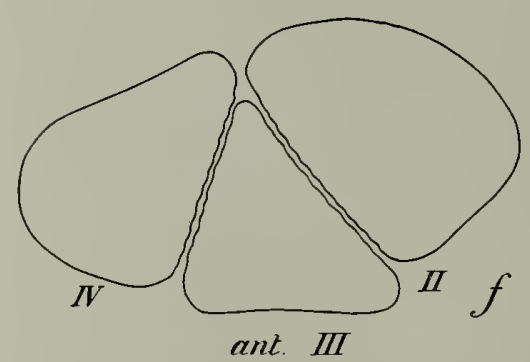

Figure 45. Outlines of transverse sections of metatarsals II, III, and IV, of the right foot of the type of Gorgosaurus; $\frac{1}{3}$ natural size. ant, anterior; $d$, toward the proximal end; $e$, at midlength; $f$, toward the distal end. (See $d, e, f$, Figure 44$) ;{ }^{*}$ surface of attachment of Mt. I.

sreater than the transverse one. The front face is narrow and somewhat elevated toward the outer side where it curves evenly backward. The outer and back faces are flat and meet postero-externally sharply at a little less than a right angle. The inner 
face, applied to metatarsal III, is flat and sharply angulated where it meets the front and back faces.

Above midlength the shaft becomes triangular in cross section being narrowly and prominently rounded in front, with a broad, flat external face, and less extensive, sub-equal, flat postero-. and anterointernal faces meeting at an obtuse angle, while the postero-internal face meets the external one at an angle of about 47 degrees. Here the antero-posterior diameter is considerably greater than the transverse one, and the posterior (postero-internal) face is directed obliquely inward.

Toward the lower end the shaft is narrower as seen from the front. Transversely it is here subtriangular in outline with a rounded anteroexternal face directed obliquely outward. The bone extends inward to meet metatarsal II behind No. III with a broad posterior face, and an equally broad antero-internal one fitting closely against metatarsal III, the maximum transverse diameter being less than the antero-posterior one.

Metatarsal II is a heavier bone than No. IV but has very much the same shape reversed. The proximal end is larger and the shaft is thicker with the angulation of the anterior face above the midlength more broadly rounded.

The distal end of metatarsal III is larger on the inner than in the outer side, and of the two pits which occur, one in each of its concave sides, the inner one is somewhat larger and deeper than the other. The articulating surface is flat transversely and runs up in front farther than it does behind. In front there is an excavation above this surface, extending across the bone, and deepest at its mid-breadth. Posteriorly the distal end is narrower than in front, and is depressed longitudinally at the middle, leaving a slight prominence on either side on which the articulating surface encroaches.

In the distal end of metatarsals II and IV the lateral excavations occur but with the development in each of a pit only on the side next to metatarsal III. The articulating surface is convex transversely as well as fore and aft, and is continued upward in front only slightly more than it ascends behind. In contrast to metatarsal III the lower ends in Nos. II and IV are broader behind than in front. With this greater breadth there is posteriorly a more pronounced median excavation, between very prominent lateral convexities and dividing the articular surface behind.

In metatarsals II, III, and IV the front and free lateral faces of the shaft are smooth. Where these bones are in contact the surface is roughened. Distally on the posterior prominences, anteriorly above the articulating surface, and in and near the side excavations rugose, longitudinal striations are developed. The small, well-defined surface 
(Figure 7) on metatarsal II for the attachment of metatarsal I is moderately rough, and on the external face of No. II proximally toward the front there is a roughened boss of considerable size, also a decided roughness occurs along the outer, angulated edge of the posterior face of No. IV near its midlength.

Metatarsal III is hollow near its distal end for a distance of about $120 \mathrm{~mm}$., the space having a maximum diameter of $22 \mathrm{~mm}$. In metatarsals II and IV a cavity, having about the same diameter as that of No. III, is continuous through the whole length of the shaft.
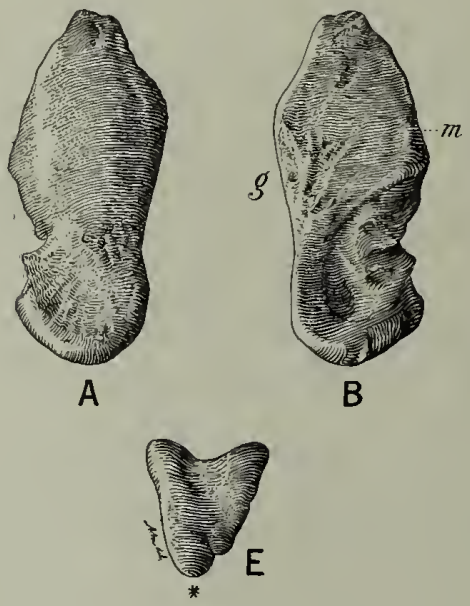
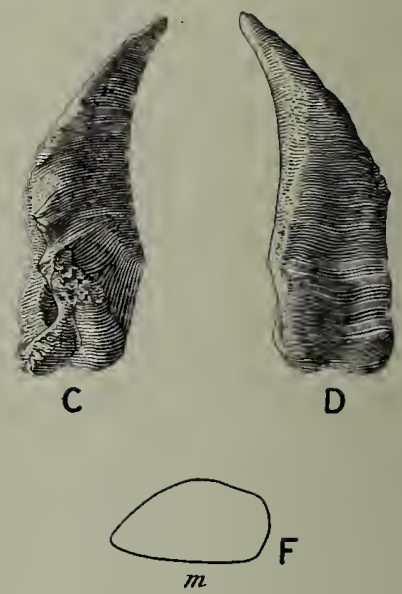

Figure 46. Metatarsal I of right foot of type of Gorgosaurus; $\frac{1}{3}$ natural size. A, posterior aspect; $B$, anterior aspect; $C$, interior (dorsal) aspect; $D$, exterior (plantar) aspect; $E$, inferior aspect; $F$, outline of transverse section near midlength at $g ; m$, surface of attachment to metatarsal II, * dorsal side.

Metatarsal I (Figure 46) is greatly reduced and is a very short but stout bone representing the distal end only of the element. In the type this vestigial bone is preserved wholly. It is in place in the right foot but has shifted slightly in the left. It is attached to the inner side of the posterior face of metatarsal II at the latter's midlength and is hidden when the metatarsus is viewed directly from the front. Its general direction is downward at an angle of about 40 degrees to the longitudinal axis of metatarsal II. In its posterior position, gained by rotation backward and outward from the inner side of No. II, its dorsal face is directed inward and the plantar face outward, the external face is turned to the front, and the internal one to the rear. In describing the bone in position, therefore, the external and internal faces will be referred to as the anterior and posterior ones respectively. 
Distally the bone is broad on the plantar side, narrows to an irregullarly rugose dorsal face, and is larger on the posterior than on the anterior side. The distal articulating surface is rather small, is developed most on the posterior side, and does not extend far upward either dorsally or externally. It has a shallow median groove which passes into a broad depression in the plantar face. Above the distal articulating surface the anterior and posterior faces are excavated, very shallowly posteriorly, but deeply with the development of a large pit anteriorly.

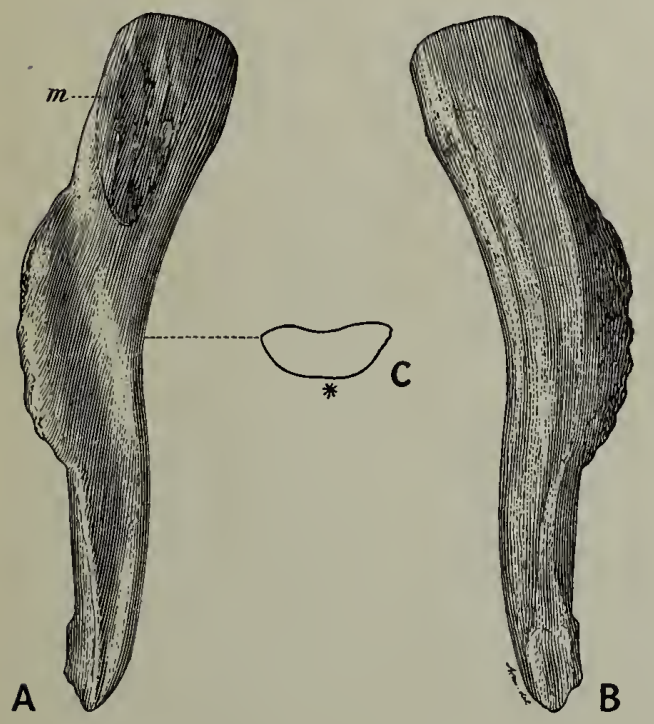

Figure 47. Metatarsal $\mathrm{V}$ of the left foot of the type of Gorgosaurus; $\frac{1}{3}$ natural size. A, inner view: B, outer view; C, outline of transverse section near midlength; $m$, surface of attachment to Mt. IV; ${ }^{*}$ outer side.

In its upper half the bone is very obliquely truncated on its anterior side and ends above in a thin edge, the truncation providing a surface, large in proportion to the size of the bone, for contact with metatarsal II. This surface is rugose, slightly convex, and narrowly rounded in outline above. From the deep anterior pit two large, clearly defined grooves cut across the roughened dorsal face and disappear posteriorly. The surface of the bone is roughened for muscular attachment on all faces distally.

Attention was drawn in 1914 in the original description of Gorgosaurus (ante p. 7) to the presence in this carnivore of a fifth metatarsal represented by a vestigial proximal end. This bone is in place in both hind limbs of the type specimen, as well as in the left one of another individual of this species represented by a partial skeleton (Cat. No. 350) of the 1914 collection from the Belly River formation of Red Deer river. The fifth metatarsal occurs, reduced in like manner, in the Triassic Anchisaurus colurus Marsh, from Connecticut, in the Jurassic species Hallopus victor Marsh, and Compsognathus longipes Wagner, from Colorado and Bavaria respectively, and the Cretaceous Ornithomimus altus Lambe, from Alberta.

Metatarsal V is a short, laterally compressed, curved bone, representing the proximal end only of the element and recalling to mind the vestigial fifth of Ornithomimus altus. In the type it is preserved 
in each foot and is in place at the proximal end of metatarsal IV. It is about $8 \frac{1}{2}$ inches long, or slightly more than $\frac{1}{3}$ the length of No. III, and a little less than twice the length of No. 1. It narrows downward and is proximally roughly elliptical in transverse section with the greater diameter fore and aft. At the lower end it is narrower from front to back but has much the same thickness from side to side as it has above. In lateral aspect it is slightly curved with the front outline concave and the back one convex. Prominent rugosities are developed on the back border at its midlength, accentuating the curve of the bone and giving it the appearance of being abruptly bent at the middle. On the inner face proximally there is an irregularly oval roughened area, marking the surface of contact with metatarsal IV, and the lower end is rugosely striated in the direction of the bone's length.

Digit $I$ in its pendant position at the high level has its plantar surface facing outward with an inclination to the rear due to a slight twist in its downward curve. This digit is not opposed to the other three nor has it their same general direction but it is set almost at right angles to them, certainly nearly at right angles to the forwardly directed third digit. In the original description of Gorgosaurus digit I was stated to have a "forwardly rather than a backwardly directed position in the foot." A further study, however, makes it clear that a direction rather midway between these extremes is the true one. The first digit could have been of little use in the foot on account of its shortness, its direction, and its height above the others. The tip of its ungual only reaches the level of the lower end of the second metatarsal and consequently must have been some distance above the ground when the animal walked. In the domestic turkey the claw of the first digit just touches the ground when the bird is standing, although the first metatarsal, supporting two phalanges, is applied to the co-ossified metatarsals only slightly above their lower end instead of at the mid-height of the metatarsus as in Gorgosaurus.

The second, third, and fourth metatarsals with their elongation, their very close contact, and their distal divergence, need only to be co-ossified where in juxtaposition to produce a bone remarkably similar to the tarsometatarsus of the majority of birds.

Measurements of Metatarsals of Right Limb of Type.

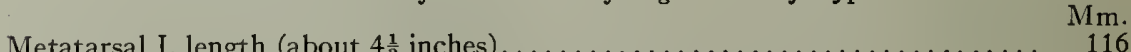

Breadth of distal articulating surface at extremity of the bone........... 31

Length (vertical) of surface for contact with metatarsal II .............. 80

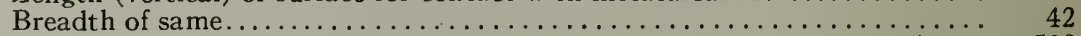

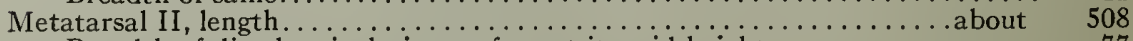

Breadth of distal articulating surface at its mid-height................ 77

Metatarsal III, length....................................... 594

Breadth of distal articulating surface at its mid-height................ 92 


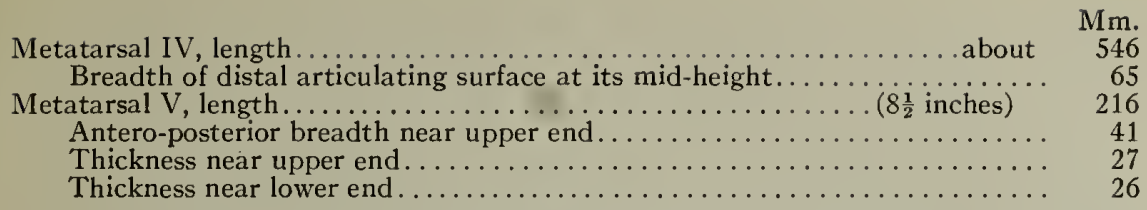

Phalanges. The phalangeal formula is-2 I, 3 II, 4 III, 5 IV, agreeing with that of Allosaurus, Ornithomimus, and Theropodous dinosaurs generally so far as known. The longest digit is No. III, and as metatarsal III projects beyond metatarsals II and IV, the anterior end of this digit is considerably in advance of that of the digits (II and IV) on either side of it. Digit IV is only slightly longer than No. II, and No. I is the smallest, being much reduced and less than one-half the length of No. III.

The phalanges are robust and decrease in size toward the front; they are broader than above, are constricted in the middle, and arched longitudinally beneath. In all, with the exception of the claw shaped terminal one in each of the four digits, there is a pit in each side of the anterior end. Of digits II, III, and IV those of No. III are more nearly bilaterally symmetrical than the others which develop a greater height anteriorly and posteriorly on the side next to digit III, with the exception of the penultimate one in digits II and IV which is enlarged in front on the side away from digit III.

In phalanges 1 II, 1 III, and 1 IV the proximal surface for articulation with their respective metatarsals is shallowly concave. In the other phalanges the proximal articular surface is pronouncedly concave in a vertical direction and somewhat convex transversely, there being a tendency in the more distal and shorter phalanges to form a median vertical angulation which results in a backward extension of the upper margin and less conspicuously of the lower one also. In all the phalanges the margin of the proximal articular surface is sharp-edged throughout.

The distal articulating face in the phalanges is transversely concave and vertically convex, and fits closely into the proximal face of the phalanx in front. It extends well back on to the upper and lower surfaces of the phalanx, permitting a large amount of rotation in a vertical plane.

In phalanges 1 II, 1 III, and 1 IV (as well as in their metatarsals) the distal articular face is extended farther back on the upper than on the lower surface of the bone, conspicuously so in No. 1 of digit III. In the other phalanges of these digits the reverse is the case, the lower extension being the greater, especially in No. 2 of digit II. Judging the amount of phalangeal rotation from the extent of the articular surface, the phalanges of the second row were capable of a greater rotation upward than those farther forward in the foot. It is apparent 
also that the downward rotation of all the phalanges in advance of the first row was sufficient to admit of the digits being almost closed on themselves.

The upper surface of the phalanges is excavated behind the termination of the articular face. In the lower surface of Nos. 1 of the three principal digits there is a decided rugose area bounded on either side by a roughened ridge; this occurs also in the more anterior phalanges with less relief, sometimes with an absence of the ridges. As regards the anterior lateral pits, they are equally developed on either side of the phalanges in digit III and in No. 1 of digit II, but in the other phalanges the pit on the side next to digit III is usually the larger and the deeper of the two.

In both the right and left pes all the phalanges are present in the type with the exception of the ungual of digit III in each. These are represented by the pointed distal end in the left foot and by an abnormal (diseased) claw in the right foot. As the distal articular face of the penultimate phalanx of digit II is considerably larger than that of the corresponding phalanx of digit III there appears to be no doubt that the ungual of II was larger than that of III. The ungual of digit IV was smaller, and that of digit I was the smallest.

The unguals curve evenly downward, taper to a point, and are narrower above than below, the upper and lower surfaces being respectively broadly angulated and flatly convex transversely. In cross section they are subtriangular with the height and basal breadth nearly equal. The lateral face on the side away from digit III is larger and flatter than the opposite face, giving the bone in its general forward direction a decided inclination away from digit III. The junction of the lower surface with the larger and flatter of the two lateral faces is angulated to a moderate degree; on the other side the lower surface turns more rapidly upward. On each lateral face a groove curves from the tip to near the lower surface proximally, an indistinct branch of the groove being sometimes given off, near the proximal end of the bone, with an upward and backward direction. The groove on the side next to digit III is deeper and much more pronounced than the other and in this respect is in accord with the unequal development of the lateral pits in phalanges of digits II and IV already referred to. As the phalanges of digit III were bilaterally symmetrical and had equal sized pits on either side, it is probable that the ungual of this digit was also evenly balanced and had lateral grooves of equal depth.

In digit I (or hallux) the proximal phalanx is small and slender in comparison with the corresponding ones of the other three digits. The - ungual phalanx is nearly as long, but not so stout as that of digit IV. In these two phalanges the side facing to the front, or the side which 
would be the nearer to digit III if digit I were directed forward instead of outward, is the one in which occurs the greater development of the lateral pit and groove, in the proximal and distal joints respectively.

In the phalanges generally the surface of the bone is usually roughened by irregular striations, having a somewhat longitudinal direction, in the neighbourhood of the lateral pits and grooves, on the side and superior faces proximally, and especially on the proximal part of the lower surface. In the midlength region generally the bone is smooth but the lower surface of the unguals is inclined to be rugose throughout. The smooth articular surfaces have their boundaries distinctly defined by a line of demarcation.

\section{Measurements of Phalanges of Right Pes of Type.}

The length of the phalanges as given below, is taken from the middle of the proximal articular surface to that of the distal one, and in the unguals in a straight line to the tip, and the breadth is that of the distal articular surface at its midheight.

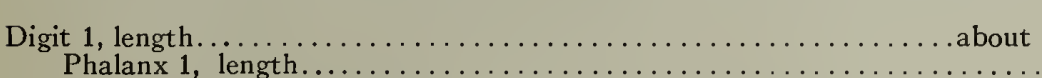

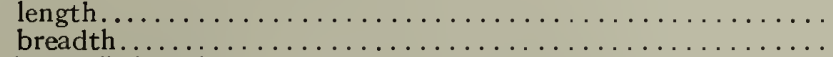

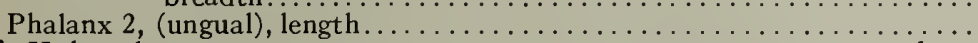

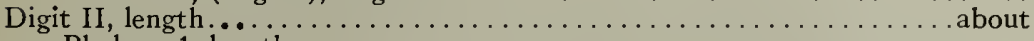

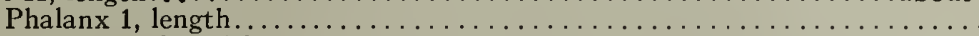

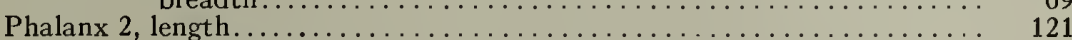

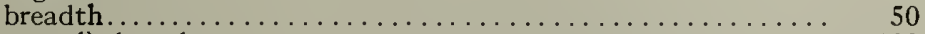

Phalanx 3 (ungual), length..................................... 120

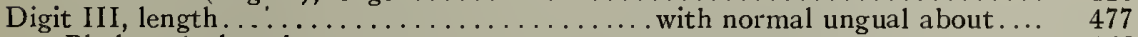

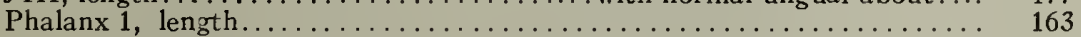

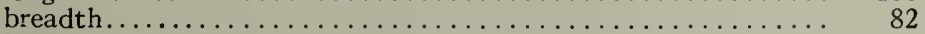

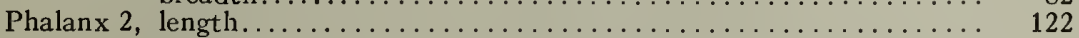

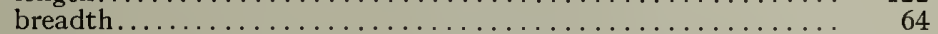

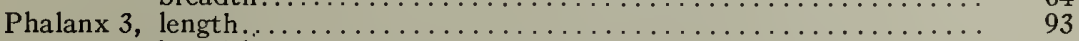

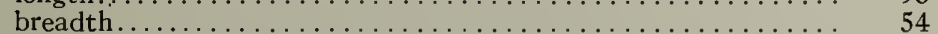

Phalanx 4 (ungual, abnormal in shape), length.......................... 45

Digit IV, length ....................................... 410

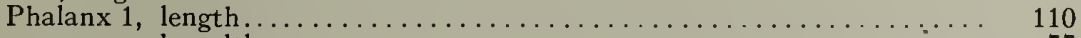

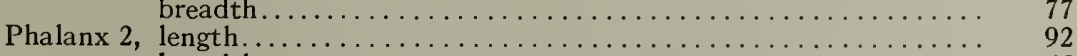

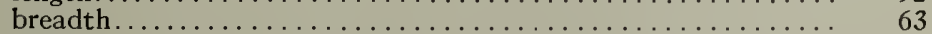

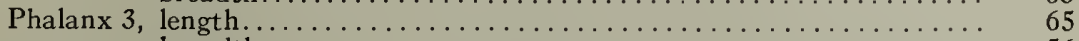

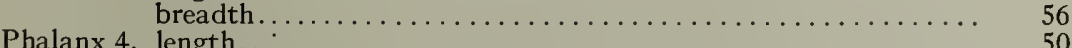

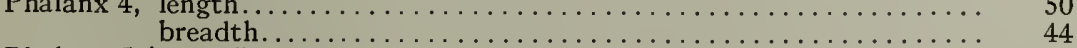

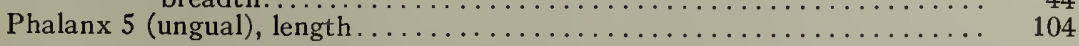

Some of the bones of the type specimen show signs of having been injured, and others of having been diseased in places, in the lifetime of the animal.

The right third dorsal rib had been broken or very much bent, and the thirteenth and fourteenth ventral ribs of the right side had undoubtedly been fractured. The injury is indicated by a thickening of the bone and a roughness of the surface next to where the parts had knit. Also the fibula of the left leg is irregularly thickened near its distal end and has every appearance of having been broken. 
The ungual phalanx of digit III of the right pes is abnormal in shape and appears to have been diseased; it is quite small and amorphous. The penultimate joint of the same digit has been similarly affected but to a much less extent. Both phalanges give every evidence of having been affected when the reptile was alive. Metatarsal IV of the left pes shows two roughened areas evidently the result of a diseased state of the bone (Figures 6 and 7 ). One of these about the midlength of the bone is protrudent, the other at the distal end is less conspicuous but more extensive.

\section{REMARKS ON THE SUPPOSED APPEARANCE, HABITS, ETC.}

One may pass from the osteology of Gorgosaurus, as revealed by the type described in the foregoing pages, to a consideration of the animal as it probably was in life. The questions naturally arise: what was this creature's appearance? On what did it feed ? Was it active or otherwise in its movements? What was the nature of its surroundings? Answers to these questions must be based on conjecture to some extent but certain structural characteristics of the skeleton are prominent and lead to obvious conclusions. The teeth, for instance, are those of an animal that lived on flesh. The feet were intended for movement on land only. The peculiarly short fore limbs definitely point to the use of the long hind ones as the only means of progression. The structure of the tail and its size lead to the belief that it was rather rigid and of use principally as a support and balance. The presence of a cuirass of close set abdominal ribs indicates the habitual assumption of a prone attitude. And the horizontal expansion at the lower end of the large pubic bones was evidently developed to assist in supporting the weight of the body. From these, and other less conspicuous skeletal peculiarities, it is possible to form some idea of this dinosaur's distinctive features when alive.

Gorgosaurus was lightly built for its size and had long bird-like hind limbs on which the moderately slender, lizard-shaped body, tapering to the narrow head and into the long tail, was balanced when the creature stood or walked. The principal limb bones were hollow and empty spaces occurred in the thickest parts of the vertebræ and phalanges but not in the slender bones or parts that were flattened or attenuated. The animal walked on the strong hind limbs only, the fore ones being extremely short and relatively feeble. When seated or stretched on the ground the pubic bones received some of the weight of the body. The pointed teeth were conspicuous objects in the large mouth. The tail, forming nearly one-half of the creature's total length, was thick at the base, broadly oval in cross section, and tapered gradually to the tip. It was not very flexible and served mainly as a counterpoise to the weight in 
advance of the hip and as a support. The trunk was only slightly deeper than broad, and was broadly rounded above and flattened beneath where it was strengthened by the series of abdominal ribs extending its full length. The neck was moderately short and on the throat the skin was probably loose and baggy. No trace of the skin has been found so that its characters are unknown. The full length of Gorgosaurus was about 29 feet. In the forwardly inclined position assumed in walking the top of the head was nearly 11 feet above the ground, and the back above the hips a little under 9 feet.

The tail of Gorgosaurus was that of a land animal. It was almost circular in cross section throughout its length and not laterally compressed as in that of the trachodonts which was a swimming tail-an organ of propulsion. In Gorgosaurus the chevron bones were short with a fore and aft extension in those of the distal half of the tail where its contact with the ground was most constant. The tail functioned as a balance and its inflexibility was due principally to the interlocking of the lengthened zygapophysial processes.

Was this reptile agile, alert, and quick of movement? Was it capable of capturing its prey by a sudden rush from some place of concealment, or by overtaking it after a pursuit possibly of some length? Was its victim eaten when killed? Did it engage in spirited encounters with its own kind as depicted in Knight's well known restoration of Dryptosaurus in accordance with Cope's views subsequently modified? The writer believes that Gorgosaurus was sluggish and not a quick mover, and that it fed, not on the fresh flesh of animals necessarily of its own killing but rather on carcasses found or stumbled across during its hunger impelled wanderings.

In the flat, wooded country of the west in which Gorgosaurus lived during Belly River Cretaceous times it had as contemporaries large numbers of the plant eating trachodonts frequenting the rivers and lakes. On the land were other herbivores-several kinds of horned dinosaurs and two or three species of armoured dinosaurs. It is to be presumed that Gorgosaurus fed on these when chance offered. Living at the same time were other carnivorous dinosaurs mostly of smaller size and about which, with the exception of the slender Ornithomimus, little is known. Fish abounded, as well as amphibians, crocodiles, turtles, and small mammals, and these also may have enticed the appetite of Gorgosaurus.

The fact that Gorgosaurus was a land dweller may account to some extent for the scarceness of its remains as compared with those of the trachodonts and the other plant eaters as the rule probably held then with dinosaurs as now with mammals that flesh eaters are less numerous than the herbivores on which they subsist. It may also partly account for the absence in the rock of impressions of its skin. The amphibious 
trachodonts, of whose tuberculated skin impressions are commonly preserved, were entombed generally in water laid deposits and were probably rapidly covered after death before decomposition had gained much headway, whereas the bodies of the land dwelling carnivorous dinosaurs probably seldom found their way into river or lake. It is reasonable to assume that the carnivores, in common with the horned dinosaurs and armoured dinosaurs-being all land dwellers-were subjected to atmospheric conditions after death with the result that skin impressions would be less liable to occur.

It does not follow that because skin impressions of Gorgosaurus and other carnivorous dinosaurs have not yet been found that the skin was delicate and smooth; for of the many forms of horned dinosaurs known the skin impression of one only, viz., Chasmosaurus belli, Lambe, has been discovered revealing the presence of an outer layer of rather small polygonal plates ${ }^{1}$ which imply a rough and by no means thin or delicate covering. The thick bony scutes of the armoured dinosaurs are usually well and abundantly preserved though not generally in place.

The four restoration drawings forming Figure 48 are based on the very complete type skeleton of Gorgosaurus and represent the creature standing, sitting, feeding, and lying stretched at full length. They are the work of Mr. Arthur Miles, prepared under the writer's direction.

The semi-erect position in standing or walking, given in Figure 48a, provides a perfect balance at the hip. Thus poised with the body and head stretched forward, the tail lightly touched the ground. The thighs, judging from the shape of the head of the femur and its position in the acetabulum, were inclined slightly outward. The feet were not far apart and made a double track when the animal walked. If a turn from a straight course were made it is probable that a balance was preserved by a swing of the tail. If this reptile were capable, under strong impulse, of making a rapid forward movement, the tail, functioning fully as a balance and assisting in regulating direction, would probably leave the ground. The perfect balance of the body would allow of a natural and easy movement of the head to the ground but it is not thought that a much more erect position than the one shown in Figure 48 was habitual or long sustained when standing or walking. It is believed that a reptile of the size of Gorgosaurus was not capable of jumping.

The size and shape of the pubic bones suggest the frequent assumption of a sitting or squatting position (Figure 48b). In this position

\footnotetext{
1 On the fore limb of a carnivorous dinosaur from the Belly River formation of Alberta, and a new genus of ceratopsia from the same horizon, with remarks on the integument of some Cretaceous herbivorous dinosaurs, by Lawrence M. Lambe; Ottawa Naturalist, vol. XXVII, p. 131, p. XIV, 1914.
} 


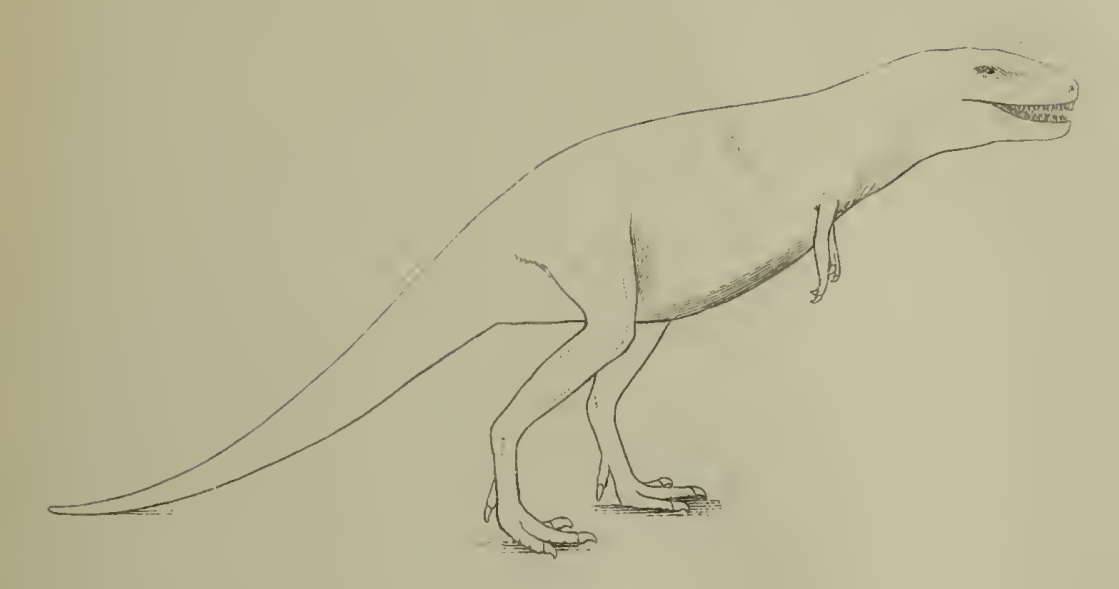


the animal's weight would be borne by the pubes, the base of the tail, and the feet, the legs being well bent at the knee with the thighs directed forward and slightly outward, in fact very much in the positon in which the left limb was found when the type skeleton was discovered (Figure 6). This position of rest, and particularly the recumbent one of repose at full length (Figure 48d) were probably those most frequently assumed by a reptile having the form, and the supposed sluggish disposition of Gorgosaurus. The fore legs were probably of assistance in minor changes of position when prone, or when rising to a sitting posture, and also for receiving the weight of the fore part of the body when bringing its full length to the ground.

It is believed that Gorgosaurus did not eat while standing but that a semicrouching posture (Figure 48c) was adopted when feeding. The minute fore limbs were too short to be of any use in this connexion and the hind feet were incapable of grasping an object as the first digit was not opposed to the other three. The powerful, clawed toes may have been used to tear flesh from bones. It may be supposed that after a carcass had been sufficiently torn by the claws that the animal sank to a crouching posture for its meal.

An interesting fact in connexion with the type of Gorgosaurus is that none of the teeth shows signs of wear to any extent. The tips of the teeth where most abrasion would be expected, especially in the larger side ones, are almost perfect, the delicate denticulations of the sharp edges remaining intact to and over the pointed end. This indicates either extreme juvenility, or that the food eaten had little abrasive effect on the teeth and was obtainable with little exercise of strength. But the type of Gorgosaurus represented an individual of large size which though not aged had probably reached maturity, and it follows, therefore, that the only conclusion to be drawn from the state of the teeth is that the food was soft, non-abrasive, and obtainable without much effort. It is believed, therefore, that Gorgosaurus confined itself to feeding upon carcasses of animals that had not been freshly killed, that it was not as an intrepid hunter but as a scavenger that it played its useful part in nature, and no doubt its services were fully required when we consider the immense numbers of trachodonts, ceratopsians, stegosaurs, and other dinosaurs and reptiles that lived and died at this particular time of the Cretaceous period.

The prevalence of tree trunks and leaves in the Belly River formation of Alberta indicates that this western land was well wooded in Cretaceous times. The country was low lying, dotted with lakes, and traversed by eastwardly flowing rivers. Glades and sparsely wooded tracts no doubt in terspersed the heavily timbered areas affording suitable environments for the varied and numerous reptiles both large and small. The 
swamps, rivers, and inlets of the southern sea had their quota of waterfrequenting and purely aquatic types. Water plants abounded. On the land were ferns and shrubs of various kinds besides a diversity of trees-pines and other conifers, cedars, poplars, oaks, birches, elms, and maples.

The type of Gorgosaurus is an example of a land dinosaur entombed in a water borne deposit. One can conceive that the body of this animal, floating with the left side uppermost, was stranded feet first in shallow water, and that the right limbs, touching bottom first, were forced upward toward the back into the position in which they were found. With the settlement of the body into the sand all the bones of the right side would be held firmly in position, accounting for the presence of all the bones of the right side in the type. In the case of the left side of the specimen the loss of a number of parts, notably the scapula, fore limb, and the left half of the cuirass of ventral ribs, could result from the body lying with that side uppermost in shallow water, possibly more or less exposed to the air, for a considerable interval of time subject to the action of water or the depredations of animals or both.

It was in a land of the above character that Gorgosaurus played its part in the economy of nature, and although many of this reptile's habits and characteristics are at present only surmised, others are clearly indicated by its fossil remains.

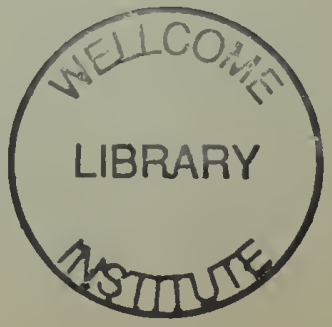





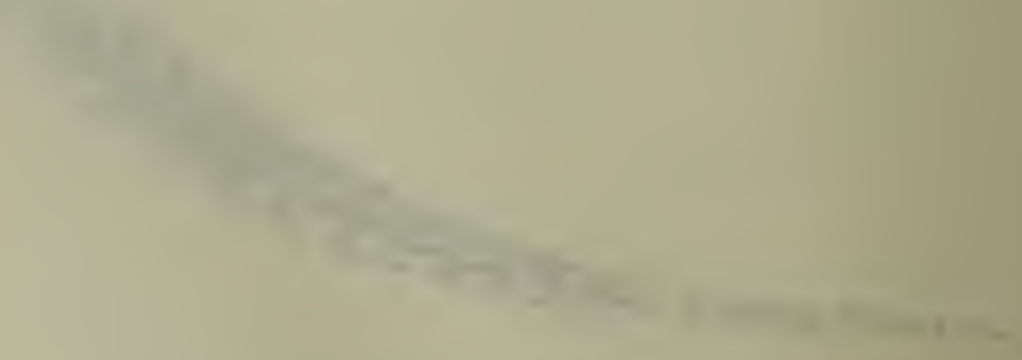



